Portland State University

PDXScholar

Dissertations and Theses

Dissertations and Theses

Winter 3-30-2015

\title{
Bicyclist Compliance at Signalized Intersections
}

Samson Ray Riley Thompson

Portland State University

Follow this and additional works at: https://pdxscholar.library.pdx.edu/open_access_etds

Part of the Transportation Engineering Commons

Let us know how access to this document benefits you.

Recommended Citation

Thompson, Samson Ray Riley, "Bicyclist Compliance at Signalized Intersections" (2015). Dissertations and Theses. Paper 2222.

https://doi.org/10.15760/etd.2219

This Thesis is brought to you for free and open access. It has been accepted for inclusion in Dissertations and Theses by an authorized administrator of PDXScholar. Please contact us if we can make this document more accessible: pdxscholar@pdx.edu. 
Bicyclist Compliance at Signalized Intersections

by

Samson Ray Riley Thompson

A thesis submitted in partial fulfillment of the requirements for the degree of

Master of Science

in

Civil and Environmental Engineering

Thesis Committee:

Christopher Monsere, Chair

Kelly Clifton

Miguel Figliozzi

Portland State University

2015 
(C) 2014 Samson Ray Riley Thompson 


\begin{abstract}
This project examined cyclist red light running behavior using two data sets. Previous studies of cyclist compliance have investigated the tendencies of cyclists to run red lights on the whole by generalizing different maneuvers to their end outcome, running a red light. This project differentiates between the different types of red light running and focuses on the most egregious case, gap acceptance, which is when a cyclist runs a red light by accepting a gap in opposing traffic.
\end{abstract}

Using video data, a mathematical model of cyclist red light running was developed for gap acceptance. Similar to other studies, this analysis utilized only information about the cyclist, intersection, and scenario that can be outwardly observed. This analysis found that the number of cyclists already waiting at the signal, the presence of a vehicle in the adjacent lane, and female sex were deterrents to red light running. Conversely, certain types of signal phasing, witnessing a violation, and lack of helmet increased the odds that a cyclist would run the red light. Interestingly, while women in general are less likely to run a red light, those who witnessed a violation were even more prone that men who had witnessed a violation to follow suit and run the red light themselves. It is likely that the differing socialization of women and men leads to different effects of witnessing a previous violator. The analysis also confirmed that a small subset of cyclists, similar to that found in the general population, are more prone to traffic violations. These cyclists are more willing to engage in multiple biking-related risk factors that include not wearing a helmet and running red lights. 
Although the model has definite explanatory power regarding decisions of cyclist compliance, much of the variance in the compliance choices of the sample is left unexplained. This points toward the influence of other, not outwardly observable variables on the decision to run a red light.

Analysis of survey data from cyclists further confirms that individual characteristics not visible to the observer interact with intersection, scenario, and visible cyclist characteristics to result in a decision to comply (or not) with a traffic signal. Furthermore, cyclist characteristics, in general, and unobservable individual characteristics, specifically, play a larger role in compliance decisions as the number of compliance-inducing intersection traits (e.g. conflicting traffic volume) decrease. One such unobservable trait is the regard for the law by some cyclists, which becomes a more important determinant of compliance at simpler intersections. Cyclists were also shown to choose non-compliance if they questioned the validity of the red indication for them, as cyclists.

The video and survey data have some comparable findings. For instance, the relationship of age to compliance was explored in both data analyses. Age was not found to be a significant predictor of non-compliance in the video data analysis while it was negatively correlated with stated non-compliance for two of the survey intersections. Gender, while having significant effects on non-compliance in the video dataset, did not emerge as an important factor in the stated non-compliance of survey takers. Helmet use had a consistent relationship with compliance between the video and survey datasets. Helmet use was positively associated with compliance in the video data and negatively associated with 
revealed non-compliance at two of the survey intersections. When coupled with the positive association between normlessness and stated willingness to run a red light, the relationship between helmet use and compliance solidifies the notion that a class of cyclists is more likely to consistently violate signals. It points towards a link between red light running and individuals who do not adhere to social norms and policies as strictly as others. Variables representing cyclists and motorists waiting at the signal were positively related to signal compliance in the video data. While an increased number of cyclists may be a physical deterrent to red light running, part of the influence on compliance that this variable and the variable representing the presence of a vehicle may be due to accountability of cyclists to other road users. This relationship, however, was not revealed in the stated noncompliance data from the survey.

Efforts to increase cyclist compliance may not be worth a jurisdiction's resources since nearly $90 \%$ of cyclists in the video data were already compliant. If a problem intersection does warrant intervention, different methods of ensuring bicyclist compliance are warranted depending on the intersection characteristics. An alternative solution is to consider the applicability of traffic laws (originally designed for cars) to bicyclists. Creating separation in how laws affect motorists and cyclists might be a better solution for overly simple types of intersections where cyclists have fewer conflicts, better visibility, etc. than motorists. Education or other messaging aimed at cyclists about compliance is another strategy to increase compliance. Since cyclists appear to feel more justified in running red lights at low-volume, simple-looking intersections, it would probably be prudent to target messaging at these types of intersections. Many cyclists are deterred by 
high-volume and/or complicated looking intersections for safety reasons. Reminding cyclists of the potential dangers at other intersections may be a successful messaging strategy. Alternatively, reminding cyclists that it is still illegal to run a red light even if they feel safe doing so may be prudent. Additionally, messaging about the purpose of infrastructure such as bicycle-specific signals or lights that indicate detection at a signal may convince cyclists that stopping at the signal is in their best interest and that the wait will be minimal and/or warranted. 


\section{For Basildon Beauregarde}

(Baz, Bazzy Boo, Boofaloo, Bubba, Baz to the bone - I love you, buddy) 


\section{Acknowledgements}

I would like to acknowledge my committee, especially Chris Monsere, for their guidance, support, and...patience. For the generous funding that got me started on the road toward studying bicycle compliance, I'd like to thank the Oregon Department of Transportation, the Dwight David Eisenhower Graduate Fellowship program, and the Oregon Transportation, Research and Education Consortium (OTREC)/National Institute for Transportation and Communities (NITC). I also want to thank my wonderful community of friends and chosen family who have been nothing but supportive (that includes you, fellow lab members). A special thanks to Sarah Binns who called and texted me relentlessly to make sure I was actually awake in the mornings and to Baz, who was irritating enough to get me out of bed when all else failed. 


\section{Table of Contents}

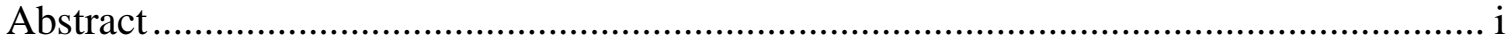

Acknowledgements ........................................................................................... vi

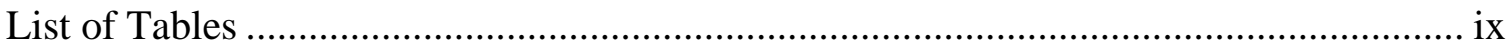

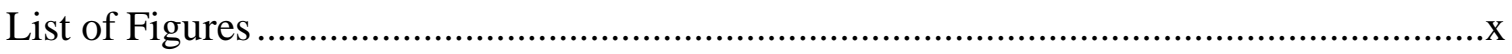

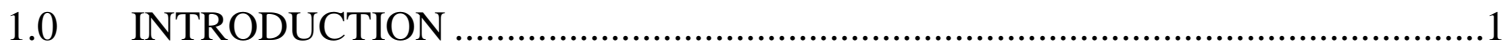

1.1 Motivations \& Objectives ................................................................ 4

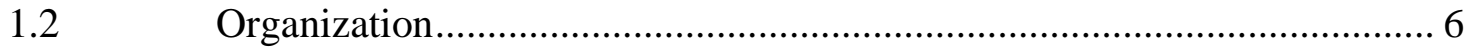

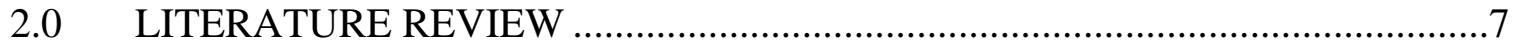

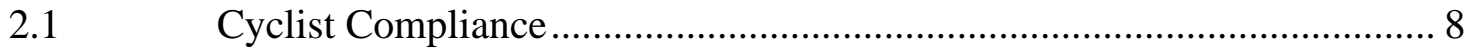

2.1.1 Rates of Infringement and Associated Factors ......................................... 8

2.1.2 Attitudes and Reasoning Regarding Infringement................................... 12

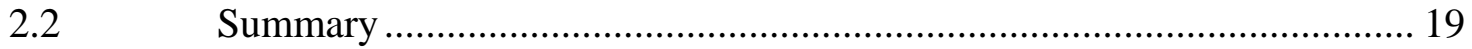

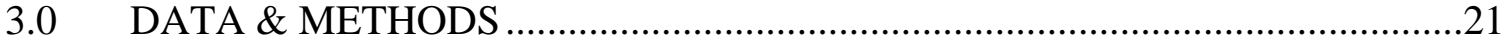

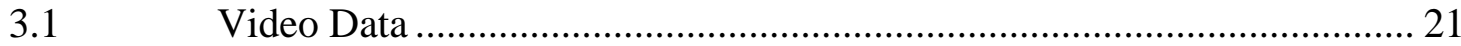

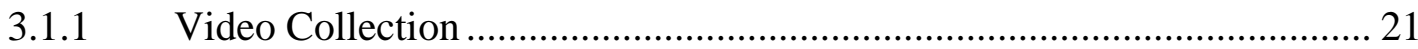

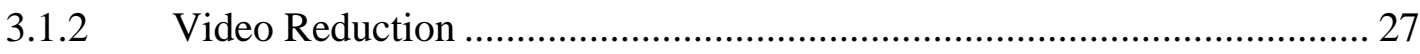

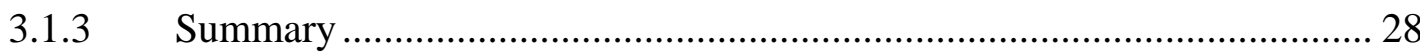

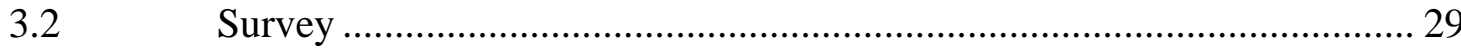

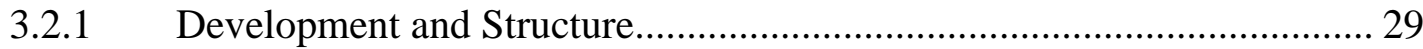

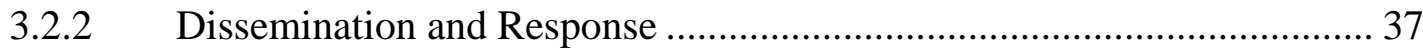

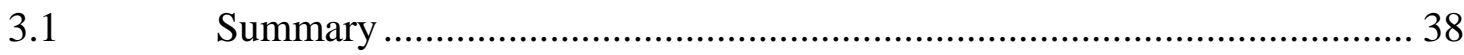

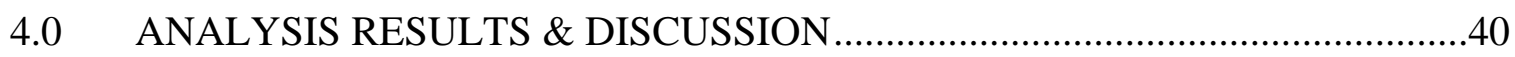

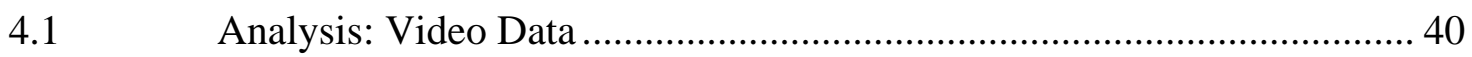

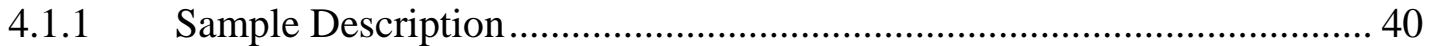

4.1.2 Modeling Compliance (Video) ............................................................... 42

4.1.3 Gap Accepted Model ………………………………………………... 43

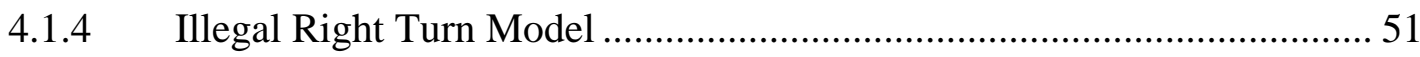

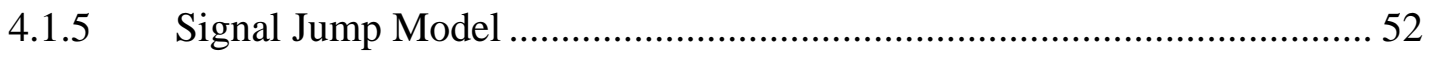

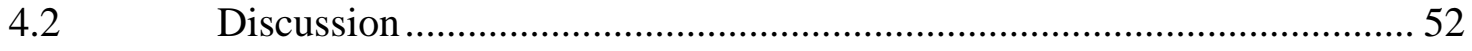

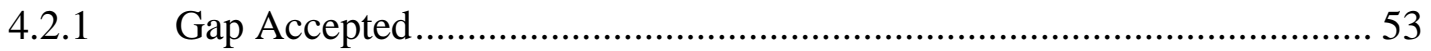




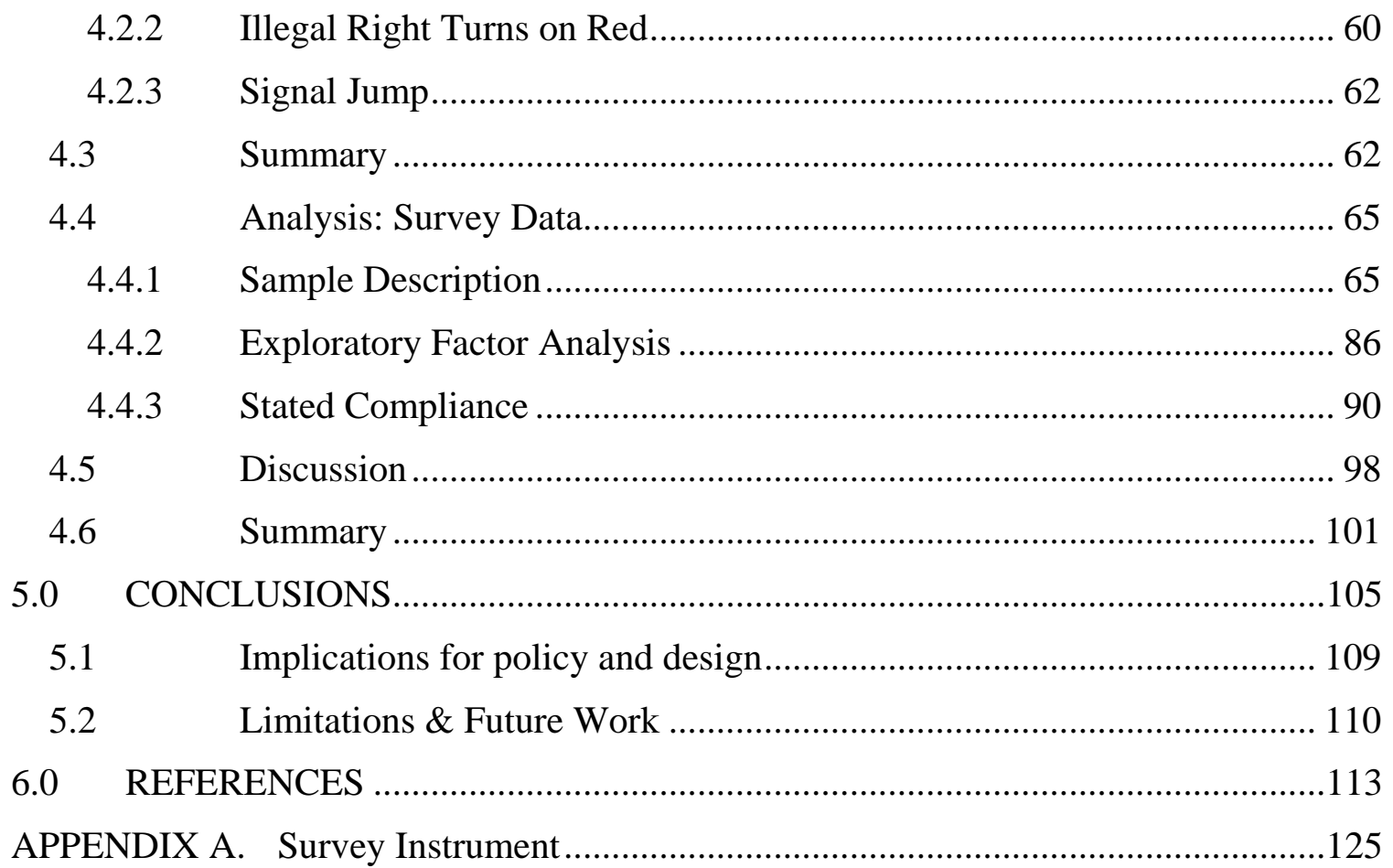




\section{List of Tables}

Table 4.1 Characteristics of Cyclists and Intersections from Video Data ...................... 41

Table 4.2 Characteristics of Qualitative Video Data Variables .................................... 42

Table 4.3 Binary Logit Results (Gap Accepted Model) - All Observations ................... 46

Table 4.4 Binary Logit Results (Gap Accepted Model) - No Broadway/Lovejoy Observations

Table 4.5 Binary Logit Results (Gap Accepted Model) - Random Broadway/Lovejoy

Observations 49

Table 4.6 Binary Logit Results (Illegal Right Turn Model) ....................................... 51

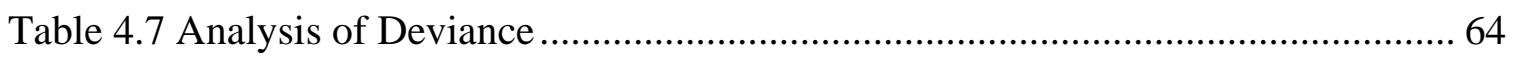

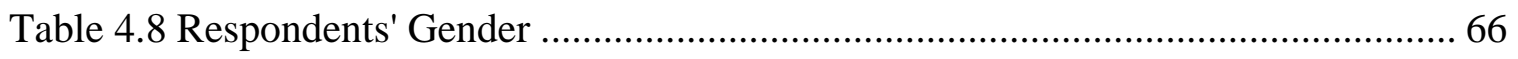

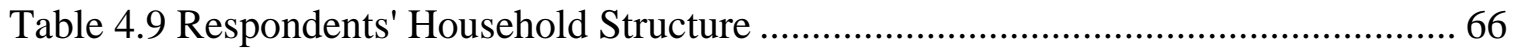

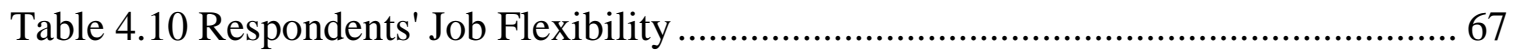

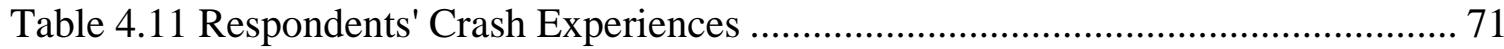

Table 4.12 Respondents' Crash Severities with Other Road Users ............................... 72

Table 4.13 Respondents' Crash Severities with Road Objects \& Surfaces ..................... 72

Table 4.14 Respondents' Reported Driving-Related Risk Behaviors ............................ 74

Table 4.15 Respondents' Reported Biking-Related Risk Behaviors.............................. 75

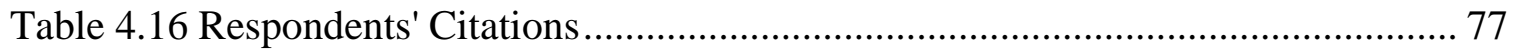

Table 4.17 Percent of Strongly Agree and Agree Responses per Justification ................ 78

Table 4.18 Summary of Personality Scores ........................................................... 79

Table 4.19 Factor Loadings for Red Light Running Scenarios ...................................... 89

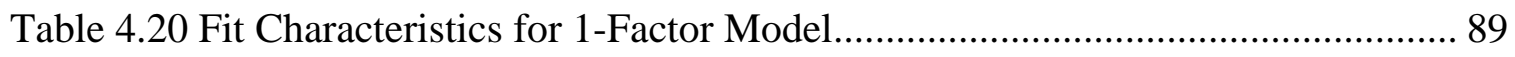

Table 4.21 Stated Non-Compliance at Survey Intersections ...................................... 90

Table 4.22 Variable Correlations with Stated Compliance ........................................... 93 


\section{List of Figures}

Figure 2.1 Bicyclist Non-Compliance and Cross Traffic on Pennsylvania Ave, Washington D.C. 10

Figure 2.2 Observations of Bicyclist Red Light Running at San Francisco Intersections 11

Figure 3.1 NW Broadway and NW Lovejoy Street, Portland, OR ............................... 22

Figure 3.2 N Rosa Parks Way and I-5 SB Off-Ramp, Portland, OR ............................. 23

Figure 3.3 NE Broadway and N Williams Avenue, Portland, OR ................................ 23

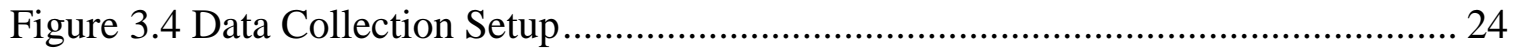

Figure 3.5 Pearl Street and E 18th Avenue, Eugene, OR ............................................ 25

Figure 3.6 NW Buchanan Avenue and NW 9th Street, Corvallis, OR .......................... 26

Figure 3.7 SE Johnson Creek Boulevard and SE Bell Avenue, Clackamas, OR ............ 26

Figure 3.8 SW Lombard Avenue and SW 5th Street, Beaverton, OR ........................... 27

Figure 3.9 Framework of Cyclist Compliance Decisions ........................................... 30

Figure 3.10 Diagram of Simplified Inputs to Compliance ......................................... 32

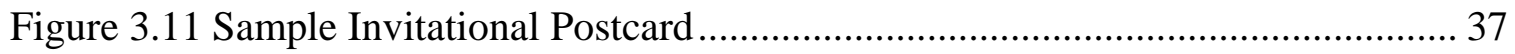

Figure 4.1 Diagram of Binary Logistic Model for Video Data ..................................... 44

Figure 4.2 Standardized Regression Coefficients (Gap Accepted Model) -- All

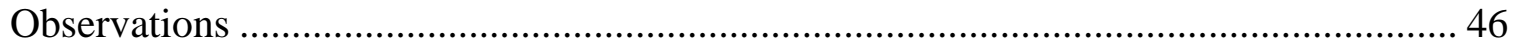

Figure 4.3 Standardized Regression Coefficients (Gap Accepted Model) - No Broadway/Lovejoy Observations........................................................................... 49

Figure 4.4 Standardized Regression Coefficients (Gap Accepted Model) - Random Broadway/Lovejoy Observations............................................................................ 50

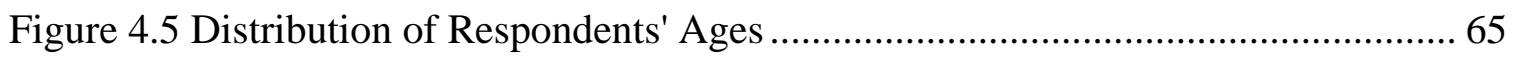

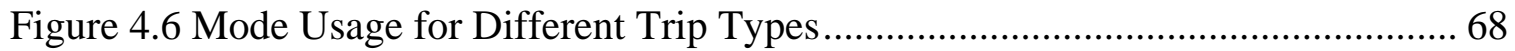

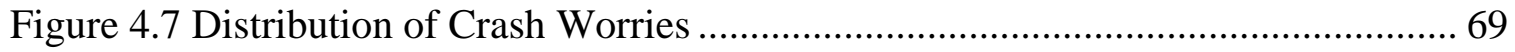

Figure 4.8 Distribution of Anticipated Severity of a Crash with a Motor Vehicle........... 70

Figure 4.9 Reported Participation in Driving-Related Risk Behaviors .......................... 73

Figure 4.10 Reported Participation in Biking-Related Risk Behaviors ......................... 75

Figure 4.11 Distribution of Impulsive-Sensation Seeking Scores ............................... 81

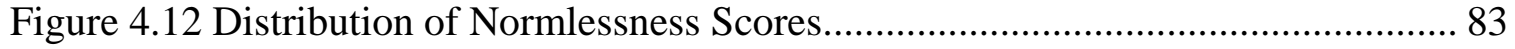

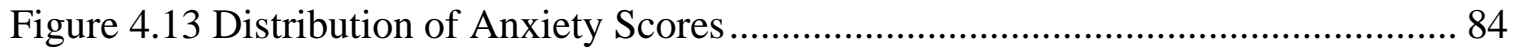

Figure 4.14 Distribution of Patience (Aggression) Scores ......................................... 85 
Figure 4.15 Output of Parallel Analysis .............................................................. 88

Figure 4.16 Intersection-Specific Analysis Survey Pictures....................................... 91

Figure 4.17 Proportion of Stated Compliance per Intersection .................................... 92

Figure 4.18 Most Influential Factor in Decision to Run Red Light (Austin) ................. 95

Figure 4.19 Most Influential Factor in Decision to Run Red Light (Eugene) ................. 96

Figure 4.20 Most Influential Factor in Decision to Run Red Light (Portland)................ 97 


\subsection{INTRODUCTION}

Increasing cycling as a regular mode of transportation has many personal and environmental benefits that have been noted in recent literature (Pucher, Dill, \& Handy, 2010; Pucher, Komanoff, \& Schimek, 1999; Rabl \& de Nazelle, 2012). Increased awareness of these benefits, paired with growing concerns about pollution and traffic congestion from personal car use, have motivated many municipalities to attempt to elevate the use of bicycles among their populations. This effort has been aided significantly by increasingly bicycle-friendly federal transportation policy and, thus, state, metropolitan planning organization (MPO), and municipal spending on bicycle infrastructure has increased (Dill \& Carr, 2003; Pucher et al., 1999). This increase in federal support for cycling, in addition to the increased costs of car ownership (American Automobile Association (AAA), 2013), has likely contributed heavily to the doubling of bicycle trips in the United States over the last two decades (Pucher et al., 1999). More recently, New York City, NY and San Francisco, CA, have reported major increases in utilitarian bike usage (Goodyear, 2013).

Even with the rapid emergence of car-sharing culture (Simpson, 2009), the current trend in declining car use (especially by young people) is likely to continue (Dutzik \& Baxandall, 2013). This trend in conjunction with the number of short trips conducive to cycling ( $48 \%$ of trips by all modes in 1999 were three miles or less)(Pucher et al., 1999) presents an opportunity for further growth in the number of bicycle trips made in the United States. As cycling becomes less and less of an "alternative" mode, it is important to evaluate our transportation system in terms of its accommodation of bicycle users. 
Crucial to the success of our transportation system is users' compliance with the devices meant to direct and control the flow of traffic. The National Committee on Uniform Traffic Control Devices (NCUTCD) requires evidence of compliance with any new form of traffic control that may be officially implemented because, since traffic control is generally implemented to mitigate conflicts between road users, the level of compliance with any device can have safety and traffic flow implications. The growing number of utilitarian cyclists makes cyclist compliance an increasingly important factor in the safety and efficiency of the transportation system.

Perceptions of cyclist compliance are fairly well documented. Anecdotally, other road users, namely motorists, view utilitarian cyclists as disobedient or even 'renegade' and instilled with a sense of bravado (Fincham, 2006; Pucher et al., 1999). One study found that $62 \%$ of the drivers surveyed agreed that "[m]any cyclists take no notice of road rules" while only $34 \%$ agreed that "[c]yclists are courteous on the road to motorists" (Rissel, Campbell, Ashley, \& Jackson, 2002). This second statement may point towards growing frustration of motorists with non-predictable behavior by other road users in the context of an increasingly volatile traffic environment. Cyclists, especially, were cited as having particularly 'erratic/unpredictable' behavior and this behavior was thought to be inherent to cyclists and not justifiable or explainable by experiences imperceptible to those viewing the cyclist (Basford, Reid, Lester, Thomson, \& Tolmie, 2002). The veracity of such perceptions is questionable, though, as it has been suggested that cyclists may be an easy target on which motorists can project their general frustrations with the transportation system (Fincham, 2006). These frustrations can also manifest themselves as dangerous 
opportunities for conflicts since drivers have been found to increase risky behavior around bike-specific facilities, possibly because there is less perceived risk of a cyclist making unpredictable maneuvers into the way of the motorist (Basford et al., 2002). This belief, combined with viewing instances of cyclist non-compliance, contributes negatively to driver attitudes toward cyclists.

In addition to the negative impact on driver perception of cyclists, non-compliance (specifically red light running) by cyclists does have clear negative safety implications. In one study, conflicts (i.e. potential crashes) were reported to be the fault of the cyclists $9 \%$ of the time (Bai, Liu, Chen, Zhang, \& Wang, 2013). Although this number is not indicative of the number of crashes, some conflicts do result in actual bicycle-motor vehicle crashes. While bicycle-related crashes on the whole are drastically under-reported worldwide (Elvik \& Mysen, 1999), few studies have managed to document the effects of cyclists' red light running on cyclist-motor vehicle crashes. Crashes resulting from a cyclist disobeying a traffic signal made up a small portion of crashes in studies from the United Kingdom (1.8\%, $\mathrm{n}=508)$ (Lawson, 1991) and Queensland, Australia (6\%, $\mathrm{n}=2008)$ (Green, 2003) (6.5\%, $\mathrm{n}=1214)$ (Schramm, Rakotonirainy, \& Haworth, 2008). In all, motorists were far more likely to be at fault in bicycle-motor vehicle crashes (Schramm, Rakotonirainy, \& Haworth, 2010). However, cyclist injuries in any crash with a motor vehicle are likely to be more severe. Studies from Queensland, Australia found that over two-thirds of cyclists involved in police-reported crashes required medical attention, and nearly a third required hospitalization (Schramm et al., 2010) and that the average risk of death or serious injury for cyclists was $27 \%$ (though it was noted that this percentage was much higher than the 
average of $13 \%$ for the region) (Watson \& Cameron, 2006). One U.S.-based study concluded that $64.3 \%$ of cyclists in crashes with motor vehicles sustained moderate or worse injury types (Hunter, Stutts, Pein, \& Cox, 1996).

Given the intensely negative social stereotypes regarding cyclist compliance, the increased use of bicycles, and the potential safety consequences of non-compliance, municipalities have begun to increase enforcement of traffic laws commonly broken by cyclists (Goodyear, 2013). Conversely, some cyclists believe that efforts to quell certain types of cyclist infringement are misguided since many traffic laws were not written with cyclists in mind and are, for this reason and/or others, unreasonable for them to follow (Grabar, 2013).

In light of the possible safety implications of cyclist compliance, the intense social perceptions, and the emerging intent on enforcement of traffic laws for cyclists, there is a need for greater empirical understanding of cyclist compliance.

\subsection{Motivations \& Objectives}

This study seeks to elucidate the determinants of cyclists compliance, specifically the decision of whether or not to run a red light. As will be evident by the review of the literature, few studies have examined cyclists compliance at signalized intersection and none that specifically address red light running have originated from within the United States. This thesis seeks to fill a gap in the literature by confirming or refuting findings on the determinants of cyclist red light running from other countries with a sample of cyclists 
from the United States. In line with previous studies, variables that may affect red light running will be analyzed using a binary logit model in which the dependent variable is noncompliance (running of the red indication) by a cyclist from video data. The study of video data deviates from other studies by recognizing the various ways in which cyclists might "run a red light". Three types of red light running were originally identified by a descriptive study of compliance at signals in Oregon (Monsere, Figliozzi, Thompson, \& Paulsen, 2013). Unlike prior studies of cyclist red light running, this one focuses on one of the types identified by the Oregon study. This type of red light running occurs when a cyclist crosses against the red by utilizing a gap in cross traffic. This maneuver is, thus, called gap acceptance. As the most egregious type of cyclist non-compliance at signalized intersections, gap acceptance is the focus of this study. Cursory evaluation is also performed for two other types of red light running.

Additionally, this thesis delves much further into determinants of red light running that are internal to the cyclist. Data from a survey of cyclists are used to explore relationships between cyclist demographic and experience-based traits similar to another study from the literature. Expanding upon existing literature in this realm, is the use of standard personality metrics to catalogue cyclists by personality types. In addition to being the first to utilize psychometrics, this is the first study of its kind that analyzes stated compliance by cyclists at intersections based on varying intersection characteristics. Thus, the study is able to examine the connections between cyclist characteristics, intersection characteristics, and compliance. 


\subsection{Organization}

For the remainder of this document, organization is as such. First, prior research on the actual rates of red light infringement by cyclists is reviewed. This is followed by a review of the personality factors that encourage risk-taking in transportation-related situations,

justifications for traffic violations, and, finally, cultural norms that may influence noncompliance. Next is a description of the data and methods used in this study followed by a discussion of the analysis and results. Finally, conclusions and implications for future work are presented. 


\subsection{LITERATURE REVIEW}

Presently, the majority of literature related to cyclist compliance with traffic laws evaluates the effectiveness of helmet laws to increase helmet use and reduce injury (LeBlanc, Beattie, \& Culligan, 2002; B. H.-Y. Lee, Schofer, \& Koppelman, 2005; Macpherson \& Spinks, 2008; Robinson, 1996). Other work has been done to document cyclist and motorist understanding of new infrastructure like bike boxes and pavement color (Dill, Monsere, \& McNeil, 2011; Johnson, Charlton, Newstead, \& Oxley, 2010). Compliance by any road user can refer to myriad behaviors at various locations in addition to compliance with an overarching policy such as a helmet law. For this thesis, it is important to narrow the scope of research enough so that the text may be meaningful. Signalized intersections are operationally important locations at which we can document compliance. In addition to the fact that intersections are the convergence of several directions of travel, making for multiple opportunities for conflict, signalization is mandated for only those intersections with enough traffic volume or another complicating safety factor to warrant this type of traffic control (Federal Highway Administration, 2009). Furthermore, violation of red indications at traffic signals is commonly cited as the cyclist behavior most aggravating for drivers (Fincham, 2006; Johnson, Charlton, Oxley, \& Newstead, 2013). The rapid implementation of bicycle-specific signals throughout the United States (Thompson, Monsere, Figliozzi, Koonce, \& Obery, 2013; Loew \& Perez, 2012) further emphasizes the need for research documenting cyclist compliance with traffic signals. 
This chapter aims to synthesize the important literature in two areas: (1) the rates of infringement by cyclists at signalized intersections, and (2) attitudes and reasoning behind non-compliant decisions.

\subsection{Cyclist Compliance}

The literature on cyclist compliance with signalized indications is comprised of studies that analyzed either: (1) the actual rates of infringement against red indication and the factors significantly associated with infringement or (2) the attitudes concerning compliance and/or the reasoning or justification for cyclists' non-compliant decisions.

\subsubsection{Rates of Infringement and Associated Factors}

To date, few studies have focused on cyclist compliance at signalized intersections. Two studies done abroad analyzed the rate of red-light running at signalized intersections and factors that affect the likelihood of this type of non-compliance while another presented a self-reported rate of red-light running for its study population. The first study looked at red-light running of users on both bicycles and electric bikes in China. It was found that, for cyclists only, $50 \%$ of riders violated the red indication. The likelihood of red-light running increased significantly with youth, decreasing group and queue size, low crosstraffic volume and witness of other users running the red light. The study identified three types of cyclists: law-obeying, risk-taking, and opportunistic. Risk-takers and opportunists violated a red interval differently with risk-takers riding through the signal without yielding and with opportunists growing impatient with the red indication and crossing during an available gap (Wu, Yao, \& Zhang, 2011). The behavior of the 
opportunists validates the assertion that increased wait time increases non-compliance of cyclists (Fietsberaad, 2003). Lastly, it was found that the majority (70\%) of noncompliant cyclists crossed during the very beginning or end of the red phase suggesting two scenarios: (1) cyclists speeding through the intersection to avoid stopping and (2) cyclists "jumping the gun" and beginning their crossing maneuver before the green phase (Wu et al., 2011).

The second study done on cyclist compliance analyzed cyclist behavior at signalized intersections in Melbourne, Australia. Researchers found the rate of red light noncompliance to be only $7 \%$ - much lower than that for cyclists in the previously-mentioned study. Researchers also found that left-hand turn violations (similar to right-hand turns in the United States) were 28.3 times as likely, indicating that non-compliant actions with few conflict points are more attractive to cyclists. Results also showed that the presence of other users deterred the infringement of traffic indications as did gender, with females being more compliant (Johnson, Newstead, Charlton, \& Oxley, 2011).

The last study from outside the U.S. analyzed self-reported accident and risk behavior incidence from a population of cyclists in Pelotas, Brazil. A high percentage of cyclists (38.4\%) reported running at least one red light in the last year (Bacchieri, Barros, dos Santos, \& Gigante, 2010).

Within the United States, two studies have included the evaluation of compliance at signalized intersections. An evaluation of cycling infrastructure in Washington D.C. yielded results of cyclist compliance related to cross traffic and delay. Parks, Monsere, 
McNeil and Dill (2012) studied compliance with signals in the Washington D.C. area as part of a wider evaluation of cycling infrastructure. Compliance at signals was related to crossing traffic and somewhat related to delay for cyclists. With varying characteristics for each intersection, it was difficult to state a definitive relationship between compliance and cross traffic, but a trend was apparent (See Figure 2.1).

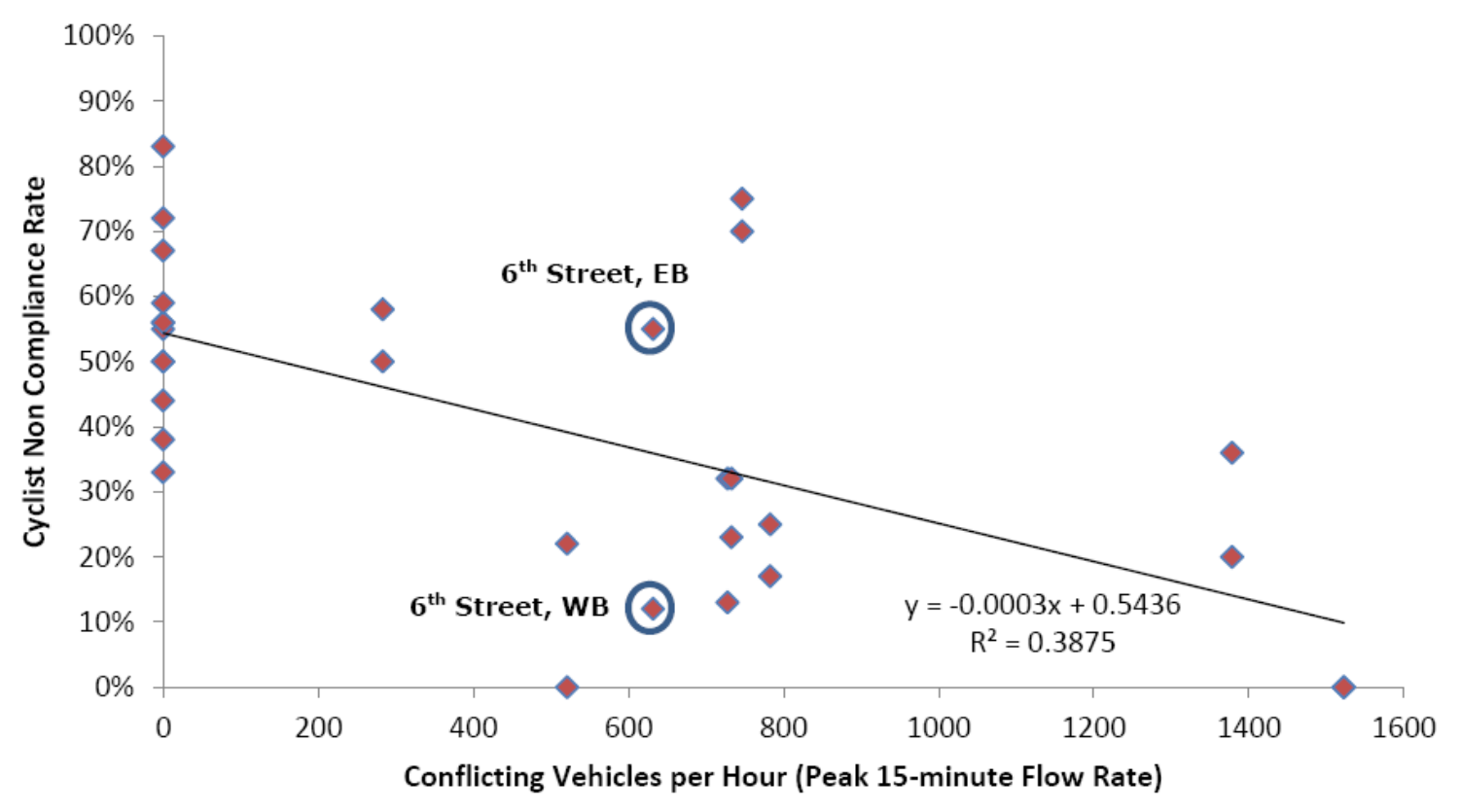

Figure 2.1 Bicyclist Non-Compliance and Cross Traffic on Pennsylvania Ave, Washington D.C. ${ }^{1}$

Rates of compliance for cyclists from the San Francisco metropolitan area were presented for 12 separate intersections (Cooper, Schneider, Ryan, \& Co, 2012). The study observed 557 cyclists in the 4-6PM hours and categorized red light running behaviors. Rates of non-

\footnotetext{
${ }^{1}$ From (Parks, Monsere, McNeil, \& Dill, 2012)
} 
compliance ranged from 4 to $36 \%$ with intersections in the upper range "generally ha[ving] more gaps in traffic" than the higher compliance locations with "steady opposing traffic" (See Figure 2.2).

\section{Bicyclist Ran the Red Light at a Signalized Intersection}

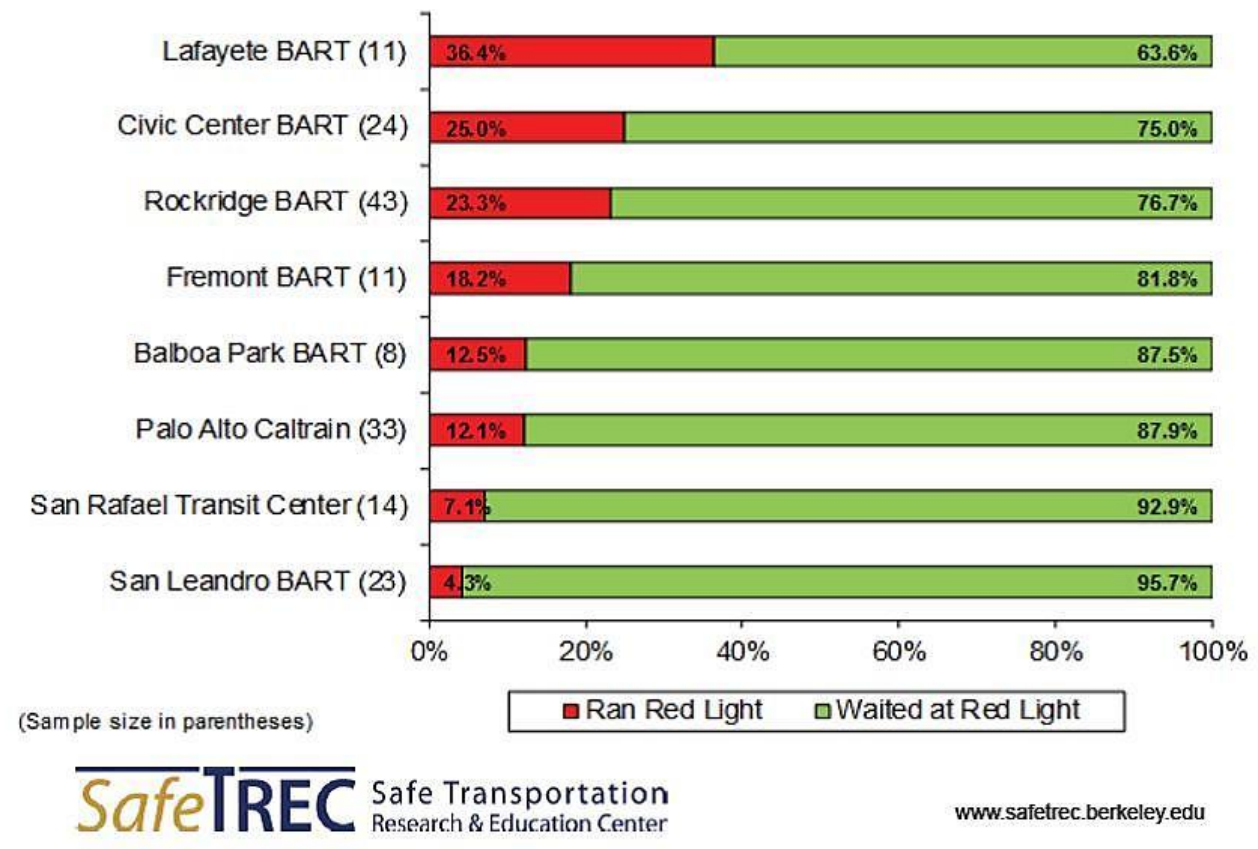

Figure 2.2 Observations of Bicyclist Red Light Running at San Francisco Intersections ${ }^{2}$

In addition to compliance with traditional traffic signals, one jurisdiction has attempted to evaluate the effectiveness of a newly-installed bicycle-specific traffic signal. This case study of a bike signal at a trail crossing of a roadway in Denver, $\mathrm{CO}$ attempted to look at

\footnotetext{
${ }^{2}$ From (Cooper, Schneider, Ryan, \& Co, 2012)
} 
compliance of cyclists before and after the installation (Denver, CO, 2009). Previous to installation, only a pedestrian signal head existed and cyclists were considered "compliant" only if crossing during the "WALK" phase. As might be expected, cyclists continued to cross during the pedestrian clearance interval since it allowed ample time for them to cross. It was shown that with the installation of a bike signal, cyclists were more likely to cross during the bicycle interval time. However, comparison of cycle phase time and signal displays of the bike and pedestrian signals revealed that, while cyclists were more likely to cross at compliant times, compliant times provided by the bike signal matched the existing behavior of cyclists.

\subsubsection{Attitudes and Reasoning Regarding Infringement}

Arguably more valuable to the study of compliance than infringement rates and factors from specific locations are the reasons behind such non-compliant actions. Psychological and sociological variables that influence cyclists' decisions to infringe at red lights are more widely applicable since they influence the general population and not just the users represented at study locations. Prominent theories of persuasion attribute the capability of a message to influence behavior to the capacity of a member of the target audience to attend to, understand, accept, and retain the message (Eagly \& Chaiken, 1993). Personality characteristics influence a person's ability to aptly complete each of these steps in the persuasion process (Cacioppo, Petty, Kao, \& Rodriguez, 1986). Thus, knowing the personality characteristics of non-compliant users can help inform campaigns to modify behavior (Caspi et al., 1997). Coupled with more empirical data about the intersection characteristics that most impede non-compliance, attitudinal information may help to 
inform messages about compliance and the design of compliance devices to elevate their ability to garner respect from cyclists. Aside from the positive safety outcomes, tempering of the somewhat hostile relations between cyclists and other road users may be an outcome of increased cyclist compliance.

Possible psychological and social reasons for infringement could be the possession of a personality type more susceptible to risk behaviors, the ability to justify infringement decisions for a variety of reasons, or adherence to the mindset of a subculture that accepts or celebrates risk and/or bravado.

\subsubsection{Personality Factors and Risk Aversion}

A fairly large body of work has been dedicated to the role of personality traits and risky behaviors in crash involvement (Elander, West, \& French, 1993; Sümer, 2003). This research has been limited to that concerning automobile drivers with one recent exception of a study concerning e-bike riders in China (Yao \& Wu, 2012). Additionally, much of this research has focused on young or novice drivers (Gregersen \& Bjurulf, 1996) and/or those with potential for or record of DWI violations (D. M. Donovan, Marlatt, \& Salzberg, 1983). Although it is true that adolescents are more risk-taking in general (Gregersen \& Bjurulf, 1996), certain personality traits related to risk-taking behavior persist into adulthood (McGue, Bacon, \& Lykken, 1993; Roberts, Caspi, \& Moffitt, 2001). Furthermore, adult risk behavior in traffic is not limited to the unlawful use or abuse of alcohol. A review of the literature related to high-risk driving by Donovan et al (1983) suggests that other factors (including personality traits) were predictive of accident involvement despite the presence 
or absence of alcohol. Lastly, the personality traits of high risk alcoholic drivers were shown to be similar to those for high risk, non-alcoholic drivers leading experts to state the need for identifying the characteristics of a "high-risk" population of drivers, of which drunk drivers are a subset (D. M. Donovan et al., 1983). This need is corroborated by evidence that motorists with severe moving violations are much more likely to have committed multiple violations, to not utilize safety belts, and to have generally poorer driving records (Retting \& Williams, 1996).

Aberrant driving and other risky driving behaviors are presented as aspects of the Proximal Context in a model of crash involvement by Sümer (2003). In other words, these behaviors are "proximal" or closely associated with a crash. These proximal factors mitigate the relationship between crashes and factors in the Distal Context which are extrinsic to a crash scenario and include personality traits and socio-demographic factors. Sümer argues that distal factors can "create a generalized tendency...to have high levels of risky driving behaviors [and]...these behaviors predict the actual accident involvement," (p. 951). It was demonstrated that these factors do in fact influence driving style (part of the Proximal Context) and, thus, contribute to automobile crashes (Sümer, 2003). Personality traits, specifically, have been noted to be "more predictive of driving performance than individual differences in physiological or psychophysiological characteristics" (D. M. Donovan et al., 1983, p. 400).

Risky driving behaviors and style are related to overall risk-acceptance in individuals as evidenced by correlation of these behaviors with non-traffic forms of risk-taking such as 
smoking, illegal drug use, alcohol abuse, delinquency, and unprotected sex in certain individuals (Bina, Graziano, \& Bonino, 2006; Caspi et al., 1997; J. E. Donovan, 1993; Everett, Lowry, Cohen, \& Dellinger, 1999; West \& Hall, 1997). Furthermore, certain personality factors were common to those people with the tendency to engage in healthrisk behaviors of any type and persons engaging in one health-risk behavior were more likely to engage in another (Caspi et al., 1997). Additionally, these personality factors were found to impact risk behavior irrespective of socio-demographic factors (Caspi et al., 1997). Characteristics most commonly explored with regard to risk-taking behavior in traffic are aggression, altruism, anxiety, normlessness, social deviance, neuroticism, and sensation-seeking (D. M. Donovan et al., 1983; Jonah, 1997; Ulleberg \& Rundmo, 2002). Sensation-seeking, especially, has been a focus in the literature on personality and driving risk (Jonah, 1997; Rimmö \& Åberg, 1999). These types of risk-taking attitudes are correlated with an intention to commit driving violations (i.e. be non-compliant in a variety of ways) (Parker \& Manstead, 1996) with violations being the most stable indicator of accident-proneness found in several studies (see Rimmö and Åberg (1999) for an example). Furthermore, aberrant riding behaviors or e-bike riders have been shown to significantly reflect at-fault crash involvement (Yao \& Wu, 2012). In itself, the literature on risky behavior in traffic makes a compelling safety case for further study of attitudes that affect risk-acceptance and lead to non-compliance, especially for cyclists for which there is no known literature. 
However, specific personality traits in themselves are not solely responsible for affecting compliance. Decisions made by road users are also based on situational variables such as stress and time commitments they may help them justify their illegal actions.

\subsubsection{Justifications}

In addition to personality factors that affect people's disposition in terms of their willingness to infringe upon some traffic laws, situational variables play a part in someone's willingness to be compliant. These situational variables can be dynamic or more enduring. A study by Peter Jones (1990) surveyed all types of road users about their attitudes on particular types of traffic policy and their willingness to comply or not. The study revealed twelve factors that influence compliance and declined to order them by importance due to site- and person-specific characteristics that could elevate the importance of one factor over the next for each individual situation. Two factors, Physical Restraint and Impedance and Visibility and Comprehensibility of Signs and Markings, dealt with physical aspects of the roadway and traffic control devices. Intuitively, respondents were less likely to be noncompliant if they were physically restrained from doing so or if traffic control devices were in good repair and had clear meaning. The remaining ten factors had more to do with how respondents justified their noncompliant actions. In applicable situations, road users felt justified in breaking laws for the following reasons: if certain users were exempt (e.g. making a turn in turn-restricted areas if buses were allowed to turn); if they lived in an area and felt that regulations were for "outsiders"; if they were in a hurry or were only going to infringe for a small period of time (e.g. parking); if they felt it was unlikely that they would be penalized for the action; if the 
regulation caused them undue burden (e.g. living just on the other side of a 'No Entry' street; if others were seen being non-compliant; or whether or not they personally identified as a law-abiding citizen. Notably, respondents also stated that they were likely to be noncompliant if they did not understand how a policy applied to them or thought that it shouldn't.

An investigation of red light infringement in Australia dealt specifically with cyclists and utilized a survey to obtain self-reported information from respondents including whether or not they had ever ridden through a red light (Johnson et al., 2013). Males and younger individuals were more likely to have infringed than females and younger individuals, respectively, and cyclists with a history of crashes were more likely to have infringed than those without a previous accident. Cyclists who were also drivers were found more likely to infringe if they had received a ticket for red light running as a driver in the last two years. The respondents also indicated reasons for their respective red light runs with left turns (analogous to right turns in the U.S. and illegal on a red in the study location), lack of cyclist detection, and lack of other road users at the time of infringement being most common. It should be noted that this last reason was sometimes related to the fact that there were no cars to help trip the inductive loops but was cited on its own as well. Less significant but mentioned reasons were a feeling of safety, when in a hurry, and when at a T intersection. Lastly, a small number of cyclists reported that they always infringed at red lights. 
Weather conditions and the associated comfort of riders might also affect levels of compliance. A study of the effects of sunshields (shade providers) placed over cyclist waiting areas found that red light running decreased significantly when waiting cyclists were shaded by a sunshield (Zhang \& Wu, 2013). Additionally, this decrease was more pronounced when weather was sunny as opposed to cloudy.

An interesting finding from the Jones study was that "cyclists admitted to ignoring many regulations, although they reported that they would usually comply with them if they were driving" (1990, p. 67). This points to factors beyond personality and justifications for infringement in general, although being on a bicycle could in fact be further justification for non-compliance. Another factor with a possible influence on cyclist compliance is identification with cycling culture.

\subsubsection{Cultural norms}

Cultural and subjective norms have been shown to strongly influence behavioral intentions in traffic. For instance, drivers were more likely to commit traffic violations when they perceived the general population of drivers to be less compliant despite the actuality of driver behaviors in general (Yagil, 1998). The same study also indicated that less negative perceptions of violators led to a higher probability of violation (Yagil, 1998).

Given the intensely negative perceptions of cyclist compliance by drivers, the dominant road users, it is not unreasonable to suggest that cyclists themselves have internalized some these negative perceptions. This sort of internalization of a subjective norm has the potential to create a cycling subculture in which non-compliance is seen as the norm and, 
therefore, more acceptable. In conjunction with the possibility that some cyclists may view themselves as part of a subculture that lends itself toward non-compliance, this subculture could also promote a culture of risk-acceptance or normalization. Although there has been some identification of an ideal, "responsible" cyclist stereotype (Gatersleben \& Haddad, 2010), most studies have found cyclist stereotypes to align more with recreational and bike messenger cyclists. Both of these cyclist sub-types have well-documented cultural markers that include risk-acceptance (Fincham, 2006) including increased disobedience with traffic laws when traveling (formally or informally) in groups or formations (O’Connor \& Brown, 2007).

\subsection{Summary}

A small body of research has explored cyclist compliance at signalized intersections. The rates of infringement found and the types of movement counted as violations in these studies are varied. Most research on cyclist red light running has not been done in the United States and no studies from the U.S. have focused solely on red light running.

The literature on the determinants of cyclist red light running, for the most part, utilize video data to look at factors external to the cyclist such as intersection configuration, cross traffic volume, and the presence of other road users. Few studies delve into factors that are not observable in order to model cyclist red light running. This in contrast to a wide body of literature on psychological and social influences on behavior, specifically risky or lawbreaking behavior. 
The following chapters outline the data and analysis methods used to explore the determinants (both observable and not) of cyclist red light running in the United States. 


\subsection{DATA \& METHODS}

The aim of this research is to quantify and categorize cyclists with respect to their willingness to comply with traffic signals when presented with a red indication. Toward this effort, two types of data were collected. This chapter details the methods used to produce the two datasets used for the analyses. All data cleaning and analysis, unless otherwise noted, is done using the statistical software R 2.15.0 (R Core Team, 2014) ${ }^{3}$.

\subsection{Video Data}

Video footage was collected to capture actual instances of compliance and non-compliance at traffic signals. This section describes how this video data was collected and reduced for analysis.

\subsubsection{Video Collection}

Video data originated from two different sources. Both sets were collected and utilized for prior studies and are not original to this thesis. The first dataset was originally collected for use in a class project on cyclist compliance at bicycle-specific signals. Data was collected by the City of Portland using city-owned video cameras in the summer of 2011 for at least 4 days at each intersection. Video consisted of two views that, when combined, allowed the viewer to see the signal indication, cyclists waiting at the stop bar, and the cyclist's complete path through the intersection. The varying views allowed researchers to record characteristics of the cyclists (e.g. clothing, bike type) and the intersection (e.g. volume of

\footnotetext{
${ }^{3}$ Analysis and data visualization in R utilized many packages that are not explicitly cited elsewhere in the text. Package names are as follows: car, chron, gdata, ggplot2, GPArotation, lm.beta, MASS, MBESS, nfactors, plyr, QuantPsyc, reshape2, scales, and RColorBrewer.
} 
cross traffic) in addition to the behaviors of the cyclists. The locations captured in this data collection were:

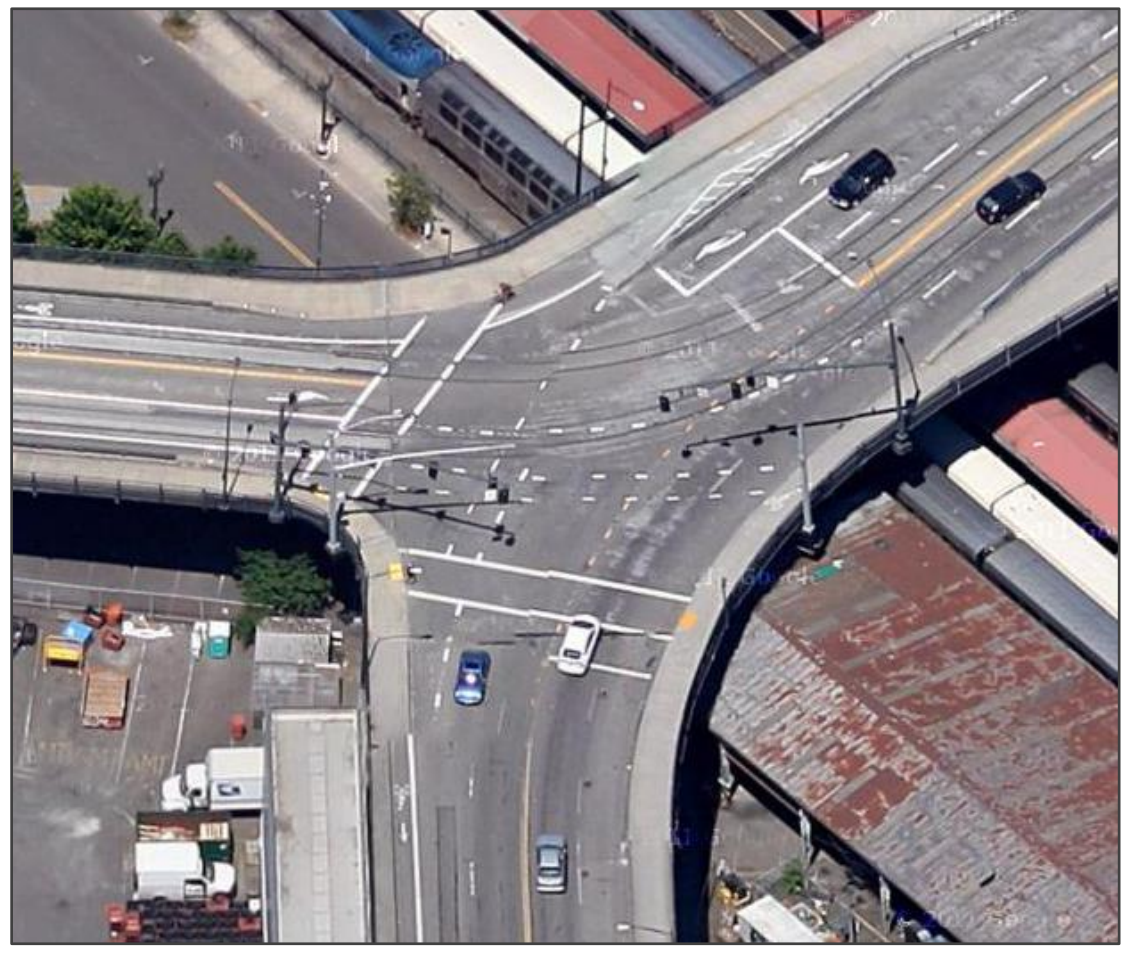

Figure 3.1 NW Broadway and NW Lovejoy Street, Portland, OR 


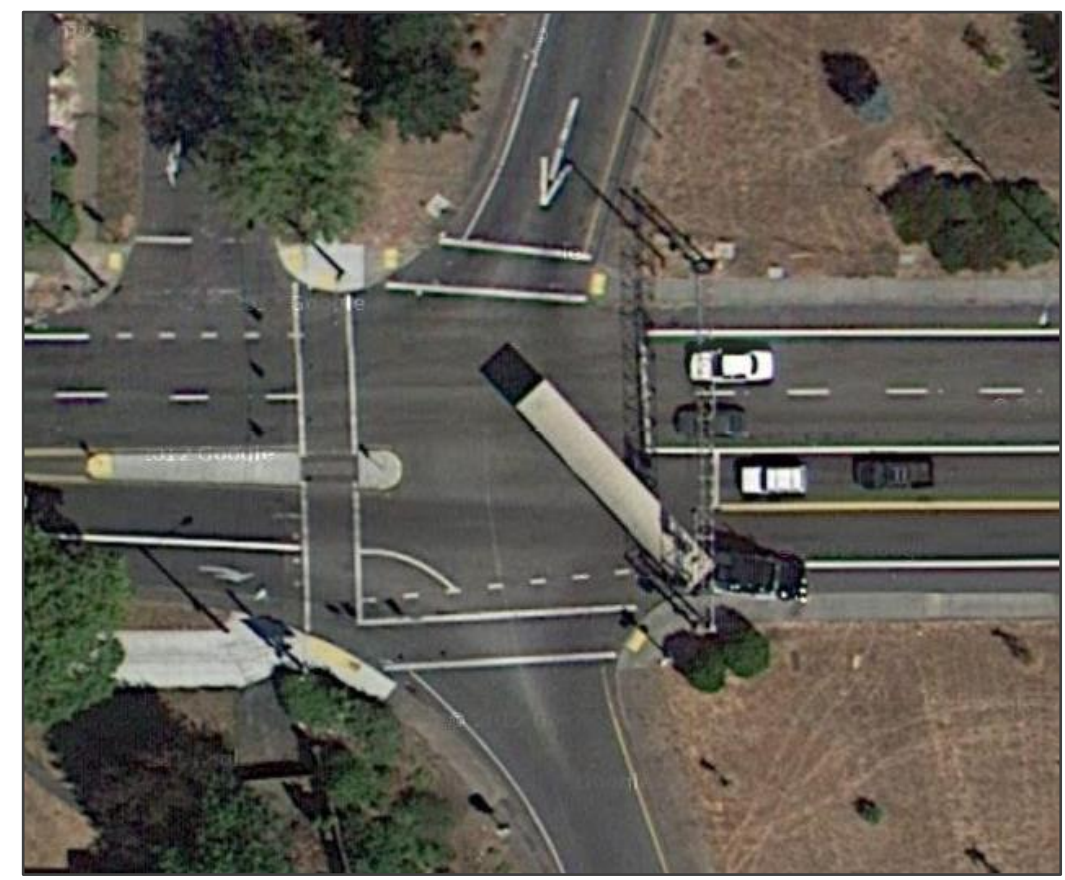

Figure 3.2 N Rosa Parks Way and I-5 SB Off-Ramp, Portland, OR

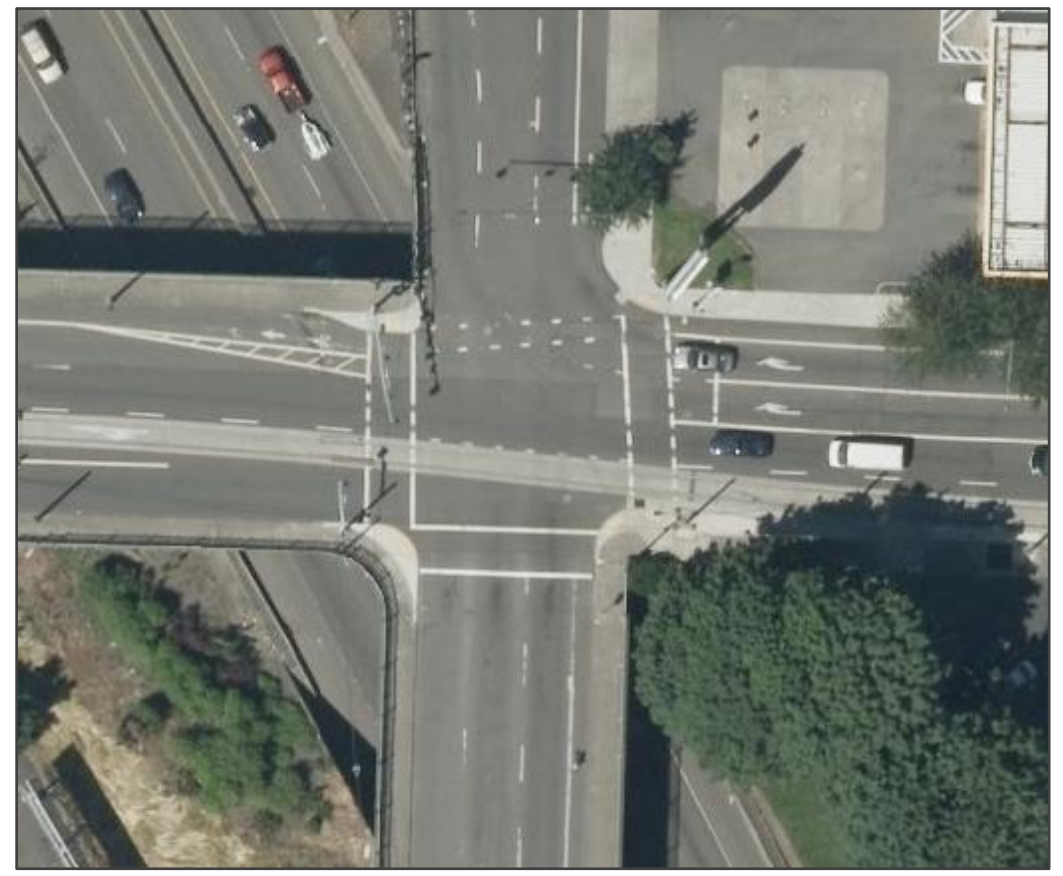

Figure 3.3 NE Broadway and N Williams Avenue, Portland, OR 

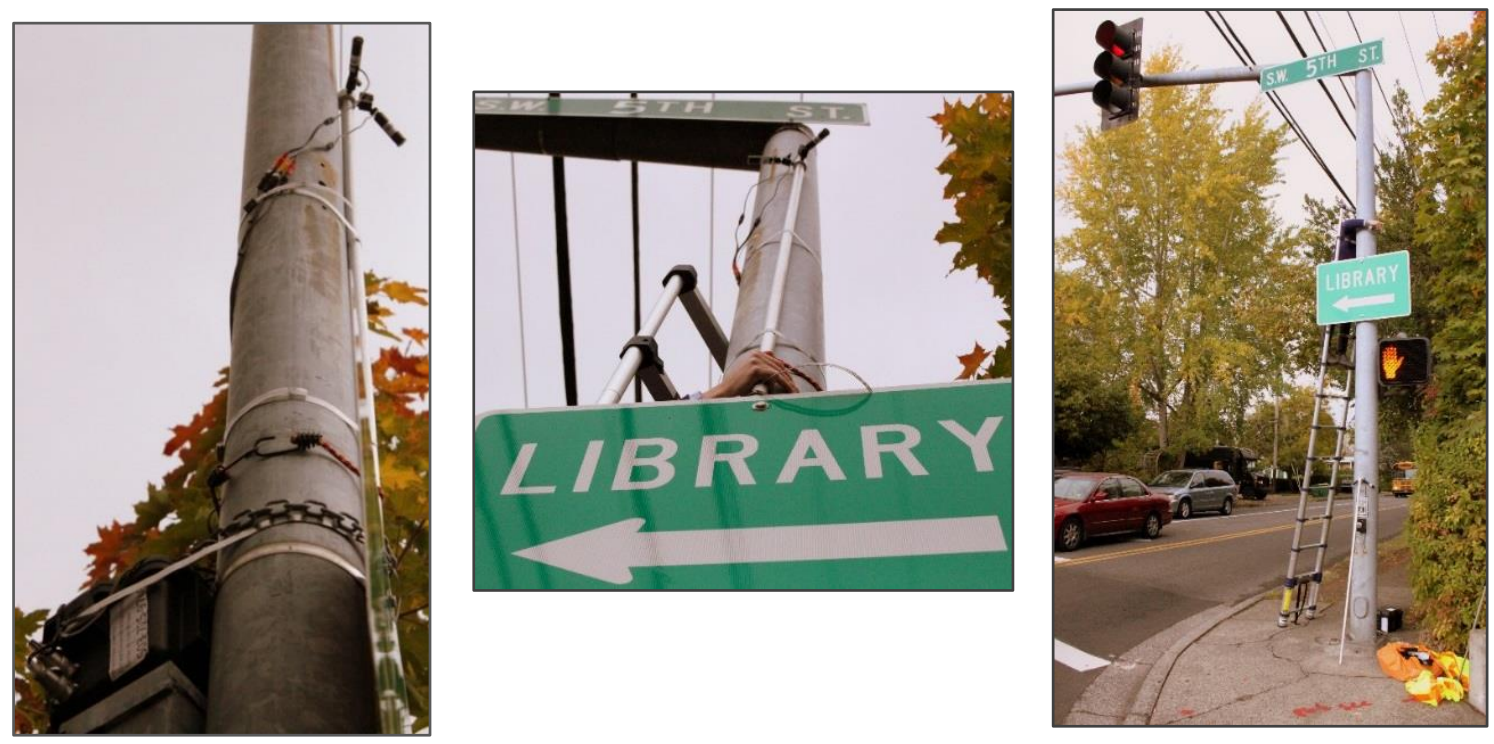

Figure 3.4 Data Collection Setup

The second video data set was collected at Portland State University for a study of bicyclespecific traffic signals which included analysis of rates of compliance at these special signals relative to traditional traffic signals. The portable video data-collection system consisted of two wide-angle camera inputs, a battery, and a digital video recorder (DVR) that combined and synced footage from both cameras into one image. The cameras were mounted to existing infrastructure, out of the view of most road users. An example of the setup can be seen in Figure 3.4. 
Views from the video mirrored those from the first data set so that the same variables could be recorded for each cyclist. Footage was taken for a more limited amount of time (at minimum of 4 hours per intersection) in the spring of 2012. Locations included in this data set are as follows:

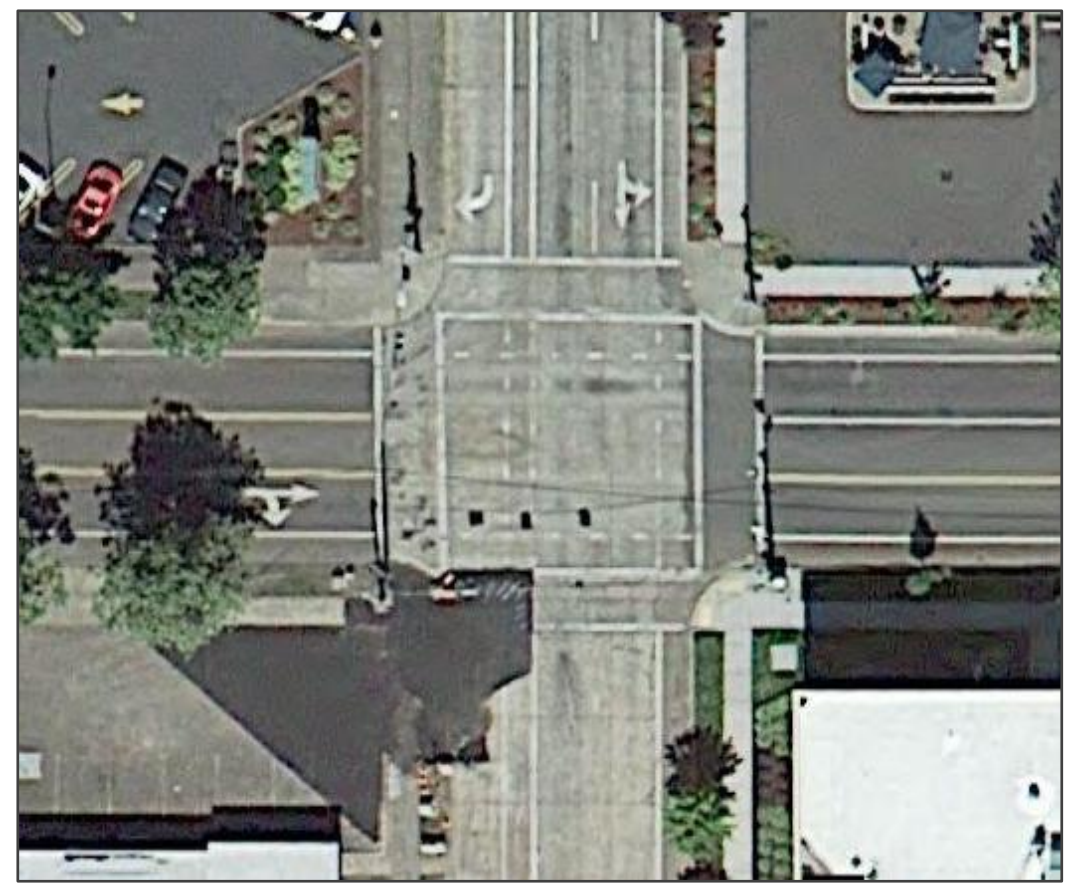

Figure 3.5 Pearl Street and E 18th Avenue, Eugene, OR 


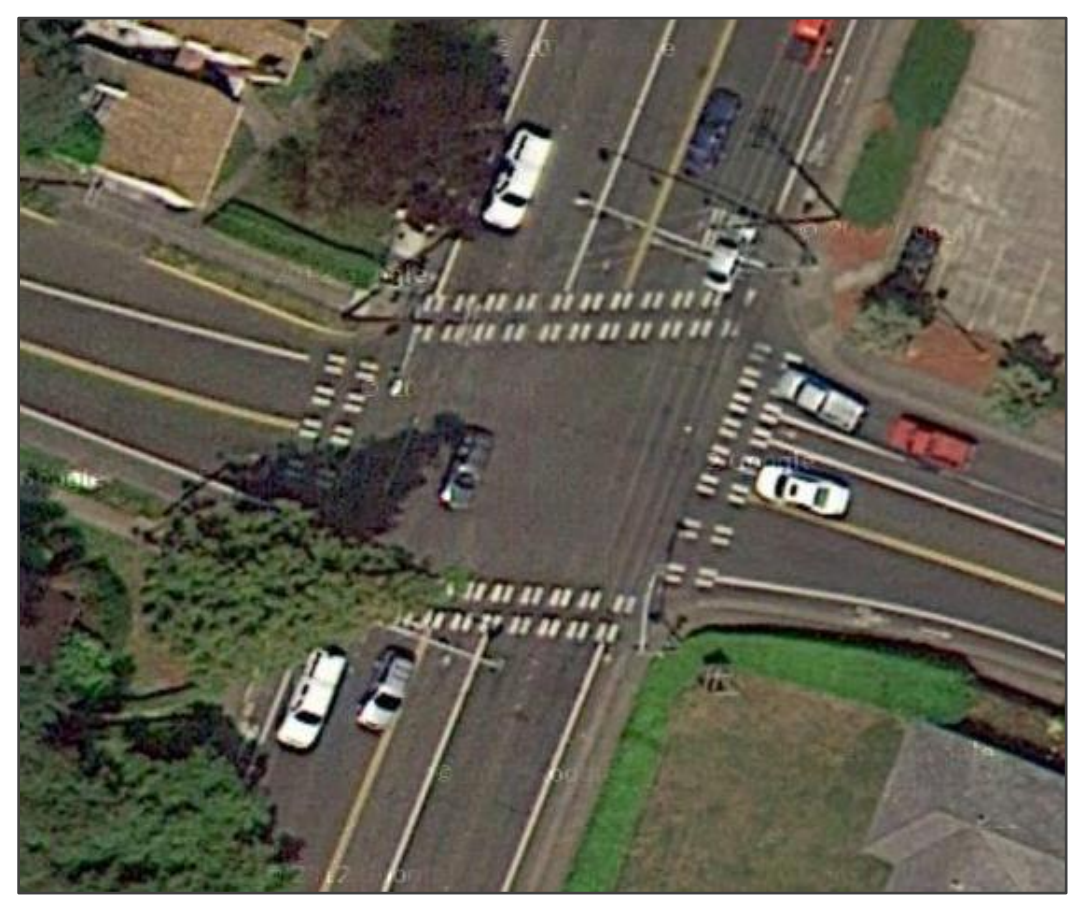

Figure 3.6 NW Buchanan Avenue and NW 9th Street, Corvallis, OR

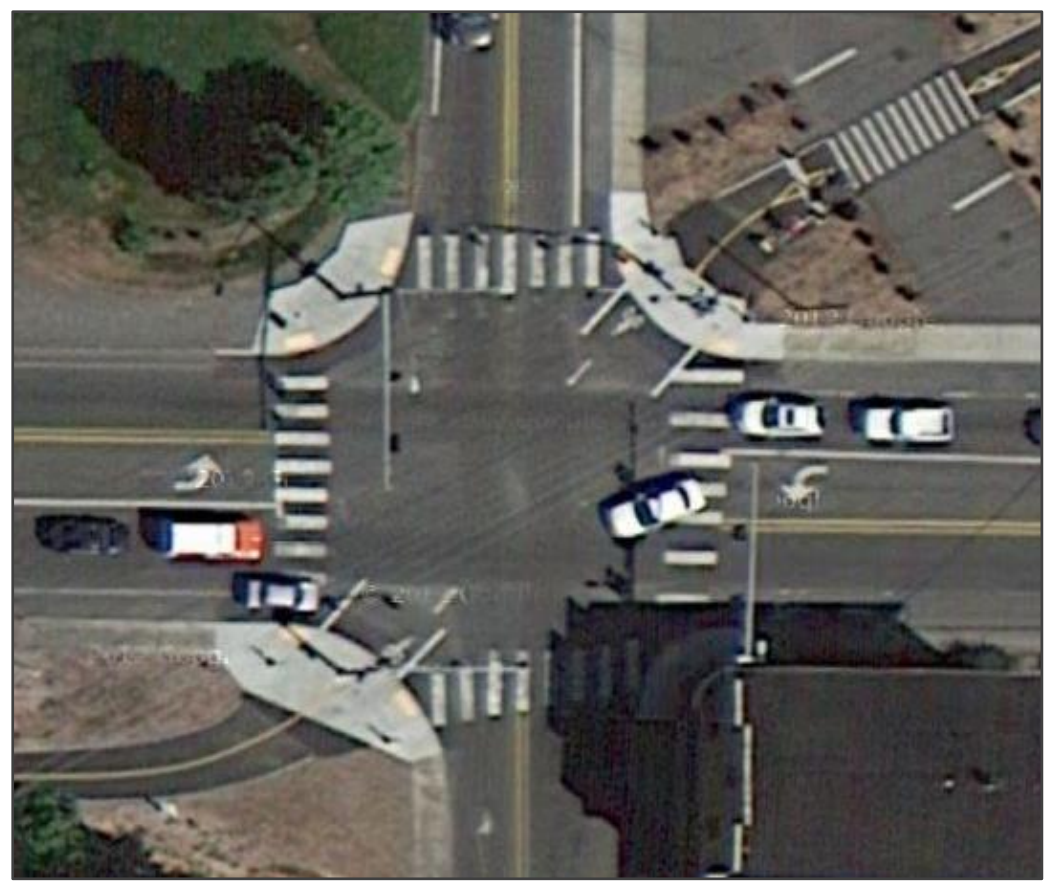

Figure 3.7 SE Johnson Creek Boulevard and SE Bell Avenue, Clackamas, OR 


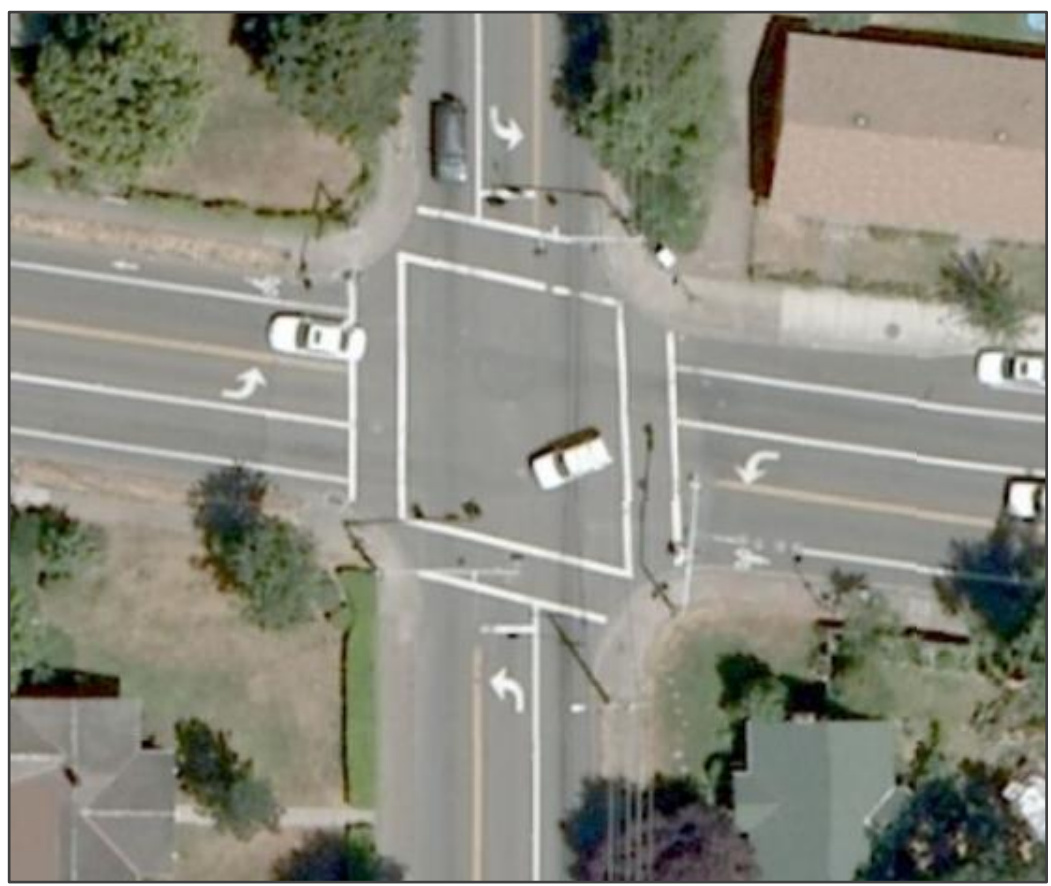

Figure 3.8 SW Lombard Avenue and SW 5th Street, Beaverton, OR

In all, this phase of data collection amassed 144 hours of video footage of more than 2600 cyclists at eight total intersections from four different jurisdictions in Oregon.

\subsubsection{Video Reduction}

Each observation in the dataset corresponds to one cyclist arriving on a red indication. Variables from this dataset relate to characteristics of the cyclist, the intersection, or the scenario. This included demographic information such as age and sex, cross traffic volumes, the number of other cyclists, and whether the cyclists was observed riding during a peak period.

The variable of most interest in this research indicates the compliance type of the cyclist. Compliance is broken into four categories: compliant, illegal right turn, gap accepted, and signal jump. A designation of 'compliant' corresponds to a cyclist who came to a complete 
stop $^{4}$ at the red indication and then either made a legal right turn or continued to wait for the green indication before beginning their forward motion. The first type of non-compliant behavior, an illegal right turn on red, was recorded for any cyclist making a right turn without first coming to a complete stop. Cyclists committing the second type of noncompliant action were was named gap accepters. These cyclists were so called because they accepted a gap in cross traffic in order to cross against the red indication. Notably, two sub-categories of gap accepters emerged in the dataset. A small number of cyclists, the "runners" not only accepted a gap in traffic but also did not wait at all, opting to "blow through" the signal, sometimes without even slowing their speed. The other sub-category of gap accepters, the "opportunists", initially stopped at the signal and waited for an acceptable gap in traffic before crossing. Ultimately, these two types were combined for analyses due to the very low number of runners. Lastly, the third type of non-compliant behavior was signal jumping. Cyclists dubbed signal jumpers began forward motion into the intersection in anticipation of the impending green signal, but nonetheless, began moving while still receiving the red indication.

\subsubsection{Summary}

Video data from two sources were combined to record a large number of cyclists at a variety of intersection types, though many intersections employed a bicycle-specific traffic signal for control of cyclist movements. Characteristics that could be obtained for each cyclists were recorded along with information about their surroundings such as cross traffic

\footnotetext{
${ }^{4} \mathrm{~A}$ complete stop was defined as a cyclist putting a foot down on the pavement or successfully completing a 'track stand' wherein the cyclist halts all forward motion and uses balance to remain upright on the bicycle without putting a foot down.
} 
volumes and the presence of other cyclists. The compliance of each cyclist was categorized into one of four five compliance types, four of which broke down the type of noncompliance in which the cyclist may have participated.

\subsection{Survey}

Quantifying cyclists' compliance is possible using the video data set, but grouping cyclists into meaningful categories is difficult due to the 'external' nature of the available data. That is, as evidenced by the literature, many aspects internal to an individual influence behavior (e.g. personality). To collect information for analysis of the "whys" behind cyclist compliance and non-compliance at traffic signals, a second data set was created using survey responses from cyclists. This data set is original to this thesis and focuses on the attitudinal and personality factors that influence cyclists' decisions to comply with red indications. The complete survey can be found in APPENDIX A on page 125.

\subsubsection{Development and Structure}

Development of the survey began with the creation of a conceptual framework of the decision to run a red light (or not). This framework can be found in graphical form in Figure 3.9 . 


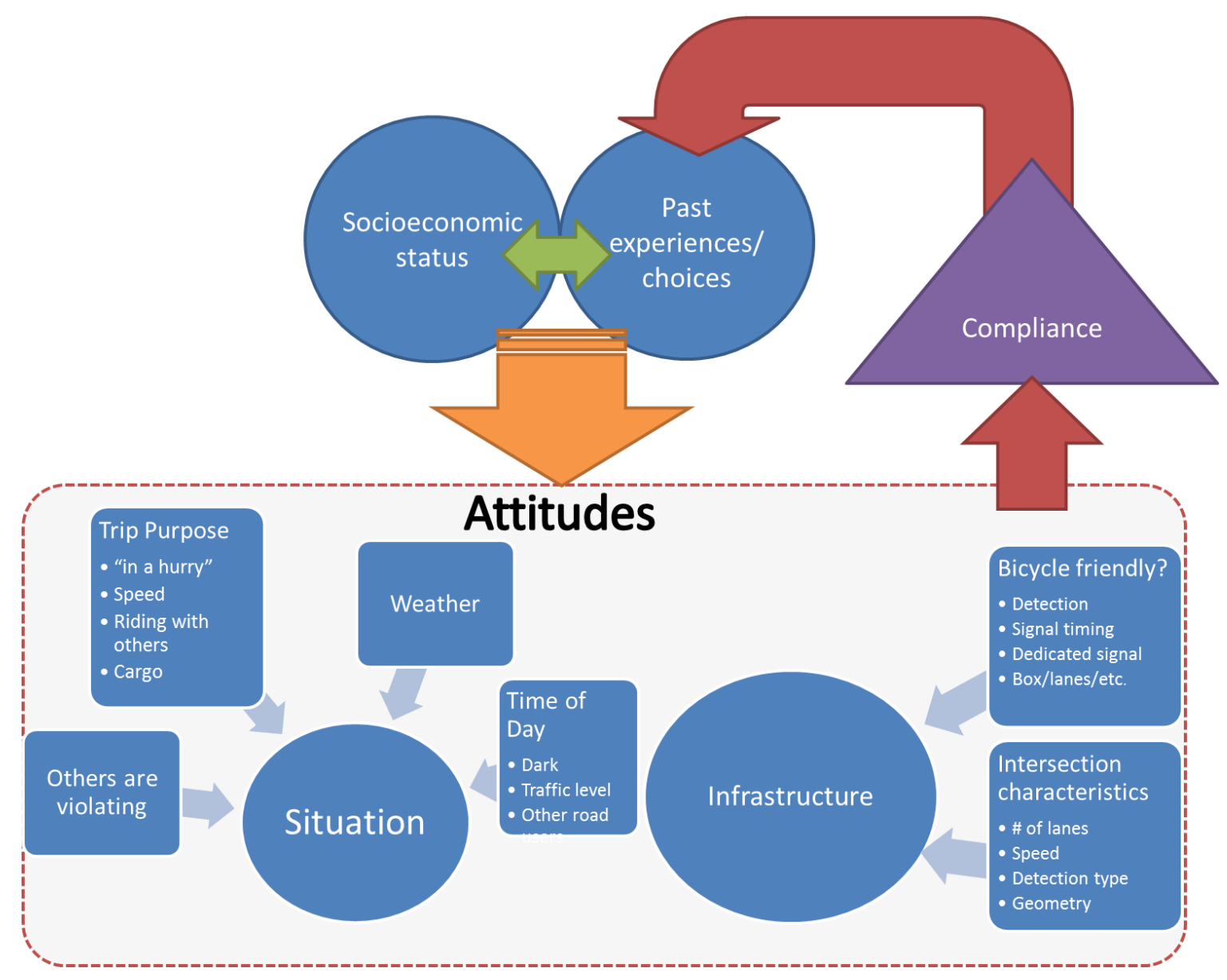

Figure 3.9 Framework of Cyclist Compliance Decisions

As is evidenced by the figure, this particular decision-making process is complicated by multiple feedback loops and components that overshadow other components. For instance, one can see that a cyclist's personality and attitudes are influenced by socioeconomic indicators and past experiences, including past experiences of running or waiting for a red light. These attitudes, in turn, influence the perception of current circumstances and past experiences and choices, which then determine how the cyclist makes decisions in the 
future. Similarly, these attitudes change how a cyclist views the roadway/intersection where they are cycling.

Ideally, every facet of the decision-making framework would be explored by the survey, but some of the more complicated concepts, such as feedback loops, are not amenable to the survey format. In order to determine the types of questions on the survey instrument, the author utilized initial results from the video dataset as well as the literature to devise two goals for the survey data. The two, not disparate purposes are as follows:

- to complement, by confirmation or opposition, findings from the video data; and - to explore aspects of compliance that had not yet been explored in the literature.

Figure 3.10 shows influencers of non-compliance that are explored by the survey using the same color-coded scheme as Figure 4.1 (page 44) with an additional color (pink) for a cyclist's past experiences and an overarching influence of personality traits (light gray). The next section describes how questions from the survey relate to each of these purposes. This makes it easy to see how the survey was designed to complement the video data. 


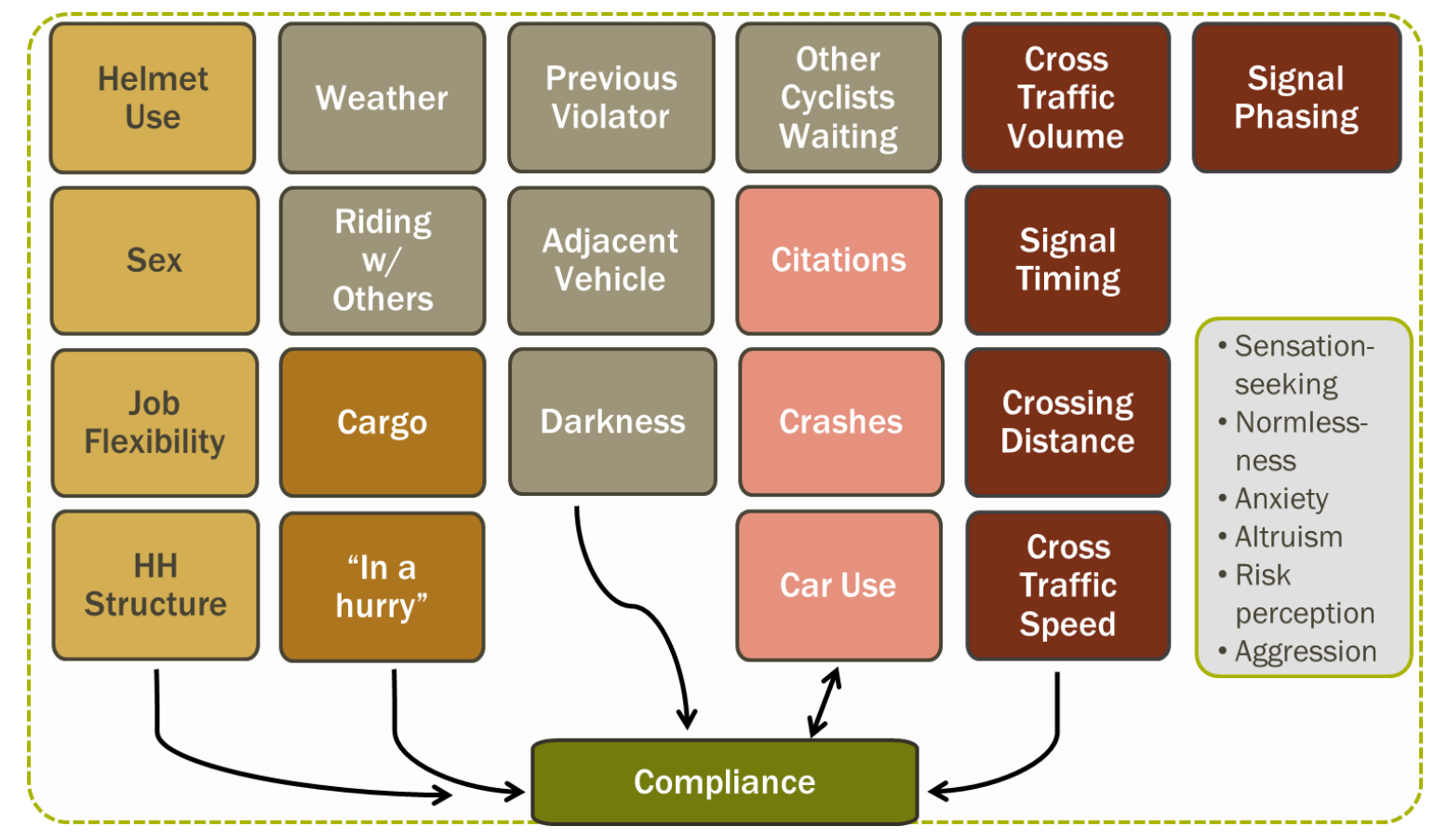

Figure 3.10 Diagram of Simplified Inputs to Compliance

\subsubsection{Complements to the Video Data}

Conclusions drawn from video footage of cyclists relate to variables that are easily discernable from the video. To further understand how these variables affect cyclist compliance, the survey asked cyclists to rate how likely they were to run the red indication at an intersection depicted in a picture. Respondents were then asked to reveal the reasons for their choice in the previous question by choosing from a set of variables relating to the physical characteristics of the intersection itself and the amount of pedestrian and vehicle traffic depicted. Furthermore, a separate question asking about justifications for red light running lists several 'reasons' that could be compared to data from video footage including whether or not the cyclist is carrying cargo, sees someone else violate the signal before 
them, the direction of travel, and if there are other possible witnesses to their transgression. Notably, although two of the possible justifications for running a red light are analogous to signal jump and right turn on red violations, the language regarding red-light running and the example video used in the beginning of the survey gear participant's definition of running a red light most closely to the gap-accepted type of non-compliance. In addition to the responses to these questions about the potential to run the depicted red light, two of the demographic questions relating to the respondent's gender and age paralleled data available from video footage.

\subsubsection{Exploration of New Variables Related to Compliance}

As discussed in the literature review, the number of previously-explored variables related to compliance is low. Several of the variables explored in the survey that are meant to compliment the video data are also not explored in previous literature. These variables have to do with intersection geometry. However, many of the newly-explored variables in this study are not discernable from video footage. As depicted in the diagram of compliance inputs, many inputs are 'internal' to the cyclist and have to do with their attitudes, previous experiences, and current circumstances. The survey collected information specific to the following for each cyclist: 
- transportation experiences;

- situations that justify red light running;

- participation in transportation-related risk-taking behaviors;

- personality; and

- demographics.

The transportation experiences explored by the survey were: cycling confidence, uses for different types of transportation including the bicycle, and crashes. Cycling confidence was obtained by asking cyclists to describe what type of cyclist they are with choices loosely based off of the four types of cyclists presented in a report by the Portland Bureau of Transportation's Roger Geller (Geller, 2009). In a second question, respondents indicated how often they used certain modes for 'Commute', 'Utilitarian', and 'Recreational' trips. Crash experience was gleaned from two questions that looked at past crashes with 1) other road users and 2) those where no one else was involved except the responding cyclist. These questions gathered specific information about the users and/or objects contributing to the crash as well as severity of injuries, if any.

One question asked about justifications for red light running. Respondents were asked to choose from a 5-point Likert scale ranging from "Strongly Disagree" to "Strongly Agree" for each of the 13 scenarios listed. Scenarios all completed the sentence "I might ride through a red light if..." and were chosen based on the author's cycling experiences as well as informal discussion with other cyclists. 
Risky behaviors were evaluated by three questions. The first question asked respondents how often they engaged in particular risky behaviors. Respondents that indicated that they sometimes used a car for various trip types were asked about both bicycle-related risk behaviors and driving-related behaviors oft evaluated in the literature (e.g. texting while driving). Respondents described the occurrence of each risky behavior with a 5-point Likert-type scale ranging from "Never" to "Always". The second question, directed only to those respondents indicating that they sometimes used a car, asked if they had received a traffic fine for any of a series of particularly risky behaviors (such as DUI and reckless driving) in the last three years. A third question asked if they had received a violation for any bicycle-related offense in that same time period.

As discussed in the literature review, a relationship exists between certain personality traits and risk-taking behaviors. Other personality traits affect a person's views on authority and societal norms. Risk-taking, normlessness, anxious, and aggressive personality characteristics all have the potential to play into compliance and were, therefore, included in the survey. These four personality traits (Anxiety, Aggression, Normlessness, and Impulsive Sensation-Seeking) were evaluated for each respondent using questions from three separate evaluation tools. Anxiety and Aggression were assessed using questions from the 100-item HEXACO Personality Inventory-Revised which measures six major dimensions of personality (K. Lee \& Ashton, 2004). These six major dimensions (referred to as Domains) are broken into Facets, of which Anxiety $^{5}$ (in the Emotionality Domain)

\footnotetext{
${ }^{5}$ Defined as a "tendency to worry in a variety of contexts."
} 
and Aggression $^{6}$ (in the Agreeableness Domain) are two. These facets were evaluated using responses to four ${ }^{7} 5$-point Likert scale questions per facet. A score is then determined for each HEXACO facet by taking the average of the responses for that facet with "Strongly Disagree" equal to 1 and “Strongly Agree' equal to 5. Normlessness ${ }^{8}$, was measured using Kohn and Schooler's (1983) Normlessness Scale which consists of four 2-point (Agree vs Disagree) questions. The score for normlessness is the count of all "Agree" answers. The sensation-seeking scale from the short form of Zuckerman Kuhlman Personality Questionnaire (2002), made of seven 2-point questions, was used to evaluate each cyclist's level of the Impulsive Sensation-Seeking ${ }^{9}$ personality trait. This personality trait is score similarly to normlessness. In addition to questions regarding specific personality characteristics, two questions asked respondents to indicate their level of worry about getting into a crash with a motor vehicle and if they thought it was likely that they would be "seriously" injured in the event that they were in a crash with a car.

Lastly, some demographic and socioeconomic type questions were asked. As previously discussed, the survey asked about age and gender to help mirror results from the video dataset. Two additional questions asked about relationship status and job flexibility. These questions were asked in lieu of more 'traditional' socioeconomic-type questions about race

\footnotetext{
${ }^{6}$ Aggression was evaluated by the Patience facet which is defined as a "tendency to remain calm rather than to become angry." Thus, aggression is the reverse scoring of the Patience facet.

${ }^{7}$ In the 100 -item version of the HEXACO-PI-R. Other versions differ in the number of questions per FacetLevel scale.

${ }^{8}$ Described as the belief that socially unapproved behaviors are required to achieve certain goals.

${ }^{9}$ This scale as questions that separately address the impulsive traits, described as "a lack of planning and a tendency to act quickly on impulse without thinking", and the sensation-seeking traits, described as "a general need for thrills and excitement, a preference for unpredictable situations and friends, and the need for change and novelty."
} 
and income since the type of job someone has (e.g. if they are punished for being late) and demographic reasons for staying 'safer' (e.g. family responsibility) seemed more likely to be directly related to level of compliance.

\subsubsection{Dissemination and Response}

Surveys reached potential respondents via invitational postcards (pictured in Figure 3.11

\section{Figure 3.4 Data Collection Setup}

\section{Hey Cyclist!}

Some exciting research on how and why cyclists comply with traffic signals is taking place at Portland State University and we need to hear from all types of cyclists. Whether you're completely compliant or a total law-breaker, your participation in this survey will be valuable (and ANONYMOUS!). This research is part of a Master's Thesis in the Dept. of Civil Engineering at Portland State University and your responses will greatly aide a graduate student (and fellow cyclist).

If you can spare just 10-15 minutes, please visit the link or scan the QR code below: You will be asked to enter the individual code printed on this postcard which helps us keep track of response rates.

Thanks!

Sam R.Thompson s.r.thompson@pdx.edu

Civil and Environmental Engineering, Portland State University

tinyurl.com/CyclistCompStudy

Code: 8701

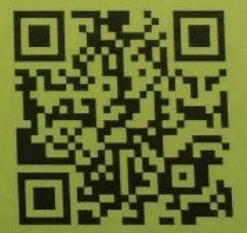

Figure 3.11 Sample Invitational Postcard 
Invitational postcards were dispersed in several ways. Initially, postcards were placed on parked bicycles in neighborhoods with high ridership in October of 2013. Postcards were also given out in "convenience survey" style to folks known by the author who then took the survey and/or passed the invitations out to others. A small number of survey postcards were also left at bike-oriented businesses such as HUB Bike Bar for patrons to pick up at their leisure. These initial attempts at soliciting responses were met with little success with a response rate of $14.3 \%$ for all distributed surveys in this time period. A second period of distribution occurred in the spring of 2014 and consisted of two intercept-style surveys. Intercepts occurred at traffic signals with historically large queues of cyclists, Broadway at Lovejoy and Hawthorne at Grand, during the AM and PM peak periods, respectively. The response rate for this distribution was much higher with $36.2 \%$ of cyclists filling out the survey. The overall response rate for the study was $27.6 \%$ with a total of 157 respondents.

\subsection{Summary}

This chapter outlined the data collection process for all data used in this thesis. In all, 2602 and 157 cyclists comprised the video and survey datasets, respectively.

Video data was collected during two different time periods and at 7 different locations in Oregon, most within the Portland metropolitan area. Video data focused on cyclists arriving at traffic signals during the red indication, and characteristics of the intersection, the scenario, and the cyclist themselves were recorded for use in analysis. The characteristic of most interest for each observed cyclist was their compliance type. 
Compliance was divided into 4 categories in order to more accurately describe the behavior of the cyclist.

A survey of cyclists was developed to collect information about the "whys" behind cyclist compliance and non-compliance. The survey sought to collect data that augmented that from the video as well as new data about cyclist compliance that could not be gleaned from video footage. Survey data was collected via invitational postcards that were, initially, distributed in locations with high bicycle. While the first attempt at distribution had little success, the second distribution period comprised of two intercept-style distributions of the postcards was fruitful.

Data from the video and survey sources were analyzed separately since collection of the two was completely separate in time and space and are not meant to be directly related. However, comparisons are made between similar information from each analysis. These analyses and comparisons are the focus of the next chapter. 


\subsection{ANALYSIS RESULTS \& DISCUSSION}

This chapter presents the analysis and results for both the video and survey datasets, which are analyzed separately. Following the results of each analysis is a discussion on the interpretation of said results and their relationship to findings from existing studies.

\subsection{Analysis: Video Data}

This section first summarizes the data available from the video dataset then presents the results of several models relating these variables to a cyclist's decision to be non-compliant in one of the three ways identified.

\subsubsection{Sample Description}

The video dataset included observations from a total of 2,602 cyclists. The two tables below (Table 4.1 and Table 4.2) summarize relevant descriptive data for the numeric and factor variables used to develop the compliance models. 
Table 4.1 Characteristics of Cyclists and Intersections from Video Data

\begin{tabular}{|c|c|c|c|c|c|c|}
\hline Variable & Description & $\mathrm{n}$ & Mean & S.D. & Min & Max \\
\hline \multicolumn{7}{|l|}{ Cyclist Characteristics } \\
\hline Helmet & Helmet worn (binary) & 2602 & 0.84 & 0.37 & 0 & 1 \\
\hline Sex & Sex (binary, $1=$ Female, $0=$ male) & 2602 & 0.33 & 0.47 & 0 & 1 \\
\hline Group & Riding with one or more other cyclists to destination (binary) & 2602 & 0.16 & 0.37 & 0 & 1 \\
\hline Clothing Type & Type of clothing worn (binary; $0=$ athletic wear, $1=$ street clothes) & 489 & 0.71 & 0.45 & 0 & 1 \\
\hline Cargo* & Carrying any type of cargo or on a cargo bike (binary) & 489 & 0.66 & 0.48 & 0 & 1 \\
\hline Violator $^{+}$ & Another cyclist violated the signal within view of current cyclist (binary) & 2602 & 0.03 & 0.18 & 0 & 1 \\
\hline \multicolumn{7}{|l|}{ Intersection Characteristics } \\
\hline Cyclist Waiting & Number of cyclists already waiting at signal & 2600 & 0.71 & 1.08 & 0 & 5 \\
\hline Vehicle Waiting & Presence of a vehicle in lane adjacent to bicycle facility (binary) & 2549 & 0.85 & 0.36 & 0 & 1 \\
\hline Traffic & Number of cars crossing the projected path of the cyclist every 30 seconds & 2602 & 7.33 & 2.46 & 1.13 & 14.40 \\
\hline Square of Traffic Volume & Square of 'Traffic' variable & 2602 & 59.71 & 43.10 & 1.28 & 207.36 \\
\hline Commute Route & Intersection is along a popular commute route (binary) & 2602 & 0.89 & 0.31 & 0 & 1 \\
\hline PDX & Intersection is in major urban area (Portland) (binary) & 2602 & 0.81 & 0.39 & 0 & 1 \\
\hline Width & Width of the intersection & 2602 & 82.8 & 10.3 & 55.0 & 90.0 \\
\hline
\end{tabular}

Unless noted, $1=$ TRUE

* Data only collected in second video dataset.

+ Variable includes all types of non-compliance including illegal right turns on red, which were numerous. 
Table 4.2 Characteristics of Qualitative Video Data Variables

\begin{tabular}{|c|c|c|c|}
\hline Variable & Description & $\mathrm{n}$ & $\%$ of Sample \\
\hline \multicolumn{4}{|c|}{ Cyclist Characteristics } \\
\hline \multirow[t]{4}{*}{ Compliance } & 0, Compliant & 1798 & 69.10 \\
\hline & 1, Illegal right turn & 599 & 23.02 \\
\hline & 2, Gap accepted & 118 & 4.53 \\
\hline & 3, Signal Jump & 87 & 3.34 \\
\hline \multirow[t]{3}{*}{ Age } & $1,<18$ years old & 60 & 2.31 \\
\hline & $2,18-50$ years old & 2521 & 96.89 \\
\hline & $3,>50$ years old & 19 & 0.73 \\
\hline \multicolumn{4}{|c|}{ Intersection Characteristics } \\
\hline \multirow[t]{7}{*}{ Location } & Portland: Broadway at Lovejoy & 1419 & 54.53 \\
\hline & Portland: Broadway at Williams & 557 & 21.41 \\
\hline & Portland: Rosa Parks at I-5 & 137 & 5.27 \\
\hline & Portland: Springwater Corridor at Johnson/Bell & 210 & 8.07 \\
\hline & Beaverton: $5^{\text {th }}$ at Lombard & 131 & 5.03 \\
\hline & Corvallis: $9^{\text {th }}$ at Buchanan & 17 & 0.65 \\
\hline & Eugene: $18^{\text {th }}$ at Pearl & 131 & 5.03 \\
\hline \multicolumn{4}{|c|}{ Scenario Characteristics } \\
\hline \multirow[t]{3}{*}{ Peak Hour } & $\mathrm{AM}$ & 1230 & 47.27 \\
\hline & $\mathrm{PM}$ & 316 & 12.14 \\
\hline & Off Peak & 1056 & 40.58 \\
\hline \multirow[t]{7}{*}{ Day } & Monday & 247 & 9.49 \\
\hline & Tuesday & 67 & 2.57 \\
\hline & Wednesday & 815 & 31.32 \\
\hline & Thursday & 679 & 26.10 \\
\hline & Friday & 288 & 11.07 \\
\hline & Saturday & 233 & 8.95 \\
\hline & Sunday & 273 & 10.49 \\
\hline \multirow[t]{2}{*}{ Weather } & Clear & 1945 & 74.75 \\
\hline & Overcast & 657 & 25.25 \\
\hline
\end{tabular}

- As perceived from video footage 


\subsubsection{Modeling Compliance (Video)}

In order to determine the relationships between individual, scenario, and intersection characteristics and the three types of non-compliant behaviors identified, each maneuver was analyzed using a binary logistic regression model with a dependent variable equal to the probability that a particular cyclist would choose that type of non-compliant behavior over waiting at the signal for a green (compliance).

Before estimation of each model, video data were divided into observations of cyclists who either moved straight through the intersection (for gap accepted and signal jump analysis) or made a right turn, for illegal right turn analysis. This step was recognizes the differences in obstacles to non-compliance between those cyclists turning right and those moving through the intersection. This was done so as not to conflate compliant right-turners with compliant through-movers during regression.

The models from the video data were estimated in the manner described above and discussed in further detail below.

\subsubsection{Gap Accepted Model}

The gap accepted model is the focus of this section and elucidates the factors that influence the choice to run a red indication due to characteristics of the cyclist, scenario, and intersection (shown in yellow, gray, and red, respectively, in Figure 4.1). Significant in the decision to accept a gap in traffic and run the red indication are the presence of a vehicle, presence of other waiting cyclists, signal phasing that separates cyclists from right-turning 
vehicles, helmet use, observing a previous violator, sex, and the interaction between sex and other visible violators ${ }^{10}$.

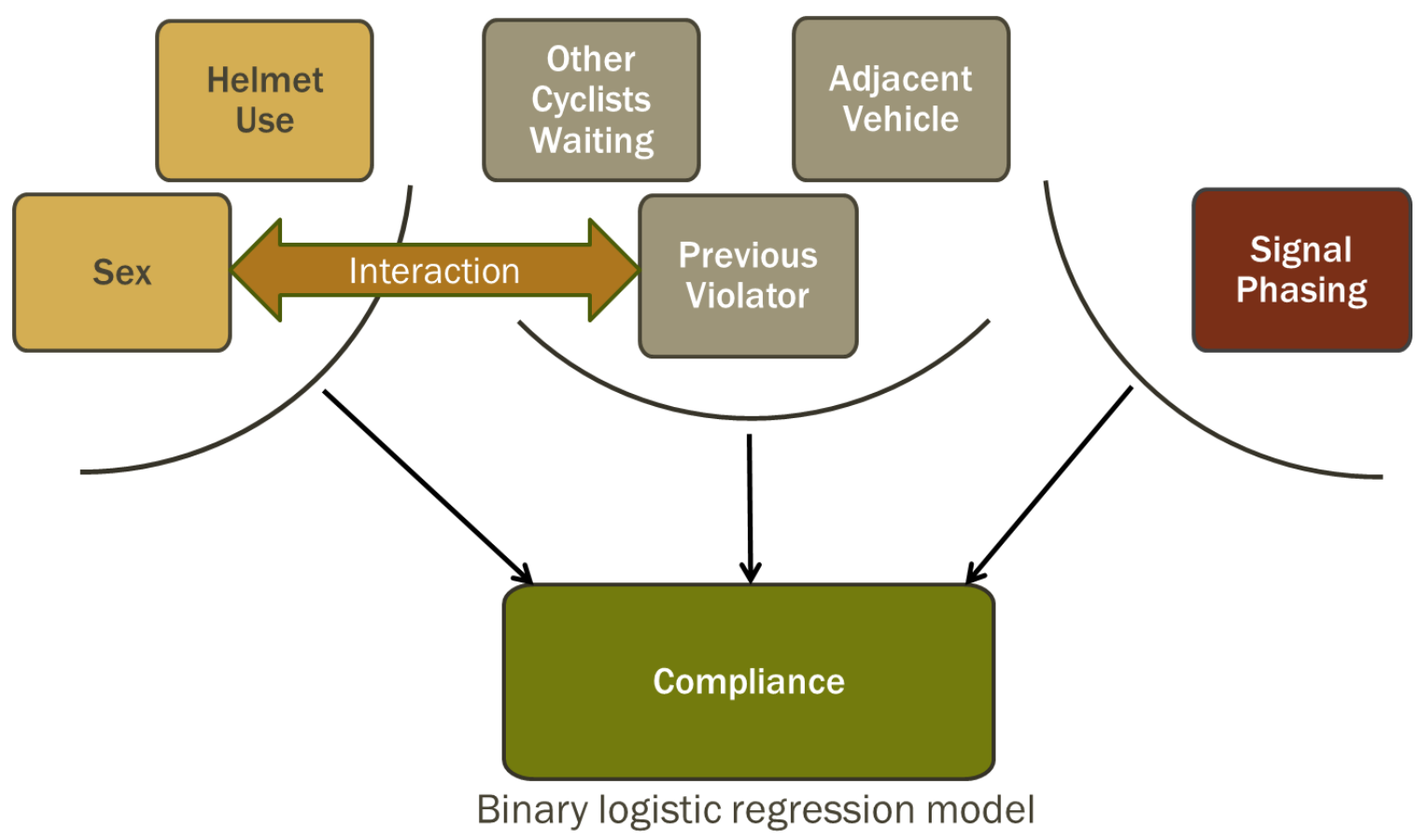

Figure 4.1 Diagram of Binary Logistic Model for Video Data

Insignificant in the decision of gap-acceptance are weather, group status, peak period, clothing type, bike type, presence of cargo, whether the intersection is on a popular commute route, urban vs. suburban context of the intersection, and the intersection width. Interactions between the two significant cyclist-specific variables (helmet and sex) and the significant intersection-specific variables were also explored. Only the interaction between

\footnotetext{
${ }^{10}$ All significant variables were significant with at the least the $99.9 \%$ confidence except the interaction between sex and witnessing a previous violator which was significant to the $95 \%$ confidence.
} 
sex and witnessing a previous violation was significant in the presence of all significant variables. Of note, a few variables were excluded from analysis due to collinearity issues with other variables or near-homogeneous variable values. Namely, these were location, age, and day of the week. Intuitively, location correlated highly with intersection widths, urban context, and signal phasing. Location was also highly correlated with day of the week since footage was only taken on certain days for certain intersections. Lastly, nearly every cyclist landed in the "18-50 year-old" age category. Thus, age was too homogenous to use as an input in the model. The initial results of the model can be seen below in Table 4.3 while the standardized coefficients are shown in Figure 4.2 in order to display the relative effect each variable has on non-compliance. 
Table 4.3 Binary Logit Results (Gap Accepted Model) - All Observations

\begin{tabular}{lrrr}
\hline & & $\begin{array}{c}\text { Likelihood } \\
\text { Variable }\end{array}$ & Ratio \\
Test $^{12}$ & Ratio \\
\hline Number of cyclists waiting $^{\text {Coefficient }}$ & -1.614 & 67.77 & 0.199 \\
Presence of adjacent vehicle & -1.767 & 53.19 & 0.171 \\
Signal phasing separates cyclists from RT vehicles & 2.211 & 45.29 & 9.126 \\
Witness previous violation & 1.534 & -- & 4.638 \\
Lack of helmet & 0.944 & 15.58 & 2.571 \\
Sex & -0.994 & -- & 0.370 \\
Interaction of sex and witnessing previous violation & 2.005 & 6.07 & 12.692 \\
\hline
\end{tabular}

Model $\chi^{2}=248.84(\mathrm{p}$-value $=2.2 \mathrm{e}-16) ;$ AIC $=626.14 ;$ Percent Deviance Explained $=29.0 \%$

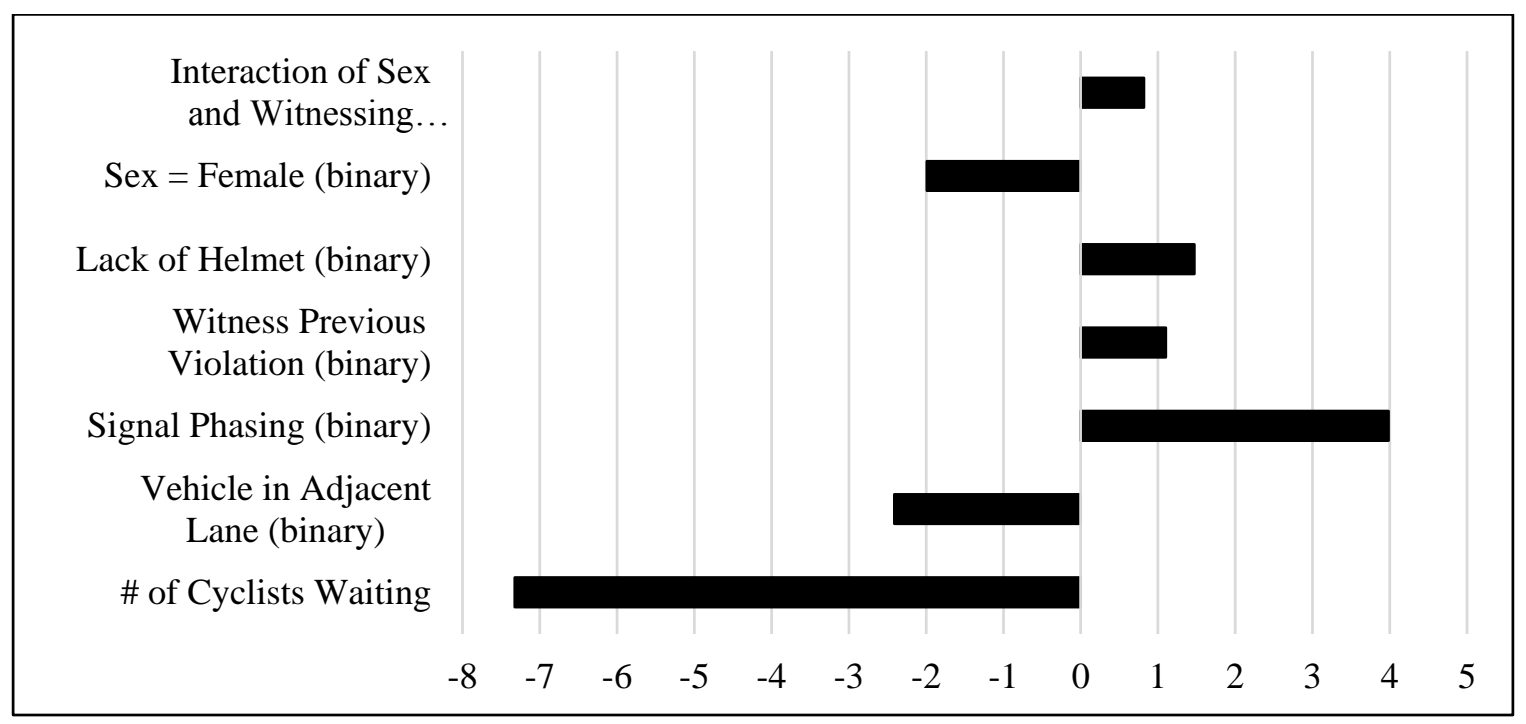

Figure 4.2 Standardized Regression Coefficients (Gap Accepted Model) -- All Observations

${ }^{11}$ Reference scenario is of a male cyclist who is wearing a helmet and stopped a non-urban intersection with no other cyclists (including prior violators), and no vehicles in the adjacent lane.

${ }^{12}$ Note that the likelihood ratio test per independent variable cannot be calculated for the sex and witnessing violation variables separate from the interaction term which combines them. This is because you cannot remove one of those terms from the model without affecting the interaction. 
The factor with the most explanatory power is the number of cyclists already waiting at the signal upon cyclist arrival. With every additional cyclist waiting ahead of the observed cyclist, the likelihood that the observed cyclist will accept a gap in traffic decreases by nearly $80 \%^{13}$. Similarly, the presence of motor vehicles also deterred gap acceptance. The presence of a motor vehicle in the lane adjacent to the cyclist was the second-most influential variable on compliance with cyclists waiting next to a vehicle $83 \%$ less likely to accept a gap in traffic.

Whether or not the traffic signal had phasing that separated cyclists from right-turning vehicles in time was another important input to the model. At locations with this type of phasing, cyclists were more than nine times more likely to accept a gap in traffic. Witnessing another cyclist violate the signal also greatly increased the odds that a cyclist would also violate the signal. Cyclists witnessing another cyclist accept a gap in traffic during their wait or approach to that same signal were 4.638 times more like to violate the signal in that same manner.

Cyclists not wearing helmets were significantly more likely to run the signal (increase in odds of $257 \%$ ). The odds of a female violating the signal, in general, (compared to a male) decreased by $63 \%$. Interestingly, though, the interaction between sex and witnessing a violation had positive effects on non-compliance (i.e. a female witnessing a previous

\footnotetext{
${ }^{13}$ It is recognized that this relationship is likely non-linear with the difference in compliance between one waiting cyclist and none greater than the difference between one and two waiting cyclists. However, for simplicity, the relationship is modeled as linear.
} 
violator had the highest odds of violating the signal, more than 12 times the base case of men who do not witness a previous violation).

As may be recalled from Table 4.2, a large proportion of the observations in the study came from one intersection: Broadway at Lovejoy. In order to evaluate possible bias in the model due to the high number of observations at this intersection, the model was estimated twice more: once without observations from Broadway at Lovejoy and once with a random sample of observations from the intersection (equal to the number of observations from two other intersections, $n=131$ ). Below are the outputs of these two alternate models.

Table 4.4 Binary Logit Results (Gap Accepted Model) - No Broadway/Lovejoy Observations

\begin{tabular}{lrrr}
\hline & & Likelihood & \multicolumn{2}{c}{ Odds } \\
Variable $^{14}$ & Coefficient & Ratio Test & \multicolumn{1}{c}{ Ratio } \\
\hline Number of cyclists waiting & -1.399 & 13.84 & 0.247 \\
Presence of adjacent vehicle & -2.598 & 63.16 & 0.074 \\
Signal phasing separates cyclists from RT vehicles & 2.379 & 39.74 & 10.792 \\
Witness previous violation & 1.385 & -- & 3.995 \\
Lack of helmet & 0.793 & 5.69 & 2.210 \\
Sex & -1.444 & -- & 0.236 \\
Interaction of sex and witnessing previous violation & 3.762 & 8.69 & 40.569 \\
\hline
\end{tabular}

Model $\chi^{2}=167.88(\mathrm{p}$-value $=2.2 \mathrm{e}-16) ;$ AIC $=323.25 ;$ Percent Deviance Explained $=35.3 \%$

\footnotetext{
${ }^{14}$ Reference scenario is of a male cyclist who is wearing a helmet and stopped a non-urban intersection with no other cyclists (including prior violators), and no vehicles in the adjacent lane.
} 


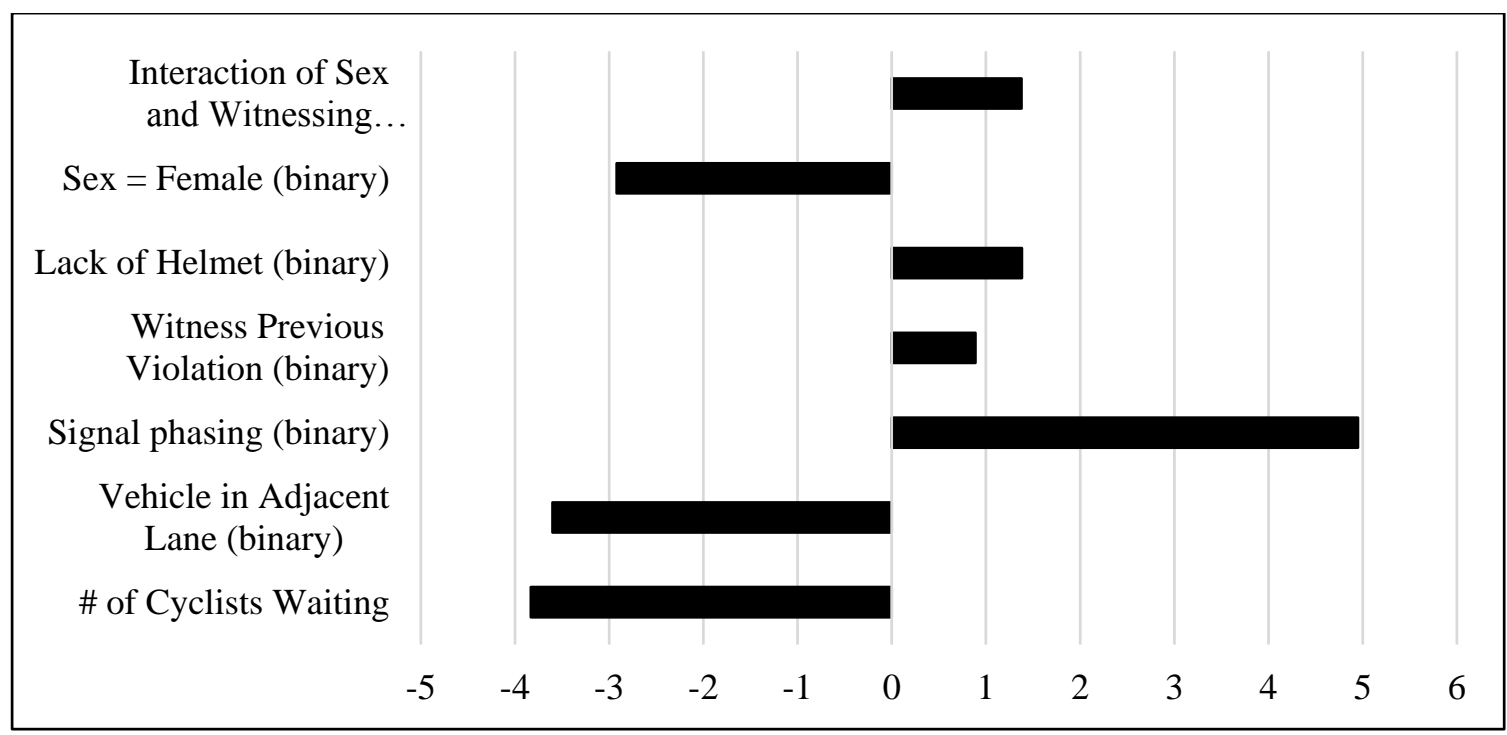

Figure 4.3 Standardized Regression Coefficients (Gap Accepted Model) - No Broadway/Lovejoy Observations

Table 4.5 Binary Logit Results (Gap Accepted Model) - Random Broadway/Lovejoy Observations

\begin{tabular}{lrrr}
\hline Variable $^{15}$ & Coefficient & $\begin{array}{r}\text { Likelihood } \\
\text { Ratio Test }\end{array}$ & \multicolumn{1}{c}{ Odds } \\
\hline Rutio \\
\hline Pumber of cyclists waiting & -1.428 & 22.146 & 0.240 \\
Presence of adjacent vehicle & -2.397 & 60.85 & 0.091 \\
Signal phasing separates cyclists from RT vehicles & 2.192 & 35.35 & 8.950 \\
Witness previous violation & 1.842 & -- & 6.309 \\
Lack of helmet & 0.862 & 7.61 & 2.367 \\
Sex & -1.393 & -- & 0.248 \\
Interaction of sex and witnessing previous violation & 2.552 & 4.93 & 20.100 \\
\hline
\end{tabular}

Model $\chi^{2}=174.8(\mathrm{p}$-value $=2.2 \mathrm{e}-16) ; \mathrm{AIC}=359.28 ;$ Percent Deviance Explained $=33.7 \%$

${ }^{15}$ Reference scenario is of a male cyclist who is wearing a helmet and stopped a non-urban intersection with no other cyclists (including prior violators), and no vehicles in the adjacent lane. 


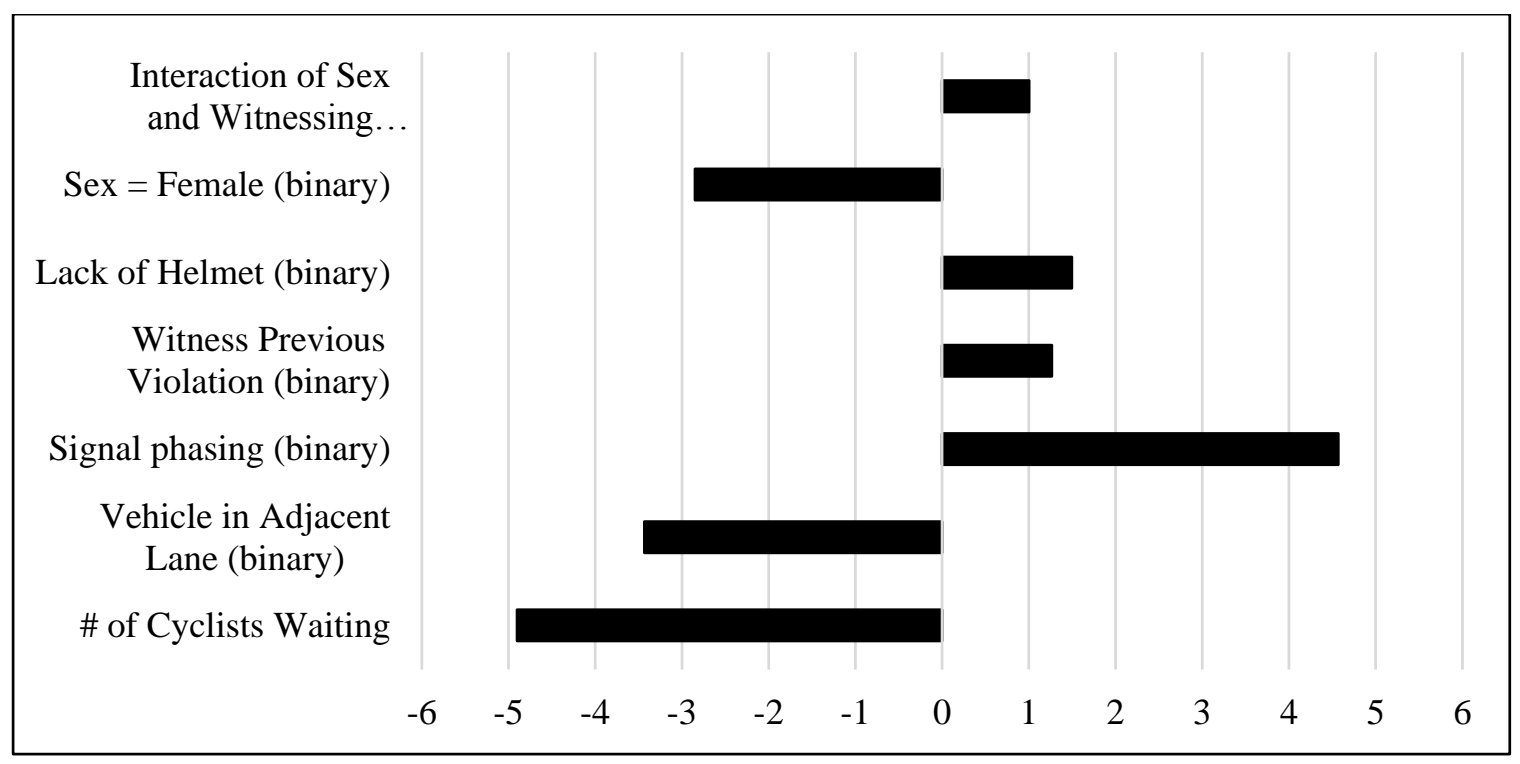

Figure 4.4 Standardized Regression Coefficients (Gap Accepted Model) - Random Broadway/Lovejoy Observations

The same independent variables proved significant in the alternate models as the original model. Also, the directionality of each of the inputs was the same. However, the relative importance of these independent variables did change between the original model and the two alternates. Compared to the two alternate models, the original model over-emphasized the role of the number of cyclists already waiting at the signal. The original model also under-emphasized the roles of sex, the interaction between sex and witnessing a violation, and signal phasing on the decision to be non-compliant. Overall, the alternate models appear to be better fits of the data than the original model with the alternate model including no results from Broadway at Lovejoy having the best indicators of goodness of fit ( $\chi^{2}=$ 167.88; $\mathrm{AIC}=323.25$; Percent Deviance Explained $=35.3 \%$ ). However, in order to best represent all the data collected, the alternate model with a more balanced proportion of 
observations from Broadway at Lovejoy will be used to discuss relationships between independent variables and red light running for the remainder of this thesis.

\subsubsection{Illegal Right Turn Model}

This model reveals the influences on the decision to make an illegal right turn on red. The illegal right turn model utilized data from only one of the video data sources since the newer source focused on cyclists moving straight through the intersection only. Because of this, the direction of travel for each cyclists was not recorded, making differentiation between compliant right turners and those compliant cyclists moving straight through the intersection was impossible. Due to this limit in available data for the model, only two locations were represented in the location variable which made analysis with respect to location binary. The base case location is at Broadway at Lovejoy.

Table 4.6 Binary Logit Results (Illegal Right Turn Model)

\begin{tabular}{|c|c|c|c|}
\hline & & Likelihood & Odds \\
\hline Variable & Coefficient & Ratio Test & Ratio \\
\hline Location: Broadway at Williams & -2.90 & 31.92 & 0.06 \\
\hline
\end{tabular}

Only one factor was significant in the model: location. While this input is technically an indicator of the signal location, the two locations have at least one significant difference in their bicycle facilities: a continuous lane free from bicycle or motorist conflicts. Cyclists turning right at Broadway and Lovejoy are not merging with or crossing the path of any motorists or other cyclists unlike at Broadway and Williams. Right-turning cyclists at Broadway at Lovejoy also do not have to wait behind through cyclists since through 
cyclists have a separate lane at the signal. Cyclists arriving at the location without special infrastructure were $94 \%$ less likely to make an illegal right turn.

\subsubsection{Signal Jump Model}

Although several factors appear to have significant effects on signal jump behavior when sole inputs of the model, no variables were found to be stable indicators of this type of noncompliance. Therefore, no model was estimated for signal jump behavior.

\subsection{Discussion}

The overall rate of red light running in this study (\# of observed violations per number of observed cyclists) is about $30 \%$ and is within the range of overall rates of compliance found in other studies of cyclist red light running - albeit on the higher end. Due to the special circumstances regarding the amount of red light running in the sample (discussed below), if those observations are removed, compliance increases to $89.7 \%$ for the sample overall. This percentage of overall cyclist compliance is well-aligned with results from one of the most comprehensive studies on cyclist compliance ever done form the Netherlands (Imbert \& te Brommelstroet, 2014) in which compliance at the nine intersections studied ranged from $80-93 \%$.

Analysis of cyclist compliance was conducted separately for maneuvers that could all be described as red light running. The maneuvers are: gap acceptance, illegal right turns, and signal jumping. Although a model could not be estimated for the signal jump maneuver, separation of the various types of non-compliance and their analyses from the general "red 
light running" is not seen anywhere else is the current literature. Further discussion of the findings from the video analysis is broken down by the three non-compliant movements.

\subsubsection{Gap Accepted}

The more complex model of the two estimated was for gap accepted red light running. Seven variables were found to be significant in the decision to run a red light in this manner. In general, relationships between compliance and these variables echo findings in the literature.

One of the most influential determinants of compliance was the number of cyclists already waiting at the signal with red light running decreasing by $76 \%$ for each additional cyclist that present. A similar, yet less pronounced relationship was seen for Chinese cyclists who were $29 \%$ less likely to run a red light for each additional cyclist already waiting (Wu et al., 2011). A possible explanation for the lower odds ratio is the fact that the Wu et al. study did not differentiate between e-bike riders and traditional bicyclists in their models of compliance when analyzing other variables. E-bike riders, who can accelerate more quickly to hit gaps in traffic, were $52 \%$ more likely (at $90 \%$ confidence) to be non-compliant overall in this same study. A decrease was also seen in the likelihood of non-compliance found in the Australian study of cyclist compliance (Johnson et al., 2011). While this thesis quantified the decrease in odds of non-compliance for each additional cyclist already waiting at the signal, the Johnson study indicated on a binary level if other cyclists were present at all. This is an important distinction since cyclists waiting in front of the cyclist in question can not only be a source of peer pressure to obey the signal, they can also 
physically impede the non-compliant action in some situations. It should also be mentioned that the Johnson study included both signal jump and illegal turning types of red light running with gap accepted types in analysis. Nevertheless, odds ratios for the effect of other cyclists on non-compliance were similar across the studies with the likelihood of a cyclist accepting a gap in traffic decreasing by $76 \%$ for each additional cyclist in this study and the presence of other cyclists, in general, decreasing the likelihood of non-compliance by $74 \%$ in the Johnson study.

The presence of a vehicle in a lane adjacent to the cyclist was also a very influential determinate of compliance. Due to concurrent phasing at most of the intersections, the vehicle present variable serves as another proxy for eyes on the road, in addition to the presence of other cyclists, that might deter cyclists from running a red light. The presence of a vehicle in this study had a much more negative effect on non-compliance (a decrease in likelihood of $91 \%$ ) compared to the other study that looked at the effects of vehicle presence (a decrease in likelihood of 62\%) (Johnson et al., 2011). Again, the Australian study combines turning red light runners with thru cyclists which likely accounts for the relaxed influence of the variable.

The most consistently analyzed determinant in research on cyclist compliance is cross traffic volume. Although it might be presumed that the variable for vehicles waiting and that for cross traffic would be highly correlated and therefore both significant, it rather seems that the former is indicative of the traffic moving with the cyclist while the latter is traffic moving opposite the cyclist. Cross traffic volume was not found to be a significant 
indicator of compliance in this study in the presence of other, significant variables. This is in contrast the findings in the literature. For instance, Wu et al. (2011), who classified cross traffic volume into 'low', 'medium', and 'high' categories by the number of vehicles per minute, found that a jump from 'high' cross traffic volumes to either of the lower two categories produced a marked increase in the odds that a cyclist would run the red light. The Johnson et al. team (2011) used counts of crossing vehicles for each individual cyclist and assigned these frequencies to bins. Still others modeled cyclist red light running against peak 15-minute flow rate (Parks et al., 2012). Comparatively, this thesis looked at the average number of cars per 30 seconds as well as the square of this cross traffic volume to assess the impact of traffic on red light running. In retrospect, this method for determining cross traffic is inferior to the Johnson et al method mentioned above since it generalizes cross traffic for every cyclist in a certain time period. This removes the ability of researchers to model more opportunistic cyclists based on specific gaps that they did or did not capitalize on in order to run the red light and may have contributed to this variables lack of significance.

Signal phasing is a variable that had not, to the author's knowledge, been addressed in previous literature and came with surprising results. Cyclists at signals where the signal phasing temporally separates them from right-turning motorists, are nearly nine times more likely to accept a gap in traffic. This is surprising given that this type of phasing is meant to alleviate a conflict by separating bicycle and motorist movements in time. Upon further scrutiny, the relationship makes sense. The phasing at these signals is such that rightturning motorists can travel concurrently with through-moving motorists except when 
cyclists are present. Thus, this phasing 'rests' in the state where motorists are given a green indication and bicyclists must wait. It is therefore possible for cyclists to travel through the intersection, conflict-free against their red indication if no right-turning vehicles happen to be present. In this instance, a violation of the signal is a tempting option for cyclists who are frustrated by the need to stop when other traffic traveling in the same direction has a green indication. This type of behavior has also been documented in Sydney, Australia where $45-69 \%$ of observed cyclists crossed the intersection during the green motorist/red bicycle phase (Bitzios Consulting, 2008). Authors of this same study also noted that cyclists with this type of phasing rarely encountered green indications (only $~ 10 \%$ of the time) and that cyclists seemed frustrated with the lack of coordination of their movements. The lack of green indications upon cyclists' approaches seems consistent with the approach conditions at the locations in this study. Additionally, the use of this type of phasing in conjunction with bicycle-specific signals and placement of these signals on popular bicycle routes means that cyclists can quickly become familiar with this signal phasing scheme and begin watching for right-turning vehicles when through-traffic has a green indication. When there are no right-turning vehicles in sight, cyclists may feel free to run the red light without fear of conflict. This raises the point of intent use versus impact with respect to specialized infrastructure for cyclists and is another situation, similar to the example given in the discussion of the right turn on red model, where alteration of the facility to reflect existing cyclist behavior may be optimal to increase compliance. Furthermore, although the majority of cyclists in this study and others are compliant, scofflaw cyclists impart the largest share of anecdotal evidence to the discourse on cyclist compliance (Imbert \& te 
Brommelstroet, 2014). Given the ability of (at least some) cyclists to find the means to travel in a way that is most advantageous to them without regard for traffic laws ${ }^{16}$ and the push to garner public support for increased bicycling facilities, it may be prudent for transportation professionals to design bicycle facilities with the opportunistic cyclist in mind in order to curb non-compliant behavior and, thus, negative rhetoric on the topic. Providing a "green wave" for cyclists and other bicycle-friendly signal timing schemes have been used with success in the Netherlands and other parts of the world and would likely reduce red light running due to cyclists' grievances with signal timing.

Previous violators are another variable shown to increase the odds that the cyclist in question would follow suit by more than six times. The relationship between the two is much stronger than that reported by Wu et al., (2011) but the directionality of the effect is similar. It is posited by that the psychological phenomenon called diffusion of responsibility (Latane \& Nida, 1981) allows cyclists to feel less responsible for committing a violation when others have already done so. This influence on non-compliance is explored again in analysis of the survey data.

Sex, too, was a significant influencer of gap accepted non-compliance. Males were found to be more likely to run red lights than females. These findings were echoed by other previously-cited studies: Johnson et al (2011) and (Wu et al., 2011). This points to differences in socialization between men and women but it is beyond the scope of this

\footnotetext{
${ }^{16}$ As evidenced by numerous studies in addition to this one: (Goodyear, 2013; Grabar, 2013; Imbert \& te Brommelstroet, 2014; Johnson, Charlton, Oxley, \& Newstead, 2013; Johnson, Newstead, Charlton, \& Oxley, 2011; Wu, Yao, \& Zhang, 2011)
} 
thesis to pinpoint the social mechanisms that contribute to this. The difference between compliance behaviors of men and women likely due to societal differences can also be seen in the way that the sex and previous violator variables interact. An interesting phenomenon occurred when these two variables were interacted. While women, in general, are less likely to run a red light, women who witness a previous violator are more likely than cyclists who fit any other combination of sex and witnessing variables to run the red indication. Again, a difference in socialization is at play here.

Helmet use is less a determinate of non-compliance and more of an indicator of the type of person who might be more likely to run a red indication. Lack of a helmet, in this study, resulted in 2.5 times the odds that the cyclist would run the red light. This finding is contrary to the other study that empirically looked at helmet use and compliance which found a positive, yet non-significant relationship between helmet use and non-compliance. As discussed in the literature review, a subset of the population is more likely to engage in risk behaviors than the rest of the population. Given the pervasive idea that bicycle helmets are a necessary safety accessory, this finding corroborates the idea this subset exists with the population of cyclists. These cyclists are, therefore, more willing to engage in multiple biking-related risk factors that include not wearing a helmet and running red lights.

The differences between model specifications depending on the inclusion of observations from Broadway at Lovejoy were also explored. While the names of significant variables remained consistent, their relative importance changed from the original model to a model with a more balanced numbers of observations from Broadway at Lovejoy. This model 
also had improved fit over the original model. One of the main differences between the original and balanced models was the role of the number of cyclists waiting at the intersection. The role of this variable was diminished when the dataset included fewer observations from Broadway at Lovejoy. This is likely due to the intersection configuration at Broadway/Lovejoy which doesn't really allow cyclists to wait side-by-side at the signal. Some of the longest cyclist queues in Portland occur at this intersection and the physical barrier to running the red light increases substantially after a few cyclists are already waiting. 


\subsubsection{Illegal Right Turns on Red}

Of the two models estimated, the simplest model was for illegal right turns on red. In this model, only one factor was significant in the decision to make an illegal right turn: a continuous lane with no vehicle or bicycle conflicts that, additionally, separates rightturning and thru cyclists. Although the direction of travel (i.e. a left turn ${ }^{17}$ ) and facility type have been found to be significant indicators of red light running behavior (Johnson et al., 2011), these two variables have not been previously cross-analyzed. Red light runners make up $23 \%$ of the overall sample in this study compared to just under two percent in the Johnson et al study (2011). Compared to the percent of left turners (38.0\% for females $62.3 \%$ for males) that were non-compliant in that study, a hefty $97 \%$ of right-turning cyclists from this analysis were technically non-compliant. This is likely due to the facility type available at the Broadway \& Lovejoy study intersection and the high proportion of observations from that location $(88.3 \%)$.

The heavy influence of facility design in this sub-study of right-turning red light runners, points to ramifications of design on cyclist behavior. Although the right turn movement at Broadway \& Lovejoy is technically illegal, arguments have been made that cyclists are behaving as intended with respect to the design of that intersection. While the current trend in adding bicycle facilities is toward explicit designation of bicycle movements via striped bike lanes, signage, dedicated signals, etc., this finding points to the potential for implicit influence on cyclist behavior. The transportation profession has already begun to embrace

\footnotetext{
${ }^{17}$ Analogous to right runs in the study locale of Australia
} 
more implicit types of influence for motorists (think: street trees and pedestrian-scale lighting that make cars adhere to lower speed limits better than a sign alone). Perhaps more intuitive facilities for cyclists are the solution to some of the other 'annoying' behaviors of cyclists (such as riding on the sidewalk or fast riding in mixed mode areas) not covered in this study.

Additionally, the discrepancy between the legal and potentially-intended use of the Broadway \& Lovejoy facility highlights the issue of traffic laws (and traffic control devices) created without cyclists in mind but that are now used jointly by cyclists and motorists. The issue, which has arisen in recent media discourse on cyclist compliance (Goodyear, 2013; Grabar, 2013), is the reasoning behind "Idaho stop" laws and the unofficial acceptance of cyclist red light running in the event that a cyclist is not detected by induction loops. While the tendency is to prevent problem behaviors through increased disincentives (such as ticketing), a new train of thought is emerging around learning from so-called problem behaviors (Imbert \& te Brommelstroet, 2014). The idea is that the ways cyclists navigate less-than-ideal infrastructure or policy/infrastructure combinations can teach professionals about design flaws instead of merely being a new vehicle for enforcement. Selected application of this type of philosophy does already happen ${ }^{18}$, but a broader recognition of the differences between cyclists and other road users could result in better design that would increase compliance.

\footnotetext{
${ }^{18}$ An example of this is in the case study of cyclist compliance with signalization at a trail crossing in Denver, $\mathrm{CO}$. The findings of the study were mentioned in the review of the literature on page 11.
} 


\subsubsection{Signal Jump}

Despite the fact that no model was estimated for the signal jump behavior, some discussion is still to be had on the topic. Similar to right turns on red, signal jump behavior has been mixed in with other types of red light running in previous analyses (Johnson et al., 2011; Wu et al., 2011). One study (Wu et al., 2011), attempted to quantify signal jump behavior within their sample by noting the time distribution of red light running movements. Movements made toward the very end of the red cycle accounted for approximately 3-7\% of the sample ${ }^{19}$. This on par with the findings from this study which had a signal jump proportion of $3.34 \%$.

\subsection{Summary}

The video data contained 20 variables relating to either the cyclist, the intersection, or the scenario for each observed cyclists in the dataset. These variables were used to estimate models for two types of non-compliance with data on the third type of non-compliance, signal jumping, unconducive to a binary logit model fit.

Illegal right turns were the most common type of non-compliance participated in by cyclists. This non-compliant maneuver was most influenced by the location at which the cyclist was observed. The geometry of the bicycle facilities at the Broadway and Lovejoy intersection are such that cyclists turning right are presented with no conflicts (other than pedestrian crossings) and a continuous, separated lane in which to take a gradual right turn.

\footnotetext{
${ }^{19}$ Due to the way phase time was normalized for all the intersections in the study, it is impossible to obtain an exact percentage for signal jump behavior.
} 
This type of facility positively influences right turns on red without stopping. The discrepancy between the legal use and intuitive use of this facility is also important and demonstrates the importance of facility design over traffic laws for cyclists. This extends to the shared use of facilities by bicyclists and motorists and issues that arise when traffic laws or facilities historically designed for motorists are applied 'as is' for cyclists.

A model of the gap-accepted type of non-compliance highlighted the presence of adjacent cyclists and vehicles as important deterrents of the illegal maneuver. Phasing separating right-turning vehicles from cyclists, lack of helmet, and witnessing another violator each further explained a moderate amount of the non-compliance in this model. Smaller, significant effects on gap acceptance came from the sex of the cyclist (female) and the interaction of sex with witnessing a previous violation.

The differences in the significant variables (or lack thereof) for the models describing three red light running types are important to note. Prior investigations of red light running by cyclists have grouped all types of red light running together. From this analysis, it is apparent that different categorizations of red light running should not be grouped together for analysis since they are influenced by different variables. While the decision to accept a gap in traffic is fairly complex, the decision to make a right turn without stopping first is much simpler. Previous analyses of variables affecting compliance have conflated the influences on these two types of movements. This, thus, has muddled the relationships between indicators and compliance, especially for gap accepted maneuvers. 
Also, the ability of cyclists to circumvent traffic laws for their own advantage is the source of much negative rhetoric on the topic of cyclist compliance. Findings from this portion of the study reveal the importance of design in influencing cyclist behavior. Attention is called the issue of intent versus impact in terms of the use of a facility by cyclists and how this principle might be applied to design decisions.

Lastly, analysis largely focuses on modeling the gap accepted non-compliant maneuver since it is the most serious and conflicted-inducing (Bai et al., 2013) type of noncompliance identified. The model chi-squared value for this model is significant. This means that the difference in residual deviance (the chi-squared value) between the specified model and a model with only an intercept term is significant (see Table 4.7).

Table 4.7 Analysis of Deviance

\begin{tabular}{lrr}
\hline Model & Residual Deviance & Deviance Explained \\
\hline Intercept only & 518.09 & -- \\
Intercept + significant variables & 359.96 & 158.12 \\
\hline
\end{tabular}

However, since the deviance is essentially the difference in expected outcomes for the dependent variable, based on the model, and the actual outcomes in the data, remaining residual deviance indicates that the model could be improved via the inclusion of other explanatory variables. Considering the fact that all possible variable options from the video data have been exhausted, this large amount of unexplained variation in expected outcomes points to the need for explanatory variables beyond those viewable by observation in modeling cyclists' decisions to run red lights. 


\subsection{Analysis: Survey Data}

This section summarizes the findings from the survey of cyclists and outlines the relationship between cyclist characteristics and their willingness to be non-compliant, justify non-compliance, and judge other cyclists with regard to compliance.

\subsubsection{Sample Description}

\subsubsection{Age}

The sample skews slightly towards younger participants (considering a lower limit of 18) with a median age of 36 and a mean age of 38 . The survey was able to capture cyclists of a wide range of ages with the youngest in the sample of age 22 and the oldest age 73 . (Note that participants had to be at least 18 years of age to become part of the dataset.)

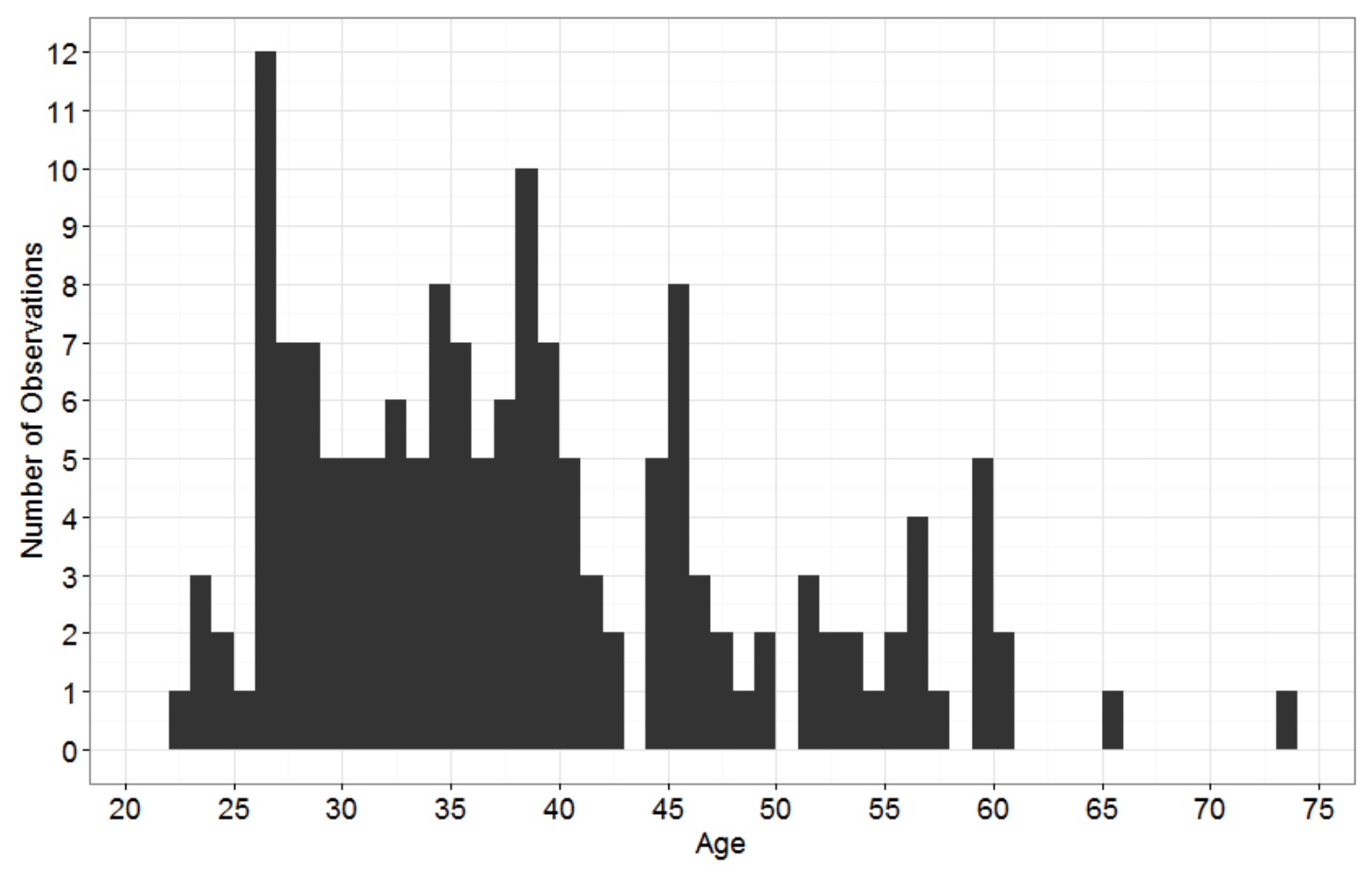

Figure 4.5 Distribution of Respondents' Ages 


\subsubsection{Gender}

The survey population was nearly evenly split down binary gender lines with just over half the respondent population identifying as "male" and just under half identifying as "female". Two survey respondents chose to write in their preferred gender both of which were "genderqueer".

Table 4.8 Respondents' Gender

\begin{tabular}{lrc}
\hline Gender & \% of Respondents & $(\mathrm{N})$ \\
\hline Male & $53.5 \%$ & $(81)$ \\
Female & $45.2 \%$ & $(71)$ \\
Genderqueer & $1.3 \%$ & $(2)$ \\
\hline
\end{tabular}

\subsubsection{Household Structure}

The largest proportion of respondents were partnered long-term with nearly half those people having children. The only underrepresented family structure was that of single parents with only one participant indicating that they were as such.

\section{Table 4.9 Respondents' Household Structure}

\begin{tabular}{lrc}
\hline Household Structure & \% of Respondents & (N) \\
\hline Single & $25.5 \%$ & $(40)$ \\
Single w/ Child(ren) & $6.4 \%$ & $(1)$ \\
Partnered & $39.5 \%$ & $(62)$ \\
Partnered w/ Child(ren) & $34.4 \%$ & $(54)$ \\
\hline
\end{tabular}




\subsubsection{Job Flexibility}

The majority of the population has a job at which they need to show up during business hours but there are no regimented shifts and no penalty for being late. Smaller percentages of the sample fell into categories on either side of the typical white collar job in with the respondent had either a very flexible schedule or had to be clocked in on time, although, there was no formal penalization for being late.

Table 4.10 Respondents' Job Flexibility

\begin{tabular}{lrc}
\hline Job Flexibility & \% of Respondents & $(\mathrm{N})$ \\
\hline Very Flexible & $15.3 \%$ & $(24)$ \\
Can Be a Little Late & $63.1 \%$ & $(99)$ \\
Must Be Clocked In On Time & $17.2 \%$ & $(27)$ \\
Penalized If Not On Time & $3.2 \%$ & $(5)$ \\
Unemployed & $1.3 \%$ & $(2)$ \\
\hline
\end{tabular}

\subsubsection{Mode Usage}

Respondents provided an estimate of how frequently they used various modes and for what types of trips. The survey clarified trip types with the descriptors "to/from work or school" for commute trips, "getting to appointments, shopping, running errands" for utilitarian trips, and "leisure or exercise" for recreational trips. Due to the nature of survey distribution, respondents were unsurprisingly, overwhelmingly bicycle commuters for "most trips". Bicycle use was not limited to commute trips, though, with half or more respondents indicating that they used a bicycle for recreational and utilitarian trips types for "most trips". Although the bicycle was the predominant mode for most respondents, 
$91.7 \%$ of the sample used a car and $77.7 \%$ used transit for at least "some trips" for any of the three trip types.

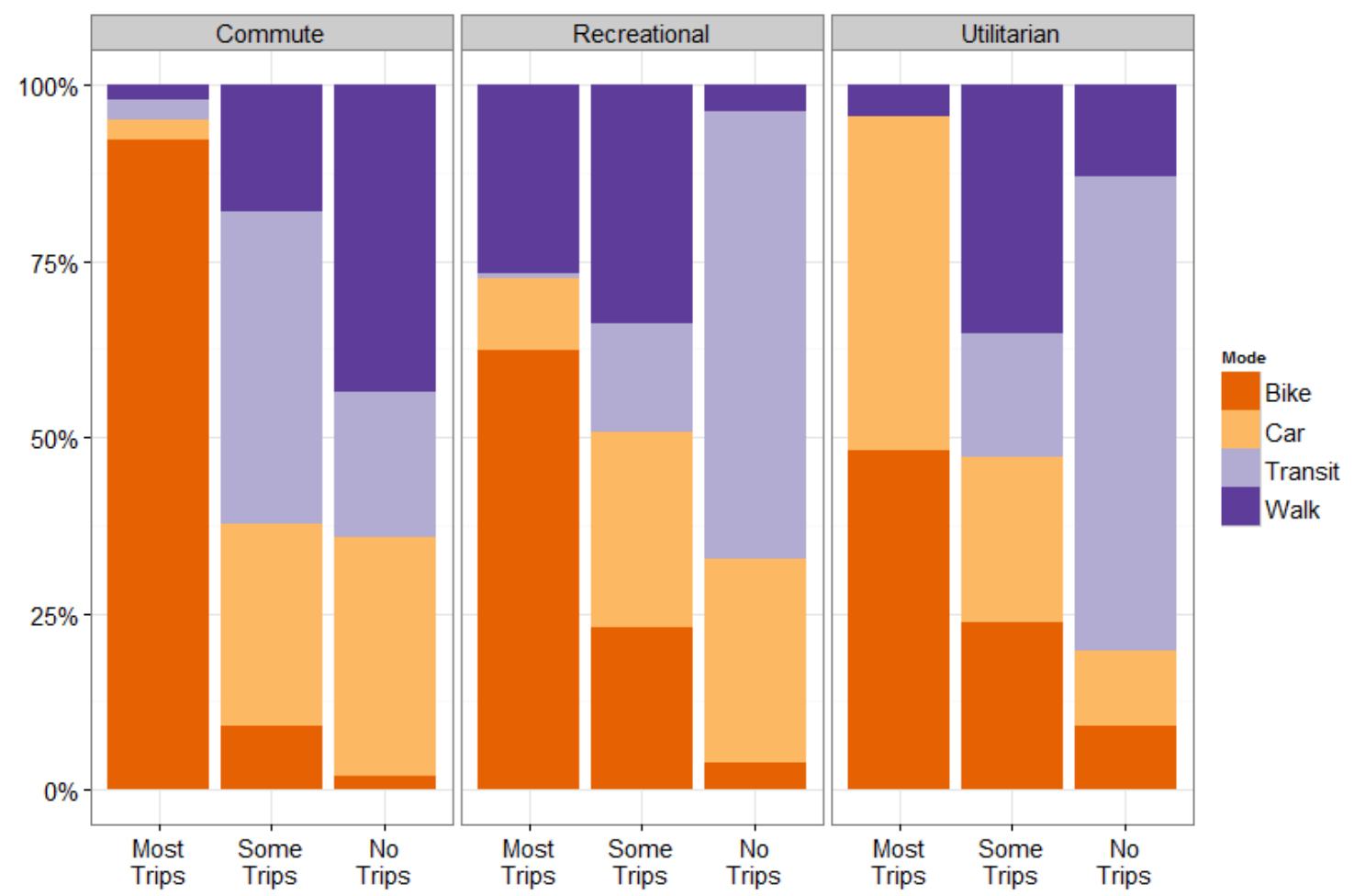

Figure 4.6 Mode Usage for Different Trip Types

\subsubsection{Worries about Crash Incidence and Severity}

Respondents' worries about being in a crash with a vehicle are somewhat normally distributed, although respondents tended to pick responses that were not neutral. Thus, two peaks on either side of the neutral value (5) emerged. 
Responses to the statement, "It is likely that I will be seriously injured if I get into a crash with a motor vehicle while on my bike" skewed towards agreeable responses with $70.7 \%$ of cyclists stating that they "Agree[d]" or "Strongly Agree[d]".

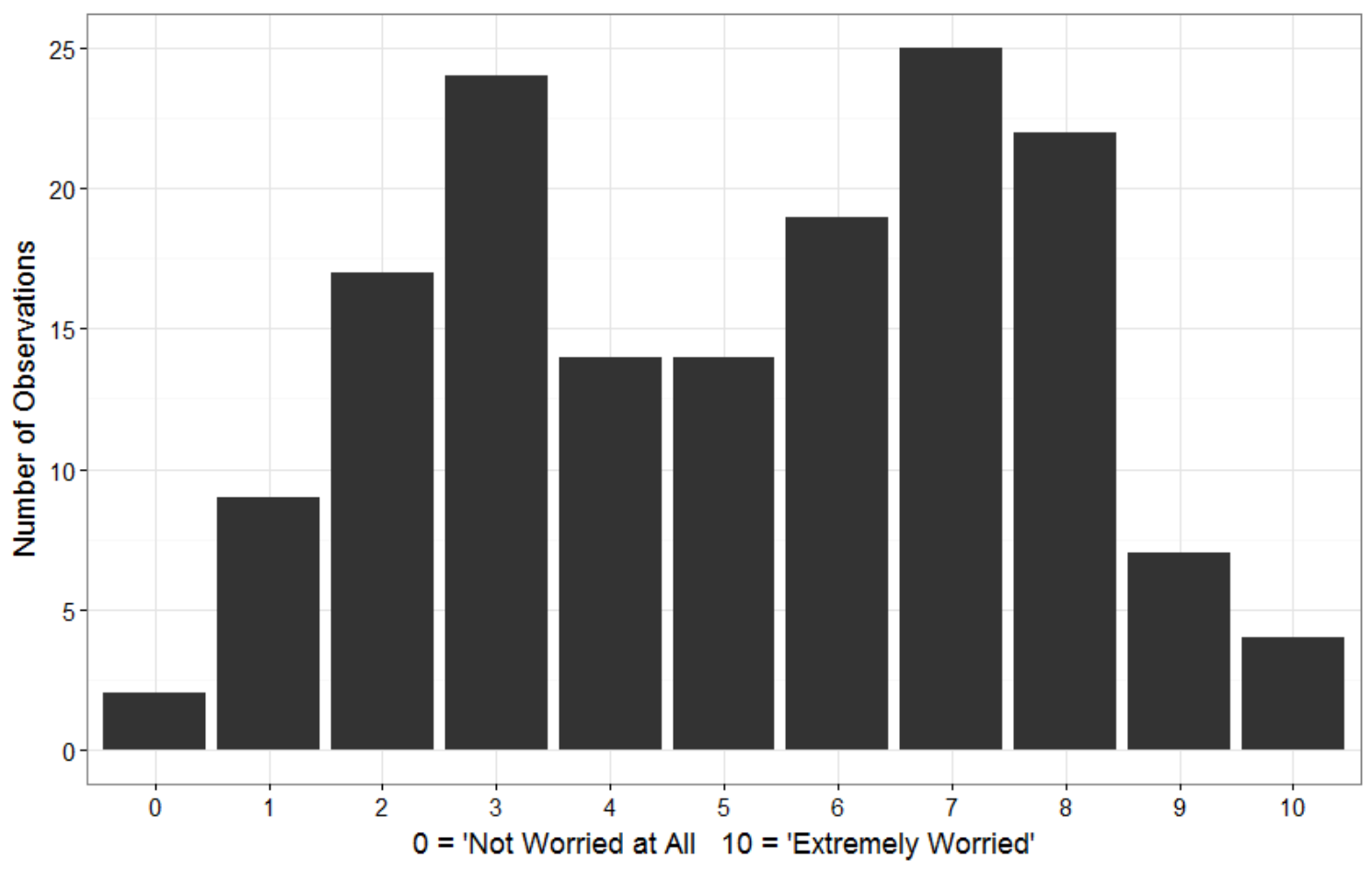

Figure 4.7 Distribution of Crash Worries 


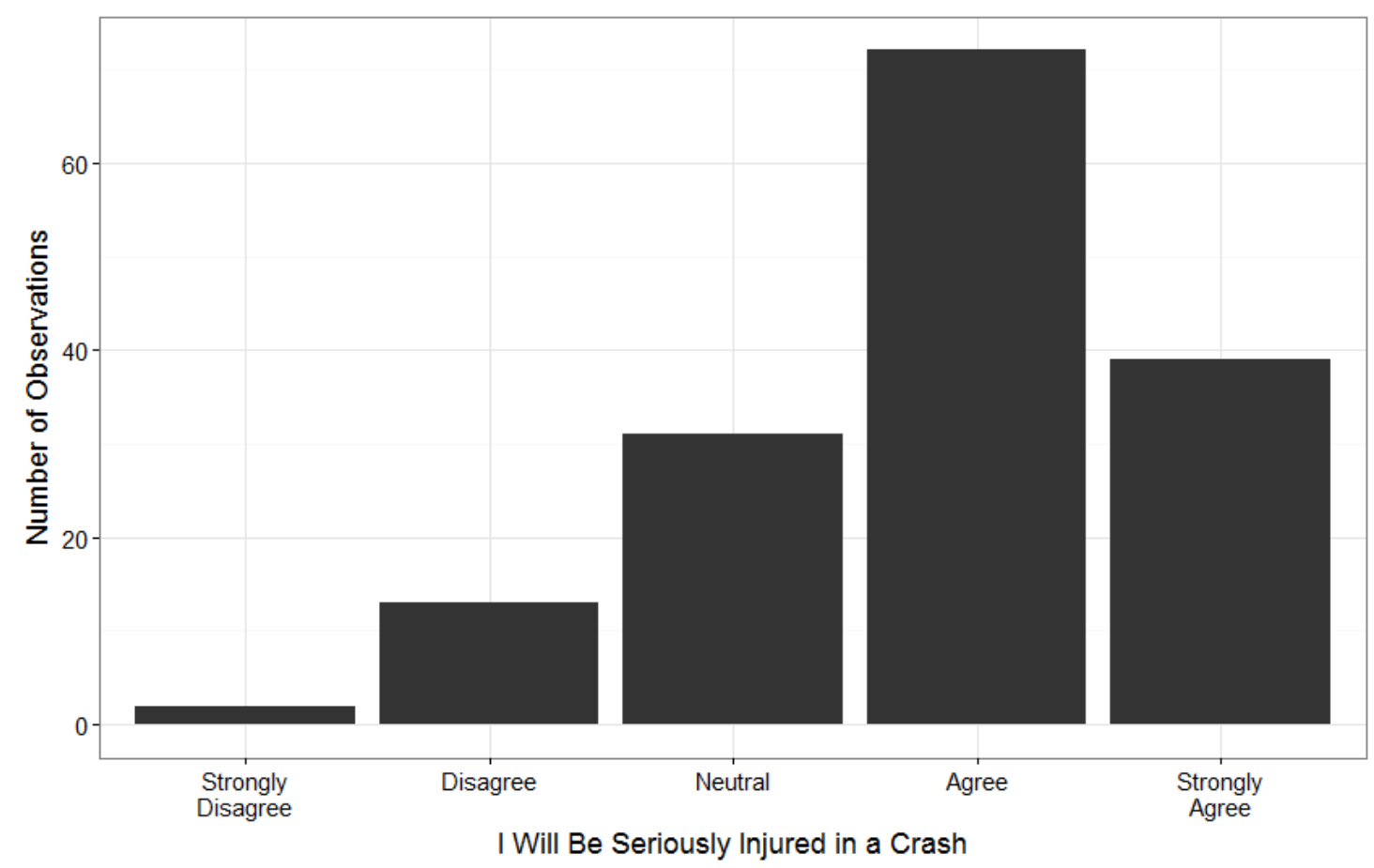

Figure 4.8 Distribution of Anticipated Severity of a Crash with a Motor Vehicle

\subsubsection{Crash Experiences}

In addition to cyclists' feelings about potential crashes, actual crash experiences were evaluated for all cyclists by type (i.e. a crash with another road user or object/surface/lost control) and severity (no injury to severe injury). 
Table 4.11 Respondents' Crash Experiences

Crash Type

Another road user

(pedestrian, motorist, or cyclist)

A road object or surface

$\%$ of Respondents

(N)

0

0

$50.3 \%$

(79)

0

1

$19.7 \%$

1

0

$12.1 \%$

1

1

$17.8 \%$

Crash Type occurred if value $=1$, not if $=0$

Just over half the sample have had no crashes of any kind while riding their bike. The other half of the sample reported having one or more crashes with another road user or road object or surface with fairly similar proportions of people having a crash of only one type or both (see Table 4.11).

Of the respondents having experienced crashes (see Tables 4.12 and 4.13), the majority sustained no or only minor injuries for both crash types though injuries tended to be more severe for crashes with road objects or surfaces. 
Table 4.12 Respondents' Crash Severities with Other Road Users

\begin{tabular}{crrrrr}
\hline No Injury & Minimal & Moderate & Severe & \% of Respondents & $(\mathrm{N})$ \\
\hline 1 & 0 & 0 & 0 & $27.9 \%$ & $(12)$ \\
0 & 1 & 1 & 1 & $4.7 \%$ & $(2)$ \\
0 & 1 & 1 & 0 & $2.3 \%$ & $(1)$ \\
0 & 1 & 0 & 0 & $41.9 \%$ & $(18)$ \\
0 & 0 & 1 & 1 & $2.3 \%$ & $(1)$ \\
0 & 0 & 1 & 0 & $14.0 \%$ & $(6)$ \\
0 & 0 & 0 & 1 & $7.0 \%$ & $(3)$ \\
\hline
\end{tabular}

Injury Type occurred if value $=1$, not if $=0$

Table 4.13 Respondents' Crash Severities with Road Objects \& Surfaces

\begin{tabular}{crrrrr}
\hline No Injury & Minimal & Moderate & Severe & \% of Respondents & $(\mathrm{N})$ \\
\hline 1 & 0 & 0 & 0 & $8.8 \%$ & $(3)$ \\
0 & 1 & 1 & 1 & $2.9 \%$ & $(1)$ \\
0 & 1 & 1 & 0 & $2.9 \%$ & $(1)$ \\
0 & 1 & 0 & 1 & $2.9 \%$ & $(1)$ \\
0 & 1 & 0 & 0 & $47.1 \%$ & $(16)$ \\
0 & 0 & 1 & 1 & $2.9 \%$ & $(1)$ \\
0 & 0 & 1 & 0 & $26.5 \%$ & $(9)$ \\
0 & 0 & 0 & 1 & $5.9 \%$ & $(2)$ \\
\hline
\end{tabular}

Injury Type occurred if value $=1$, not if $=0$. 


\subsubsection{Risky Behaviors}

Risky behaviors were defined for both bicycling and driving. Only respondents indicating that they used a car for at least "some trips" were asked about risky behaviors specific to driving. ${ }^{20}$

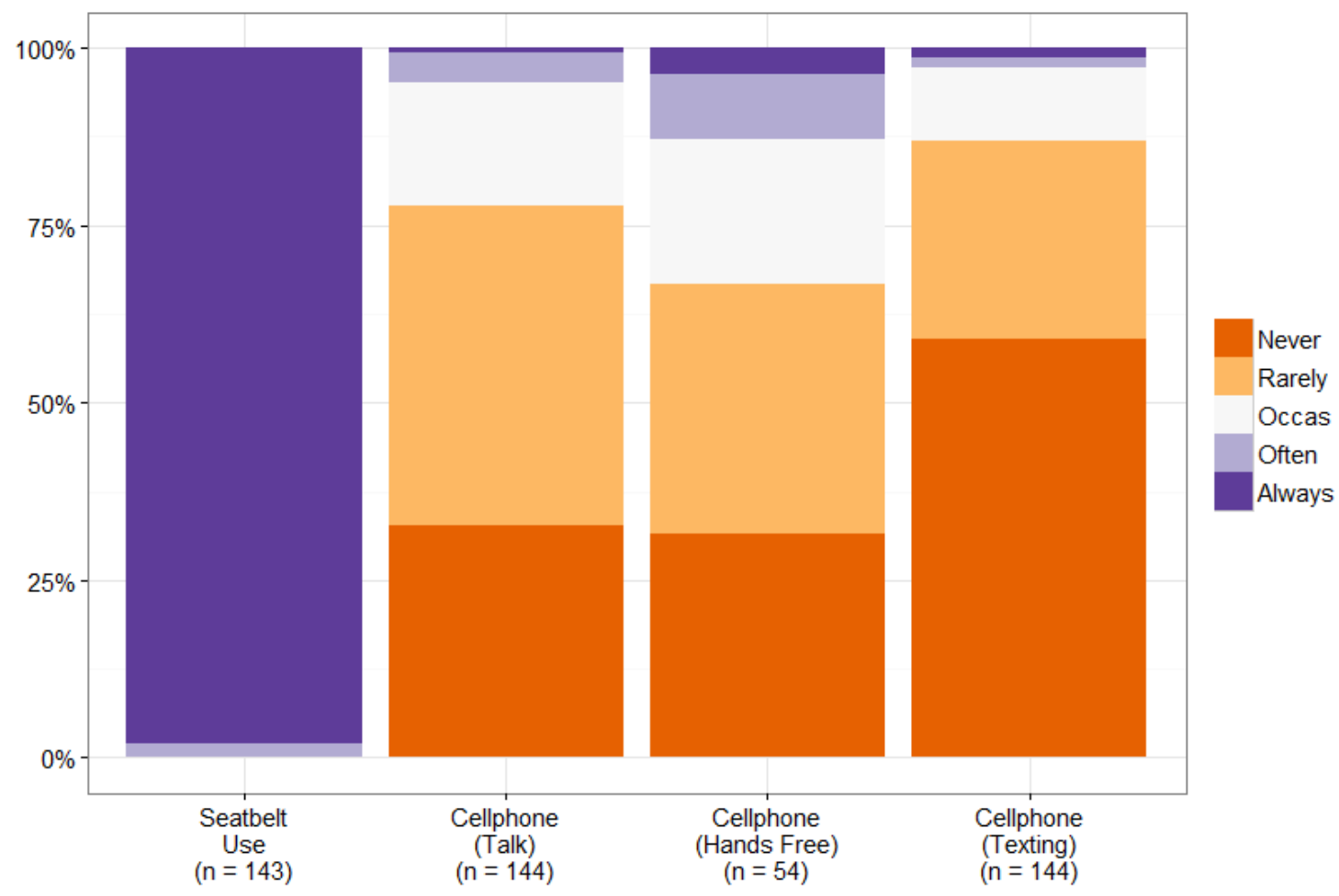

Figure 4.9 Reported Participation in Driving-Related Risk Behaviors

\footnotetext{
${ }^{20}$ Due to an error in the display logic of this question, the "Use a hands free cell phone while driving a motor vehicle" option was only displayed to respondents who used a car at least "some trips" for every trip type instead of for respondents using a car for "some trips" for any trip type. Therefore, the sample size for this risky behavior was approximately half that for the other risky driving behaviors.
} 
Table 4.14 Respondents' Reported Driving-Related Risk Behaviors

\begin{tabular}{|c|c|c|c|c|c|}
\hline $\begin{array}{r}\text { Risky } \\
\text { Behavior } \\
\end{array}$ & Never & Rarely & Occasionally & Often & Always \\
\hline Seatbelt Use & $0.0 \%$ & $0.0 \%$ & $0.0 \%$ & $2.1 \%$ & $97.9 \%$ \\
\hline $\begin{array}{r}\text { Cellphone } \\
\text { (Talk) }\end{array}$ & $32.6 \%$ & $45.1 \%$ & $17.4 \%$ & $4.2 \%$ & $0.7 \%$ \\
\hline $\begin{array}{r}\text { Cellphone } \\
\text { (hands free) }\end{array}$ & $31.5 \%$ & $35.2 \%$ & $20.4 \%$ & $9.3 \%$ & $3.7 \%$ \\
\hline $\begin{array}{r}\text { Cellphone } \\
\text { (text) }\end{array}$ & $59.0 \%$ & $27.8 \%$ & $10.4 \%$ & $1.4 \%$ & $1.4 \%$ \\
\hline
\end{tabular}

Overall, respondents did not participate in risky driving behaviors often with at least two thirds of respondents for each behavior indicating that they "Never" or "Rarely" participated in that behavior. The question format was reversed for the question on seatbelt use so that the "Often" and "Always" responses were indicative of more risk-averse behavior. Responses to this question were the most homogenous of any question on the survey with $97.9 \%$ of respondents answering that they "Always" wore a seatbelt when in a vehicle. 


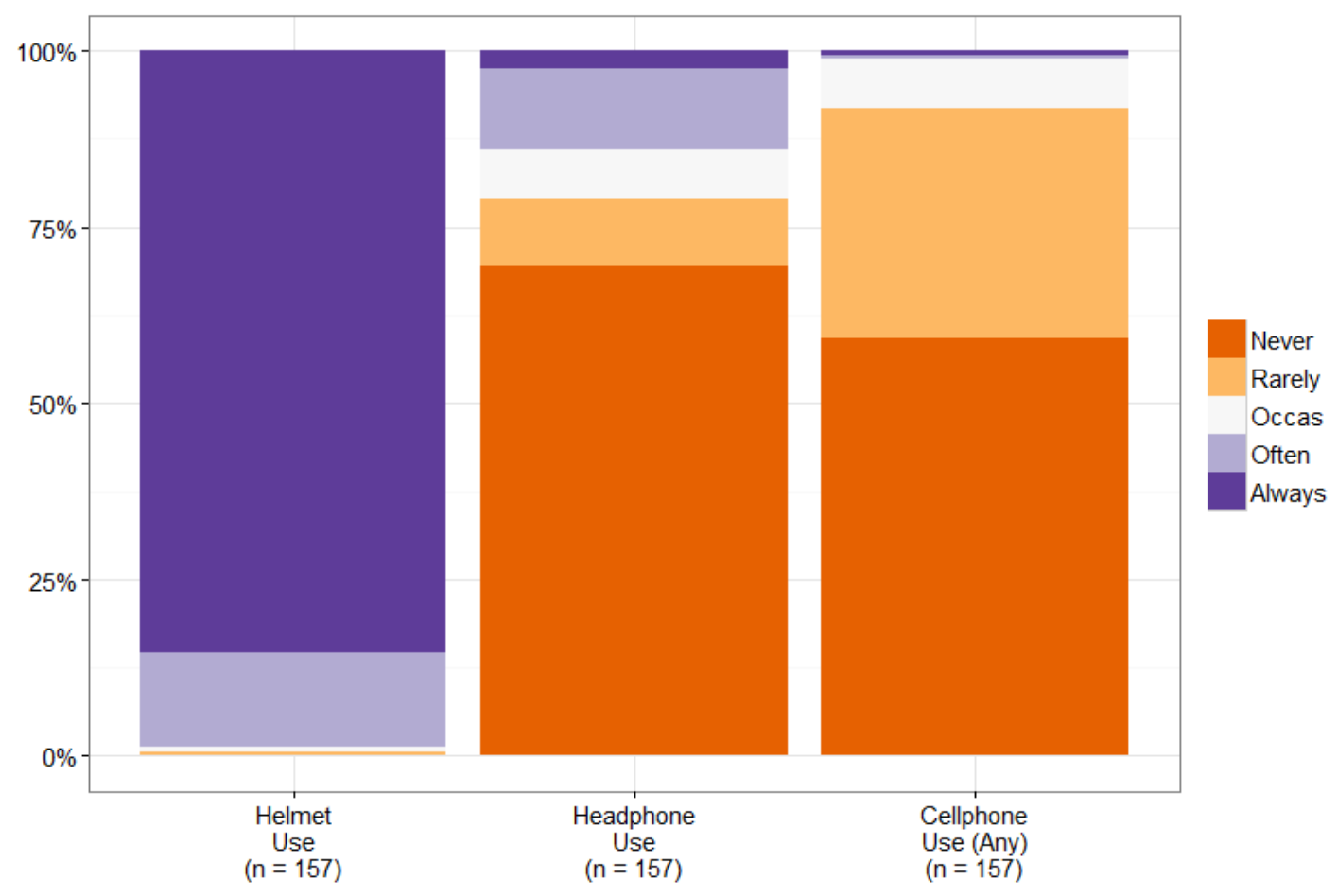

Figure 4.10 Reported Participation in Biking-Related Risk Behaviors

Table 4.15 Respondents' Reported Biking-Related Risk Behaviors

\begin{tabular}{|c|c|c|c|c|c|}
\hline $\begin{array}{r}\text { Risky } \\
\text { Behavior }\end{array}$ & Never & Rarely & Occasionally & Often & Always \\
\hline Helmet Use & $0.0 \%$ & $0.6 \%$ & $0.6 \%$ & $13.4 \%$ & $85.4 \%$ \\
\hline $\begin{array}{r}\text { Headphone } \\
\text { Use }\end{array}$ & $69.4 \%$ & $9.6 \%$ & $7.0 \%$ & $11.5 \%$ & $2.5 \%$ \\
\hline $\begin{array}{r}\text { Cellphone } \\
\text { (any) }\end{array}$ & $59.2 \%$ & $32.5 \%$ & $7.0 \%$ & $0.6 \%$ & $0.6 \%$ \\
\hline
\end{tabular}


Answer profiles were similar for bike-related risk behaviors with $79 \%$ and $91.7 \%$ of respondents answering that they "Never" or "Rarely" used headphones or a cell phone in any way, respectively. Similar to seatbelt use, the question format for helmet use was reversed and responses indicated more overall risk-aversion with regard to helmet use with $85.4 \%$ of respondents indicating that they "Always" wore a helmet and $13.4 \%$ that they "Often" wore one. These reported rates of helmet use were very similar to the observed helmet use from the video data $(84.0 \%)$. Overall, it appears that people are more likely to engage in risky behaviors while driving compared to while biking.

\subsubsection{Citations}

The survey asked about the types of citations participants had received in the last three years. With regard to driving citations, the question collected information on more serious offenses and those that indicate risky behavior. Specific offenses listed were as follows:

- Running a red light

- Exceeding the speed limit by more than $10 \mathrm{mph}$

- Reckless driving

- DUI

- Seatbelt use

- Using a cell phone (in any way)

Respondents also indicated if they had received any type of citation for a violation on a bicycle in the same time period. The majority of respondents $(77.7 \%)$ had not received a citation while driving or bicycling. 
Table 4.16 Respondents' Citations

\begin{tabular}{lrc}
\hline Received Citation & \% of Respondents & (n) \\
\hline Bicycle & & \\
Yes & $5.7 \%$ & $(9)$ \\
No & $94.3 \%$ & $(148)$ \\
Vehicle & & \\
Yes & $10.2 \%$ & $(16)$ \\
No & $81.5 \%$ & $(128)$ \\
Does not drive & $8.3 \%$ & $(13)$ \\
Both Types & $0.6 \%$ & $(1)$ \\
\hline
\end{tabular}

\subsubsection{Justifications}

One question on the survey asked about ways that the respondent might justify red light running. The question prompt was, "I might ride through a red light if..." which was followed by a series of 13 reasons or justifications (see Table 4.17). 
Table 4.17 Percent of Strongly Agree and Agree Responses per Justification

\begin{tabular}{|c|c|c|}
\hline Justification & $\begin{array}{l}\% \text { Strongly } \\
\text { Agree }\end{array}$ & $\begin{array}{c}\% \text { Agree \& } \\
\text { Strongly Agree } \\
\end{array}$ \\
\hline ...I have stopped first and there is no cross traffic. & $12 . \%$ & $49.0 \%$ \\
\hline ....another bicyclist also runs the red light. & $2.5 \%$ & $12.1 \%$ \\
\hline ...it is raining/snowing and I am cold. & $2.5 \%$ & $23.5 \%$ \\
\hline ...I am riding with a group of other adults and one of them does. & $1.3 \%$ & $24.2 \%$ \\
\hline ...it is dark out. & $0.6 \%$ & $15.2 \%$ \\
\hline ...I am running late or in a hurry. & $1.3 \%$ & $27.4 \%$ \\
\hline $\begin{array}{l}\text {...I have been waiting a long time and do not know when I will } \\
\text { receive a green light. }\end{array}$ & $21.0 \%$ & $60.5 \%$ \\
\hline ...I have already had to stop at lights several times already. & $0.0 . \%$ & $10.2 \%$ \\
\hline ...there is no one around to see me do it. & $10.8 \%$ & $45.2 \%$ \\
\hline ...I am going uphill or downhill and don't want to lose momentum. & $6.4 \%$ & $22.3 \%$ \\
\hline ...I am turning right. & $24.2 \%$ & $68.8 \%$ \\
\hline ...I know the signal is about to turn green. & $12.7 \%$ & $44.5 \%$ \\
\hline $\begin{array}{l}\text {...I am carrying a heavy backpack, pannier(s), or other load (not } \\
\text { including children). }\end{array}$ & $0.0 \%$ & $1.3 \%$ \\
\hline
\end{tabular}

When looking at the differences in the proportions of respondents that agreed with each statement, it is clear that some reasons are deemed better or more legitimate than others. The most agreed upon reason for red light running is if a cyclist is making a right turn. Nearly $70 \%$ of the sample agreed that this was a situation in which they might run a red light. Other situations with high rates of agreement were if the cyclist had been waiting at a light a long time $(60.5 \%)$, if they had stopped first and there was no cross traffic $(49.0 \%)$, if there is no one around to see me do it (45.2\%), and if they know that the signal is about to turn green (i.e. they commit a signal jump) (44.5\%). Justifications deemed least legitimate were if the cyclist was carrying cargo (1.3\%), if they had already stopped at several lights on their route (10.2\%), and if another bicyclist runs the red light $(21.1 \%)$. 


\subsubsection{Personality Characteristics}

The survey used metrics for four personality traits previously shown to lead to traffic violations or other risky behavior. Scores for each personality trait were calculated using item responses from each metric ${ }^{21}$. Descriptive statistics for these traits can be found in Table 4.18. Plots of the score distributions for these metrics in the sample population are shown below along with their interpretations. Note that for all personality traits, higher scores equate to higher levels of that personality trait.

Table 4.18 Summary of Personality Scores

\begin{tabular}{lcccc}
\hline Personality Trait & Mean & Median & Std. Dev. & $\mathrm{N}$ \\
\hline Impulsive Sensation-Seeking & 1.71 & 1 & 1.63 & 157 \\
Normlessness & 0.84 & 1 & 0.93 & 157 \\
Anxiety & 3.14 & 3 & 0.82 & 157 \\
Patience & 3.45 & 3.5 & 0.62 & 157 \\
\hline
\end{tabular}

${ }^{21}$ For more information about the calculation of psychometric scores, refer to the documentation of personality metrics in section 3.2.1. 


\subsection{Impulsive Sensation-Seeking}

The metric used to determine this personality trait asked respondents to select whether they agreed or disagreed with the following statements:

1. I like 'wild' parties.

2. I am an impulsive person.

3. I enjoy getting into new situations where you cannot predict how things will turn out.

4. I would like the kind of life where one is on the move and traveling a lot, with lots of changes and excitement.

5. I prefer friends who are excitingly unpredictable.

6. I often get so carried away by new and exciting things and ideas that I never think of possible complications.

7. I often do things on impulse.

The score for impulsive sensations-seeking is simply the count of all "Agree" answers.

The distribution of Impulsive Sensation-Seeking scores for the sample population is heavily weighted toward lower scores. This means that survey respondents are, overall, less inclined to be impulsive or thrill-seeking. 


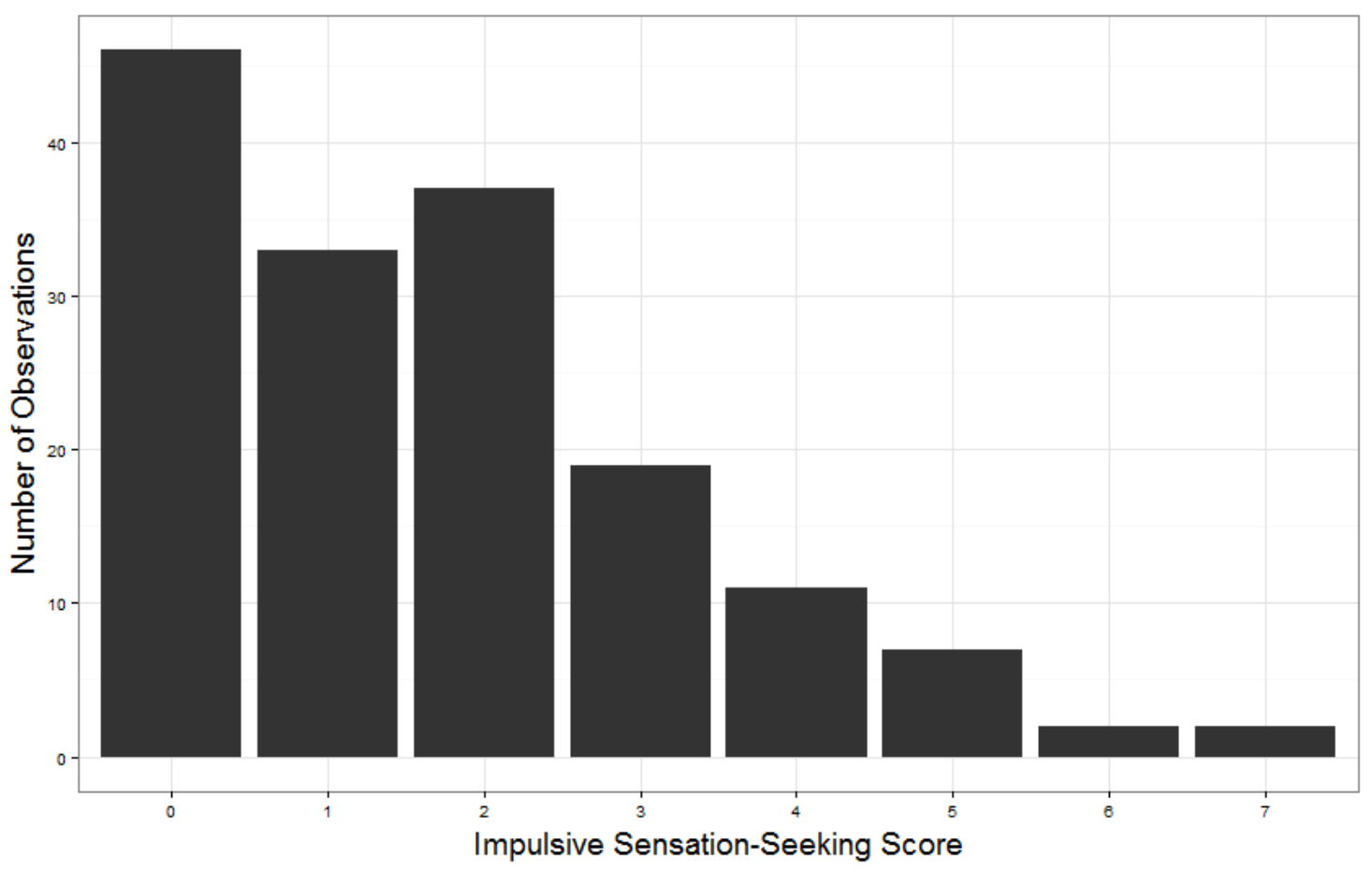

Figure 4.11 Distribution of Impulsive-Sensation Seeking Scores 


\subsection{Normlessness}

The metric used to determine this personality trait asked respondents to select whether they agreed or disagreed with the following statements:

1. I think it's alright to do anything you want as long as you stay out of trouble.

2. It is okay to get around the law as long as you don't actually break it.

3. If something works, it doesn't matter if it's right or wrong.

Additionally, in response to the prompt "Do you believe it's alright to do whatever the law allows, or are there some things that are wrong even if they are legal?", respondents were asked to choose one of the following:

- Whatever the law allows is okay (1)

- Some things are wrong even if they are legal (2)

"Agree" answers and the $1^{\text {st }}$ answer choice to the prompt were counted and became the normlessness score.

Similar to the distribution of Impulsive Sensation-Seeking scores, Normlessness scores were generally low meaning that the majority of the sample population adhere to socially defined norms and abide by rules. 


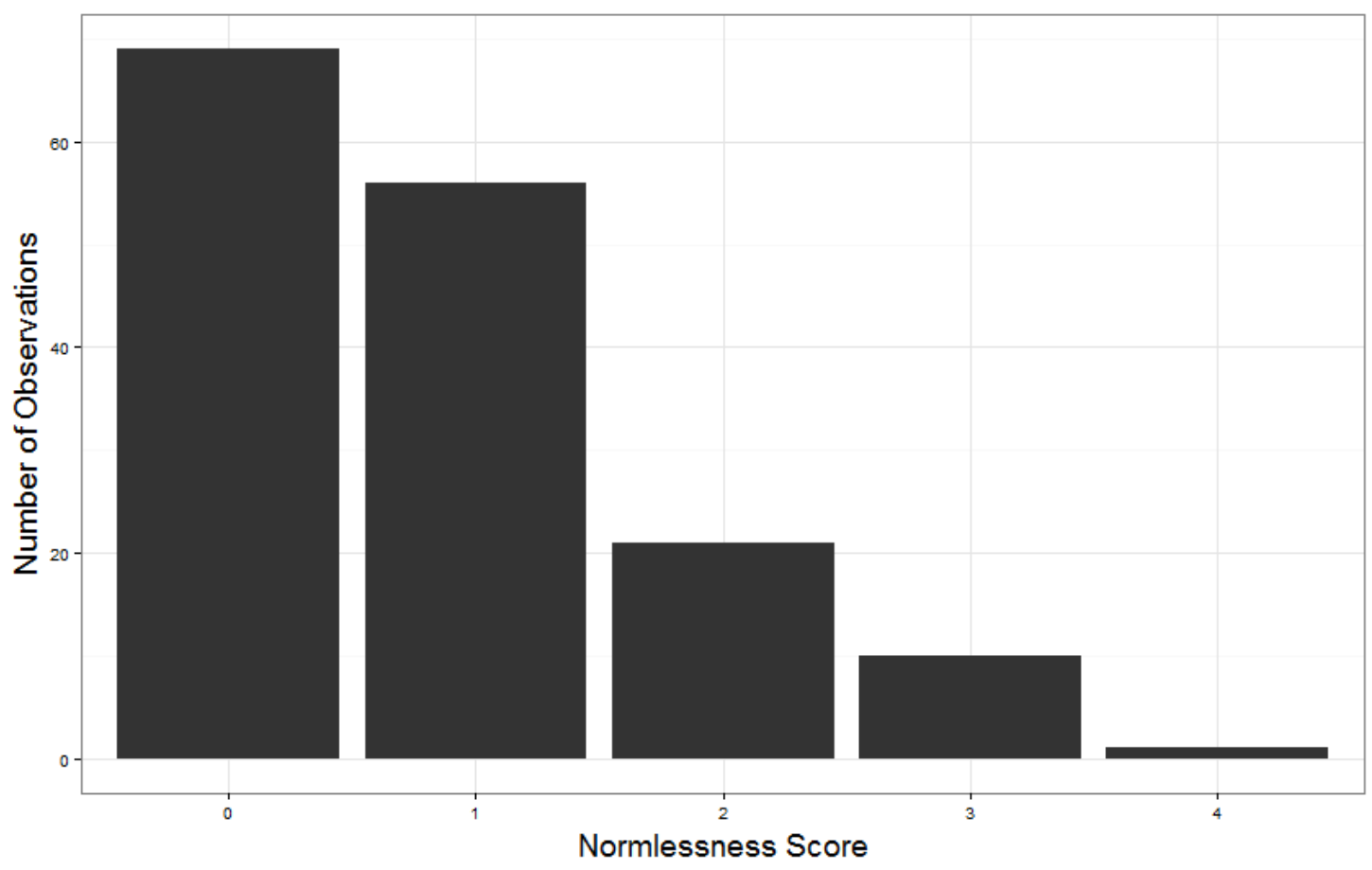

Figure 4.12 Distribution of Normlessness Scores 


\subsection{Anxiety}

Score for the Anxiety facet of the HEXACO-PIR is the mean of all Likert responses with “Strongly Disagree" equal to 1 and "Strongly Agree' equal to $5^{22}$.

Anxiety scores for the sample were relatively normally distributed but skewed slightly toward higher anxiety scores. This is in contrast to scores for the two previous personality traits, which were heavily skewed toward lower scores (i.e. less of that personality trait)

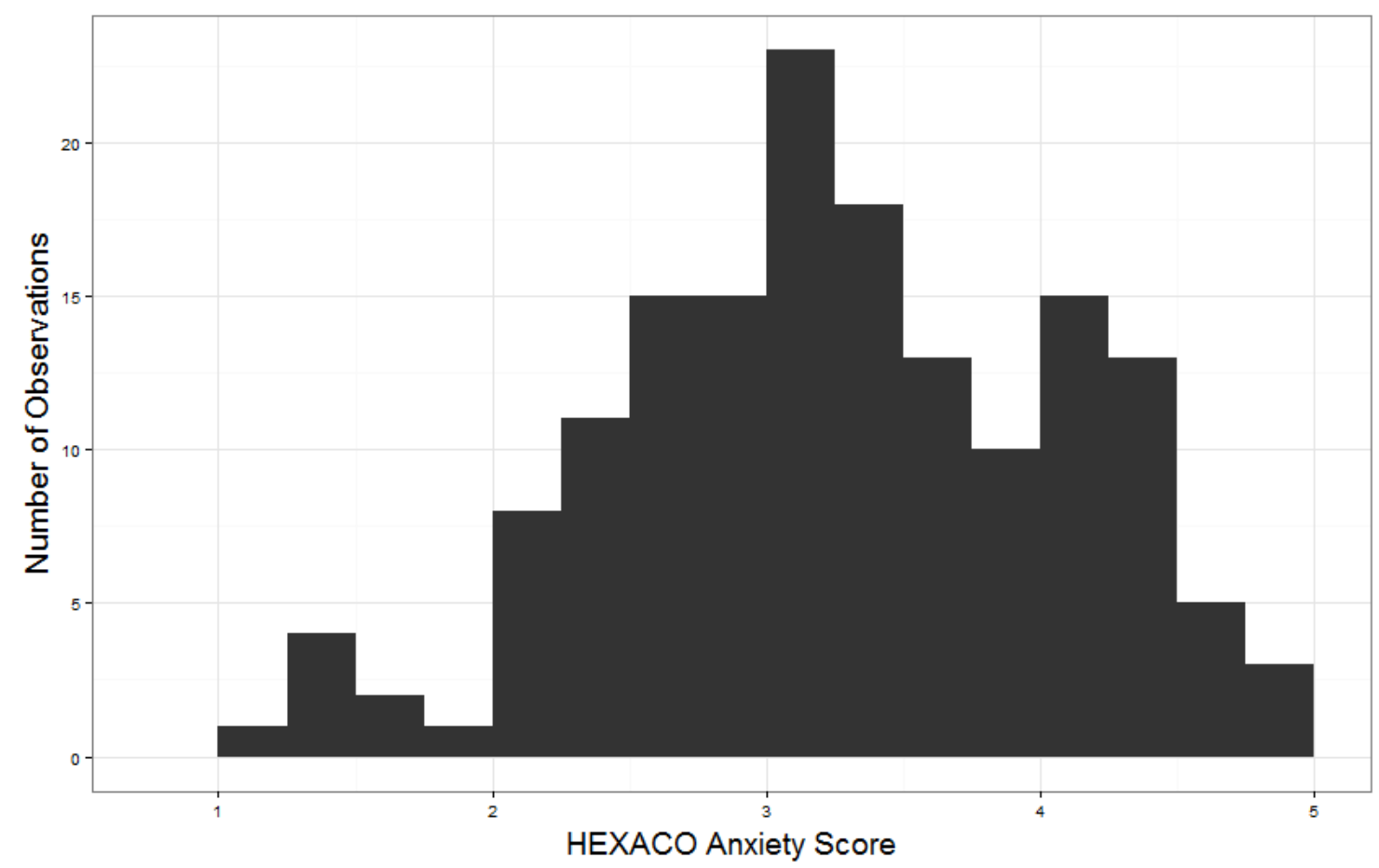

Figure 4.13 Distribution of Anxiety Scores

${ }^{22}$ Questions are too numerous to list out here but can be found online at: hexaco.org. 


\subsection{Patience}

Score for the patience facet of the HEXACO-PIR is the mean of all Likert responses with “Strongly Disagree” equal to 1 and "Strongly Agree' equal to $5^{23}$.

Patience scores were also somewhat normally distributed with a slight skew towards higher scores. Since scores for Patience are actually more indicative of a lack of aggression, this can be interpreted as a slight tendency toward lack of aggression within the sample population.

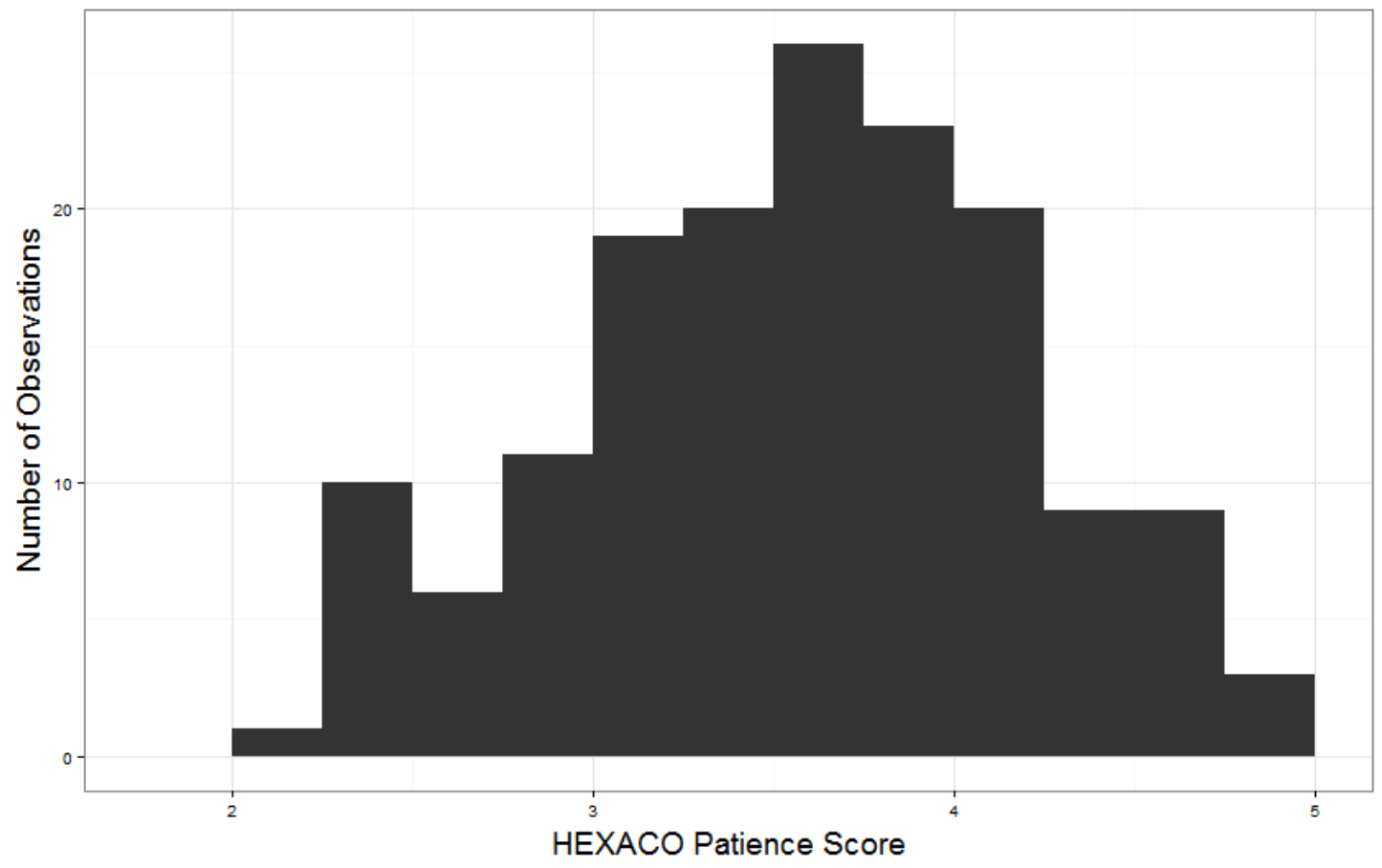

Figure 4.14 Distribution of Patience (Aggression) Scores

${ }^{23}$ Questions are too numerous to list out here but can be found online at: hexaco.org. 


\subsubsection{Exploratory Factor Analysis}

Factor analysis is a statistical tool by which the underlying structure of a dataset can be discerned via the collapse of a larger number of variables into a smaller number of latent variables, called factors. The process is useful for identifying complex relationships between variables in a dataset and resolving multicollinearity issues that would arise if these variables were used individually in the estimation of models. The concept of exploratory factor analysis (as opposed to confirmatory factor analysis) is employed when there is no a priori knowledge of the underlying factors that influence the relationships between variables and is suitable for exploring relationships between responses to questions in the survey dataset of this thesis (for an overview of factor analysis, including the distinction between explanatory and confirmatory purposes, see Rummel (1967)).

Exploratory factor analysis is used here on the Likert evaluations chosen by respondents for the set of statements that completed the sentence, "I might ride through a red light if...". Answers for the various justifications were all significantly correlated at $99.9 \%$ confidence and, therefore, could not be used simultaneously when estimating models of stated cyclist compliance (see Section 4.4.3 for discussion of these models).

There are many methods in practice for determining the correct number of factors to extract from the data. Methods traditionally used to determine this number, notably the eigenvalue value $>1$ test, Barlett's chi squared, and the scree plot, have all been shown to be problematic either because of consistent overextraction of factors (eigenvalue and scree plot), inconsistency due to sensitivity to large sample sizes (Bartlett's) or subjectivity of 
the researcher (scree plot). A more recently derived method, parallel analysis, has been deemed the new gold standard for determining the optimal number of factors (Henson \& Roberts, 2006) ${ }^{24}$. Parallel analysis ${ }^{25}$ is another function of the package 'psych' and the output of the function can be seen in Figure 4.15. The point at which the lines of simulated and resampled data cross those of the actual data can be extended down to the $\mathrm{x}$-axis to show the optimal number of factors (for factor analysis) and/or components (for principal component analysis). In this case, the optimal number of factors (1), aligns with the goal of reducing the number of variables for use in estimating regression models.

Factor analysis to extract this one factor was undertaken in the statistical program $\mathrm{R}$ using package 'psych'(Revelle, 2013). Table 4.19 presents the factor loadings on the "Ability to Justify Red Light Running" factor for each of the scenario-related answers along with their communality coefficient ${ }^{26}$. No factor loadings were ignored since all variables had factor loadings of at least 0.40 , which is generally agreed-upon as an acceptable minimum loading for a variable in personality research (Laher, 2010). Table 4.20 summarizes measures of fit for this one-factor model.

\footnotetext{
${ }^{24}$ For further reading on the problem of the number-of-factors-to-retain refer to "Choosing the optimal number of factors in exploratory factor analysis: A model selection perspective" by Preacher, Zhang, Kim, \& Mels (2013).

${ }^{25}$ An overview of parallel analysis can be found in "Determining the Number of Factors to retain in EFA: an easy-to-use computer program for carrying out Parallel Analysis" by Ledesma and Valero-Mora (2007).

26 "[A] squared variance-accounted-for statistic reflecting how much variance in measured variables is reproduced by the latent constructs (e.g., the factors) in a model. Conversely, communality can be conceptualized as how much of the variance of a measure/observed variable is useful in delineating the latent/composite variables in the model." (Lewis-Beck, Bryman, \& Liao, 2004)
} 
Factor scores, which represent the cyclist's ability to justify their red light running, were then calculated for each cyclist. These scores were later used in further analyses to determine the effect of cyclists' ability to justify red light running on their level of compliance. Since factor scores are standardized to have a mean of 0 and a standard deviation of 1 , a unit increase in the variable is equal to a unit increase in the standard deviation of the variable.

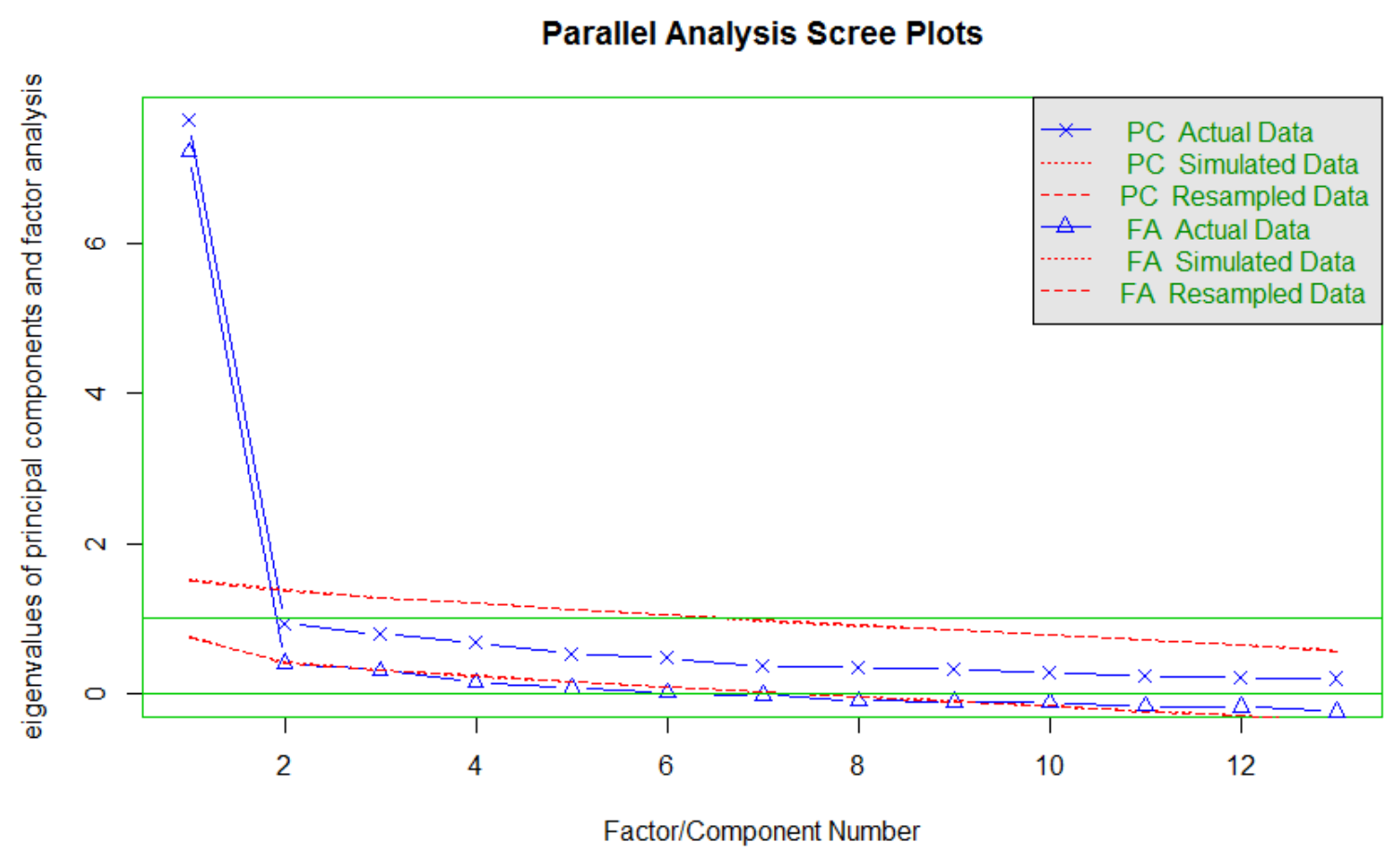

Figure 4.15 Output of Parallel Analysis 


\begin{tabular}{|c|c|c|}
\hline Scenario & $\begin{array}{r}\text { Ability to } \\
\text { Justify a } \\
\text { Red Light } \\
\text { Running }\end{array}$ & $\mathrm{h}^{2}$ \\
\hline "...there is no one around to see me do it." & 0.75 & 0.57 \\
\hline "...another bicyclist also runs the red light." & 0.80 & 0.64 \\
\hline "...I have stopped first and there is no cross traffic." & 0.82 & 0.67 \\
\hline "...I know the signal is about to turn green." & 0.72 & 0.52 \\
\hline $\begin{array}{l}\text { “...I am riding with a group of adults and one of them does." } \\
\text { "...I have been waiting a long time and do not know when I will receive a green }\end{array}$ & 0.72 & 0.52 \\
\hline light." & 0.67 & 0.45 \\
\hline "...I am running late or in a hurry." & 0.83 & 0.69 \\
\hline "...it is dark out." & 0.75 & 0.55 \\
\hline $\begin{array}{l}\text { "...I have already had to stop at lights several times already." } \\
\text { "...I am carrying a heavy back pack, pannier(s), or other load (not including }\end{array}$ & 0.83 & 0.69 \\
\hline children).” & 0.78 & 0.60 \\
\hline "...it is raining/snowing and I am cold." & 0.82 & 0.67 \\
\hline "...I am turning right." & 0.43 & 0.19 \\
\hline "...I am going uphill or downhill and don't want to lose momentum." & 0.68 & 0.47 \\
\hline
\end{tabular}

Note: $\mathrm{h}^{2}=$ the communality coefficient. The proportion of variance explained by the factor is equal to $56 \%$ (post-rotation).

Table 4.20 Fit Characteristics for 1-Factor Model

\begin{tabular}{lr}
\hline \multicolumn{2}{c}{ Measure of Fit } \\
\hline RMSEA (95\% Confidence Interval) & $0.102(0.08-00.118)$ \\
RMSR & 0.05 \\
BIC & -165.44 \\
\hline
\end{tabular}

Also important to note is the internal reliability of the scale. Internal reliability is the extent to which a set of items in a scale is able to measure actual differences in the desired trait between subjects. Although Cronbach's alpha has historically been used to measure the reliability of a scale, it has many issues. Researchers are now moving toward the use of a 
new measure of internal reliability - MacDonald's omega ${ }^{27}$. The set of 'justification' questions was determined to have high internal reliability with an estimated value of omega equal to 0.94 (and a 95\% confidence interval of 0.926-0.952).

\subsubsection{Stated Compliance}

Participants were asked to imagine themselves at the three intersections pictured in Figure 4.16 and select whether they would "Definitely Not", "Probably Not", "Maybe", "Probably", or "Definitely" run the red light at that intersection. Summaries of the proportions of these answers for each intersection are presented in Table 4.21 and Figure 4.17. Intersections appear to vary significantly in terms of their proportions of stated compliance. Indeed, a Fisher's Exact test ${ }^{28}(\mathrm{p}$-value $<0.01)$ confirms that the proportions vary significantly by intersection.

Table 4.21 Stated Non-Compliance at Survey Intersections

\begin{tabular}{rrrrrr}
\hline $\begin{array}{r}\text { Risky } \\
\text { Behavior }\end{array}$ & $\begin{array}{c}\text { Definitely } \\
\text { Not }\end{array}$ & $\begin{array}{c}\text { Probably } \\
\text { Not }\end{array}$ & \multicolumn{1}{c}{ Maybe } & Probably & Definitely \\
\hline Big & $77.1 \%$ & $19.7 \%$ & $2.5 \%$ & $0.6 \%$ & $0.0 \%$ \\
Cycletrack & $29.9 \%$ & $25.5 \%$ & $28.0 \%$ & $13.4 \%$ & $3.2 \%$ \\
& $14.0 \%$ & $14.0 \%$ & $15.9 \%$ & $27.4 \%$ & $28.7 \%$ \\
\hline
\end{tabular}

\footnotetext{
${ }^{27}$ For an overview of the problems regarding Cronbach's alpha and an overview of omega, refer to "From alpha to omega: A practical solution to the pervasive problem of internal consistency estimation" (Dunn, Baguley, \& Brunsden, 2014).

${ }^{28}$ Fisher's Exact tests were used in lieu of chi-squared tests throughout this analysis when the frequency in any cell of the contingency table being tested was less than or equal to 2.
} 


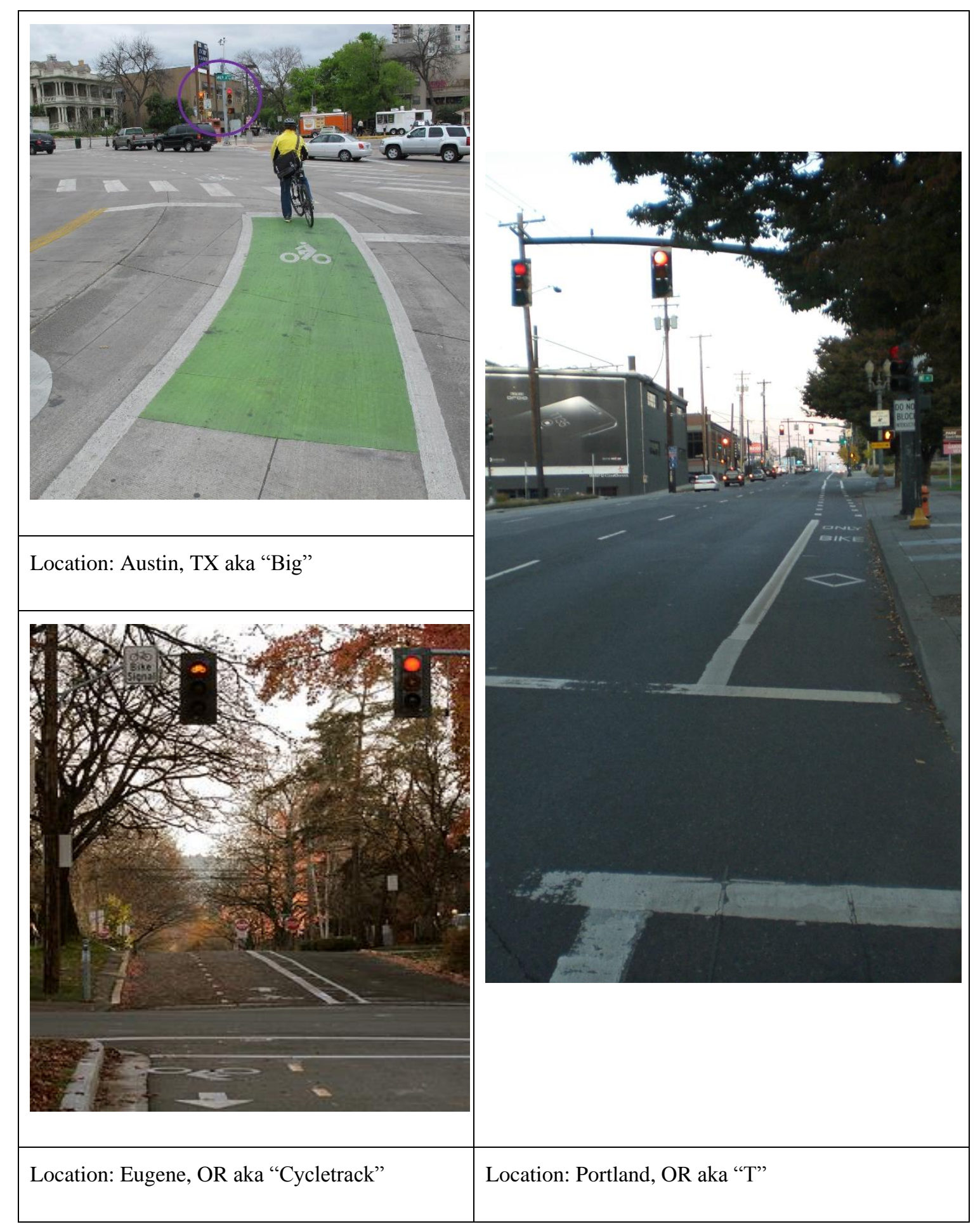

Figure 4.16 Intersection-Specific Analysis Survey Pictures 


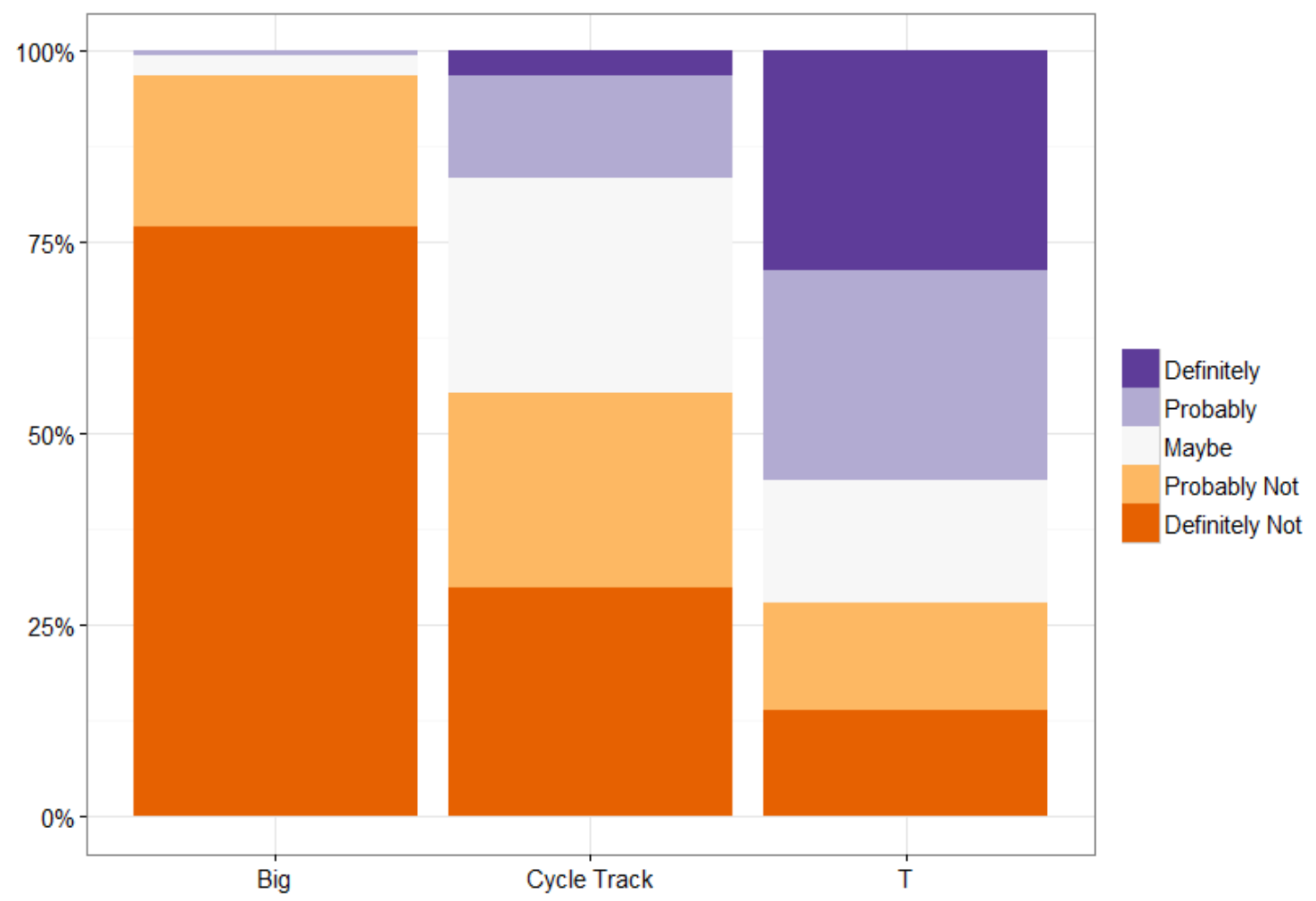

Figure 4.17 Proportion of Stated Compliance per Intersection

In order to better understand these difference, correlations between respondents' willingness to run the red light at each example intersection and their answers to relevant survey questions were analyzed. Table 4.22 presents a summary of the Pearson correlations between stated compliance ${ }^{29}$ and other survey variables for each intersection. In general, survey variables were weakly correlated with stated compliance; the exception to this was the participant's willingness to justify red light running which was derived from the Factor

\footnotetext{
${ }^{29}$ Stated compliance for each intersection was converted to a numeric format with "Definitely Not" equal to 1 and "Definitely" equal to 5 .
} 
Analysis discussed in Section 4.4.2. Interestingly, depending on the intersection, which variables were significantly correlated and the overall number of significantly correlated variables differed. The intersection from Austin had only one variable significant at the 95\% level (the ability to justify red light running) while the Eugene and Portland intersections had eight and six variables, respectively, at this significance level.

Table 4.22 Variable Correlations with Stated Compliance

\begin{tabular}{|c|c|c|c|}
\hline Variable & $\begin{array}{c}\text { Austin } \\
\mathrm{R} \text { (p-value) }\end{array}$ & $\begin{array}{c}\text { Eugene } \\
\mathrm{R} \text { (p-value) }\end{array}$ & $\begin{array}{c}\text { Portland } \\
\text { R (p-value) }\end{array}$ \\
\hline \multicolumn{4}{|l|}{ Demographics } \\
\hline Age & $-0.10(0.24)$ & $-0.18(0.03)^{*}$ & $-0.33(<0.01)^{* *}$ \\
\hline Gender $^{\mathrm{A}}$ & $-0.08(0.33)$ & $0.01(0.87)$ & $0.07(0.41)$ \\
\hline Job Flexibility & $-0.07(0.41)$ & $0.00(0.95)$ & $0.04(0.59)$ \\
\hline Household Structure $^{\mathrm{A}}$ & $0.05(0.50)$ & $-0.24(<0.01)^{* *}$ & $-0.20(0.01)^{* *}$ \\
\hline \multicolumn{4}{|l|}{ Experiences } \\
\hline $\begin{array}{l}\text { Moderate to Sever } \\
\text { Bike- } \\
\text { related Injury }\end{array}$ & $0.11(0.19)$ & $0.09(0.24)$ & $0.01(0.91)$ \\
\hline Car Use & $0.06(0.49)$ & $0.06(0.43)$ & $0.10(0.20)$ \\
\hline Citation in MV & $-0.02(0.81)$ & $-0.02(0.79)$ & $-0.09(0.31)$ \\
\hline Citation on bike & $-0.13(0.11)$ & $-0.05(0.57)$ & $0.02(0.82)$ \\
\hline \multicolumn{4}{|l|}{ Risky Driving Behaviors } \\
\hline Seatbelt use & $0.07(0.38)$ & $-0.04(0.62)$ & $-0.02(0.79)$ \\
\hline Hands free cell use & $-0.13(0.36)$ & $0.14(0.33)$ & $0.06(0.67)$ \\
\hline Cell phone use (calls) & $0.06(0.48)$ & $0.25(<0.01)^{* *}$ & $0.16(0.06)^{+}$ \\
\hline $\begin{array}{l}\text { Cell phone use } \\
\text { (texting) }\end{array}$ & $0.11(0.17)$ & $0.20(0.01)^{* *}$ & $0.13(0.13)$ \\
\hline \multicolumn{4}{|l|}{$\begin{array}{l}\text { Risky Bicycling } \\
\text { Behaviors }\end{array}$} \\
\hline Helmet use & $-0.08(0.31)$ & $-0.21(0.01)^{* *}$ & $-0.18(0.02)^{*}$ \\
\hline Headphones use & $-0.05(0.57)$ & $0.08(0.32)$ & $0.08(0.35)$ \\
\hline Cell phone use (any) & $0.14(0.07)^{+}$ & $0.21(0.01)^{* *}$ & $0.15(0.07)^{+}$ \\
\hline
\end{tabular}




\begin{tabular}{lrrr}
$\begin{array}{l}\text { Impulsive sensation } \\
\text { seeking }\end{array}$ & $-0.01(0.87)$ & $0.01(0.93)$ & $0.13(0.11)$ \\
Normlessness & $0.12(0.14)$ & $0.27(<0.01)^{* *}$ & $0.22(0.01)^{* *}$ \\
Anxiety & $-0.09(0.24)$ & $0.02(0.84)$ & $0.04(0.58)$ \\
Aggression $^{\mathrm{B}}$ & $-0.07(0.41)$ & $0.09(0.26)$ & $-0.09(0.25)$ \\
$\begin{array}{l}\text { Worried about crash w/ } \\
\text { MV }\end{array}$ & $-0.08(0.33)$ & $-0.02(0.85)$ & $0.13(0.10)^{+}$ \\
$\begin{array}{l}\text { Crash w/ MV = serious } \\
\text { injury }\end{array}$ & $0.01(0.94)$ & $0.01(0.88)$ & $0.28(<0.01)^{* *}$ \\
$\begin{array}{l}\text { Ability to justify } \\
\text { violations }\end{array}$ & $0.37(<0.01)^{* *}$ & $0.69(<0.01)^{* *}$ & $0.63(<0.01)^{* *}$ \\
\hline
\end{tabular}

A Due to the small sample size of "Genderqueer" (2) and "Single Parent" (1) responses, these observations were omitted from analysis. ${ }^{\mathrm{B}} \mathrm{A}$ positive correlation corresponds to a decrease in aggression

${ }^{+}$Marginally significant at the $90 \%$ confidence level

* Significant at the $95 \%$ confidence level

** Significant at the $99 \%$ confidence level

Respondents were also asked to "select all" factors that influenced their stated likelihood of compliance from a list of plausible choices associated with the characteristics of the intersection and their surroundings. These were as follows:

- Amount of speed of traffic to cross

- Distance to other side of intersection

- Presence of bike infrastructure (e.g. a bike lane, a bike signal, green paint, etc.)

- Complexity (or simplicity) of the intersection

- The presence of other people

- Other

When choosing the "Other" selection, respondents were prompted to expound upon their answer. Nearly half of all written-in "Other" responses $(47.5 \%)$ were related to the illegality of red light running. These accounted for $26.2 \%$ of total selections. Due to strong 
representation in the response set, and the fact that writing in another response may be a good proxy for those who feel strongly on the topic, the option was separated from the remaining "Other" answers in subsequent analysis of important determinants of stated compliance (of which the "It's Illegal" reason was 14\% overall).

Next, participants selected the one factor that was most important in their decision with regard to hypothetically running the red light for each of the three pictured intersections. For the intersection from Austin, TX, which shows backed up traffic and a complex geometry from the perspective of the cyclist, it is not surprising that factors related to those were the most frequently cited as the most important determinant of stated compliance (see Figure 4.18).

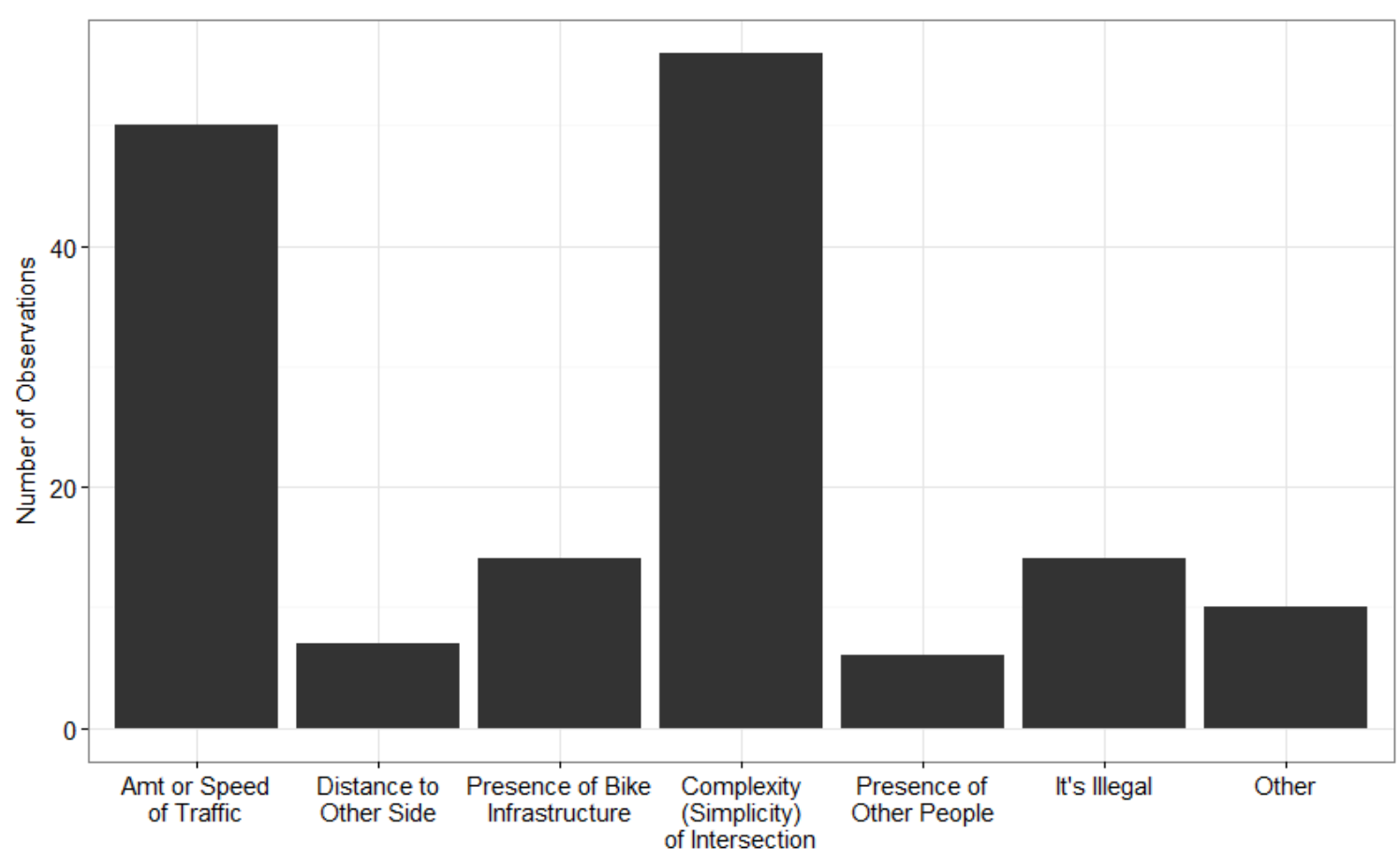

Figure 4.18 Most Influential Factor in Decision to Run Red Light (Austin) 
Give the distribution of stated compliance for this intersection, it is likely that all factors have a negative impact on the decision to run the red light.

The frequencies of the choices for most influential factor were much different for the intersection in Eugene, OR, as can be seen in Figure 4.19. Prominent determinants for this location include the amount and speed of traffic, the presence of bicycle infrastructure, and the fact that it's illegal to run a red light. Complexity of the intersection was also modestly important for this subset of the sample.

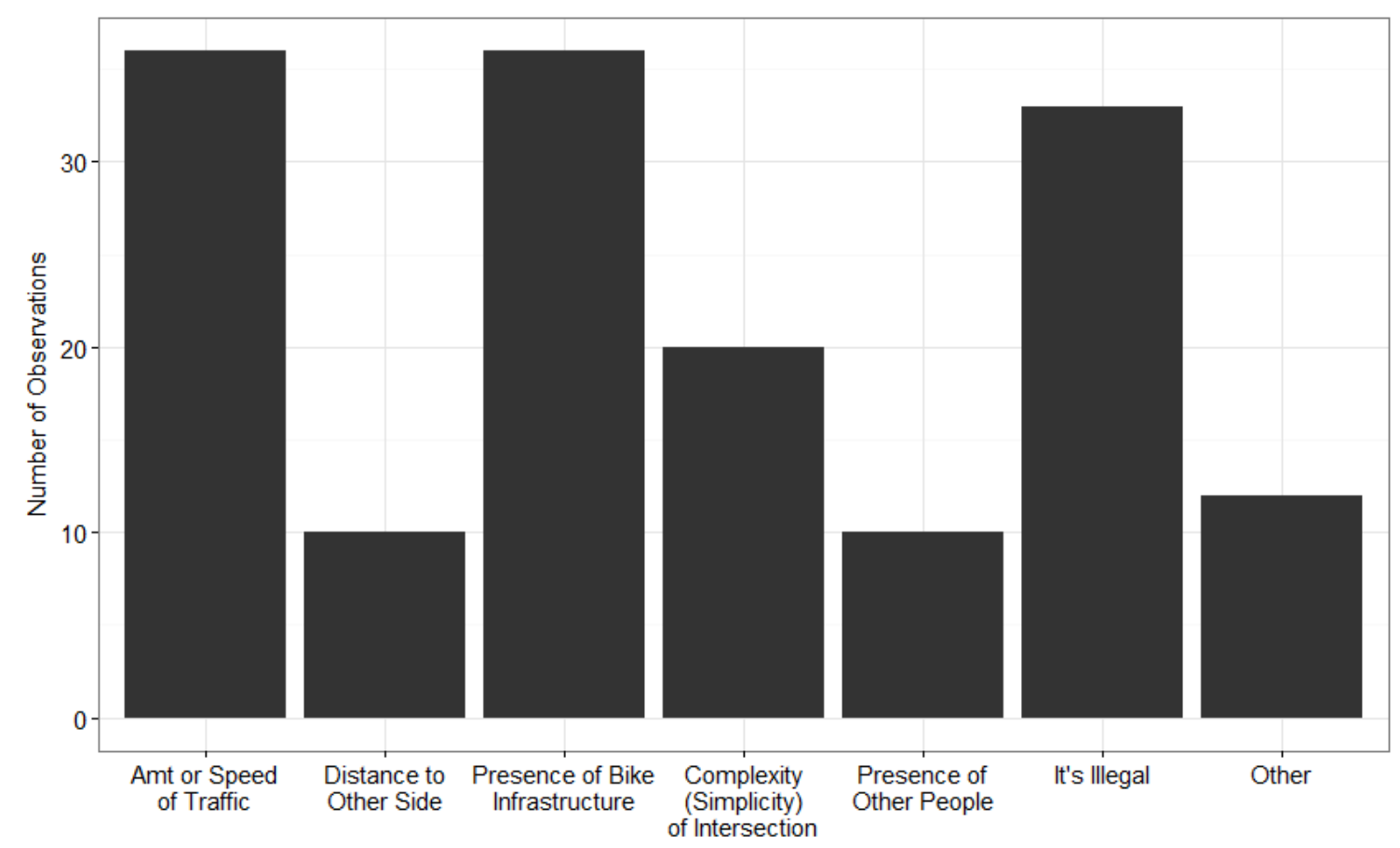

Figure 4.19 Most Influential Factor in Decision to Run Red Light (Eugene)

Figure 4.20 shows the most important factors for the intersection in Portland, OR, which appear to be the intersection complexity and other reasons. Further inspection of write-in 
entries for the 'Other' category reveals that, because of the "T" structure of the intersection (with the bike lane not creating any conflict points with a motor vehicle lane) many respondents ( $24.8 \%$ overall and $59.1 \%$ of those writing-in) question the need to stop or the validity of the red indication for bicyclists. This response was unique to this intersection with no respondent voicing a similar concern for either of the two other intersections. This response was incorporated into the plot of the most important answers below.

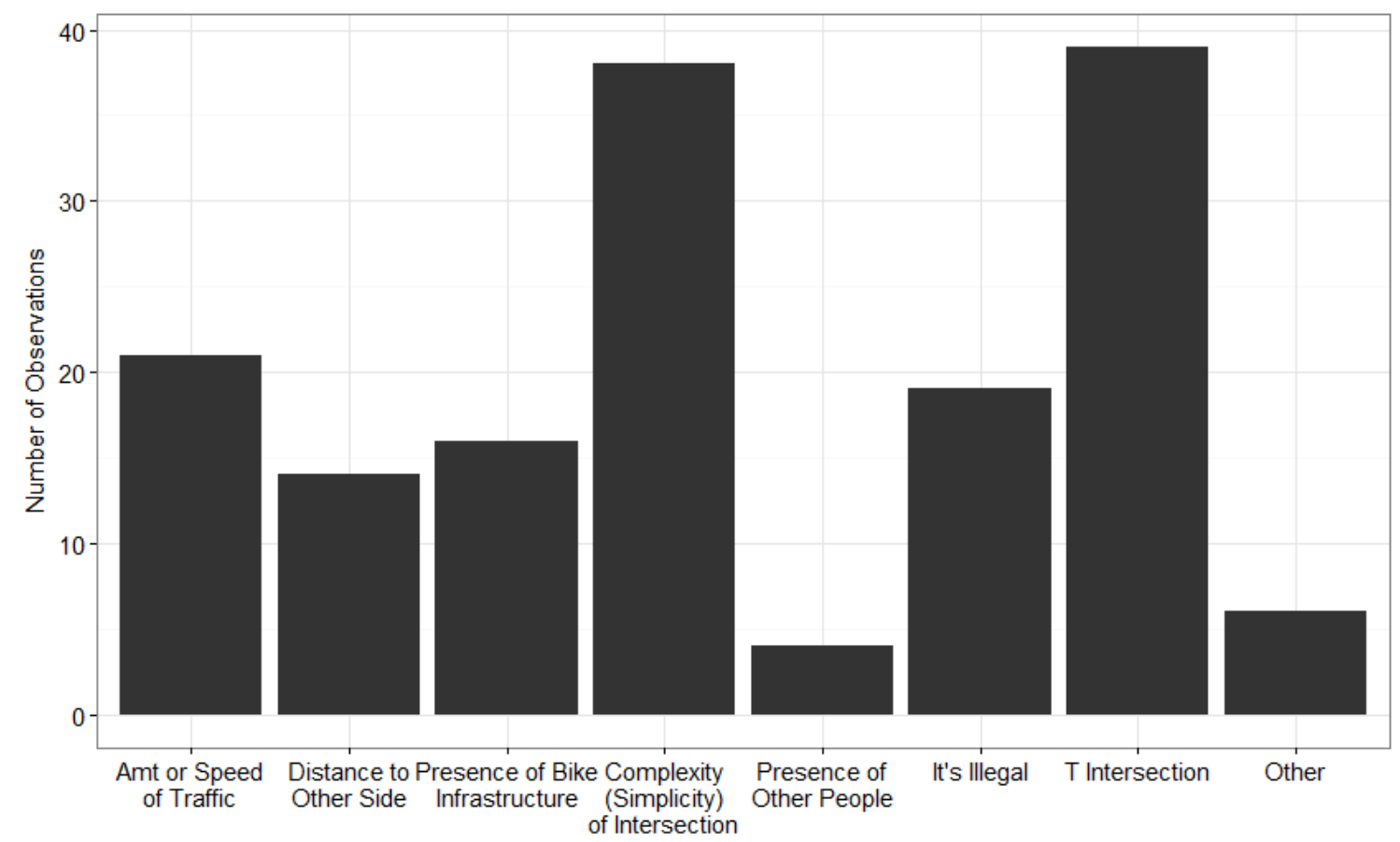

Figure 4.20 Most Influential Factor in Decision to Run Red Light (Portland)

The relationship between the bicyclist's stated compliance for each intersection and their selection of a most important factor is likely very different for each intersection given the differences in the distributions of stated compliance. A Pearson's chi-squared test of independence $\left(\chi^{2}=136.3\right.$, p-value $\left.<0.01\right)$ confirms that the proportions of reasons selected 
as "most important" differ significantly between intersections. Further significance testing was performed for the two intersections (Eugene and Portland) with more varied distributions of stated compliance. Using Fisher's exact test, it was found that, for both intersections, cyclists agreeing that they would run the red light selected significantly different factors as "most important" in their decision from those who maintained that they would not run the red light ( $\mathrm{p}$-value $<0.01$ for both intersections). For Eugene, the subset of cyclists who "Probably" or "Definitely" would run the red light chose "Complexity (simplicity) of the intersection" and "Amount or speed of cross traffic" most frequently compared to non-offenders who chose "Amount or speed of cross traffic", "Presence of bike infrastructure", and "It's illegal" in far higher proportions. For Portland, likely offenders chose "Amount or speed of cross traffic", "Complexity (simplicity) of intersection", and "T intersection" far more frequently than likely non-offenders who favored "It's Illegal" as the standout most important reason. Interestingly, the Eugene intersection picture produced a significantly higher proportion of responses equal to "It's Illegal" for the "most important factor" question than either of the other two intersections $\left(\chi^{2}=8.1, \mathrm{p}\right.$-value $=0.004$ when compared to Austin; $\chi^{2}=3.9, \mathrm{p}$-value $=0.048$ when compared to Portland).

\subsection{Discussion}

Analysis of the stated compliance of cyclists for the three intersections depicted in the survey revealed both personal and infrastructural determinants of compliance for cyclists. The stated compliance for each of the intersections was unique with respect to the others. The most complicated intersection depicted, that from Austin, TX; had the highest stated 
compliance with more than $90 \%$ of respondents stating that they "Probably Would Not" or "Definitely Would Not" run the red light. Of all the variables gleaned from the rest of the survey, the only one significantly correlated with stated compliance is the factor score representing the respondent's ability to justify running a red light. Compared with the simpler intersection depicted from Eugene and Portland, OR, it is clear that physical impediments in terms of intersection geometry and traffic play a major role in the decision to run a red light. It appears that once these impediments are removed from the scenario, other factors having to do with the individual cyclist begin to have more of an impact on red light running decisions. This is evidenced by the increase in the number of variables (8) related to stated compliance for the Eugene intersection, an obviously less complex intersection than the one from Austin. Furthermore, this interplay between intersection/scenario complexity and extent to which other factors matter in the decision to run a red light works similarly for very simple and complex intersections. The Portland intersection, with cyclists arriving on the through street of a "T" intersection, has fewer correlated variables compared to the Eugene intersection but a higher stated rate of noncompliance (56.1\% vs. $16.6 \%)$. This suggests that models such as the one presented in the section on analysis of the video data could benefit from inclusion of variables internal to the cyclist, if possible.

Similar to the differences in stated compliance between the three intersections, interesting discrepancies existed between the reasons selected as 'most important' in the decision to run the red light for each intersection. Again, for the most complex intersection, fewer and more consistent influential reasons were selected overall and as most important compared 
to the other two intersections. These differences are likely due to the same phenomenon that results in more variables correlated with the stated compliance of the Eugene intersection than that of the two others. Part of this difference can be seen by the increase in frequencies for the reason "It's Illegal" for the Eugene and Portland intersections, which were nearly two and three times the amount, respectively, of the Austin intersection.

The emergence of the "It's Illegal" reason for compliance at the stated compliance intersections also highlights a potentially important part of cycling culture: in-group policing. Many of the reasons distilled down to "It's Illegal" actually inferred that these cyclists who feel that legality is very important are a subset of policing or judging cyclists. A few example statements from these cyclists are:

- "Sharing the road means following the rules."

- "Not being a jerk."

- "I typically think cyclists who run red lights are $\mathrm{a}^{* *}$ holes and give the rest of us a bad name."

Interestingly, although judgment from fellow cyclists is apparent, the "Presence of other people" reason was one of the least selected reasons for respondents' stated noncompliance. It is possible that those who would be most influenced by other cyclists' judgment are those that already stop at most red lights and have become part of the judging class, thus, the presence of other people has little bearing on their decisions. Conversely, those who are unaffected by other cyclists' judgment do not find that reason to be important due to their disregard of judgment. 


\subsection{Summary}

The survey of cyclists had a sample population of 157 bicycle riders. The sample was split along traditional gender lines and crash experiences. The median age of the sample was nearly identical to that of Multnomah County as a whole. However, the survey population is biased in a number of other respects including ${ }^{30}$ :

\section{- Household structure}

Nearly three-quarters of the sample are partnered, 1/3 of which have at least one child in the household. Compare this to the $61.7 \%$ of people living in Multnomah County who share their households with a partner and the $24.2 \%$ of households that have children and we have a sample population that is more partnered than the average with a similar proportion of households with children.

- Flexible work schedule

Over three-quarters of survey respondents reported having at least a somewhat flexible start time to their work day. This is indicative of non-shift workers or people who are not on a timeline while at work (e.g. transporting goods or people). An estimated $49.5 \%$ of people in Multnomah County have a job where flexible work schedules are possible meaning that the sample population for the survey has more flexibility in their schedules than the average person in Multnomah County.

\footnotetext{
${ }^{30}$ Comparisons based off of data from the 2010 United States Census for Multnomah County, OR.
} 
- Commuter status

This characteristic was not compared to Census data but because of the intercept-style sampling methods, there is an obvious bias towards folks with traditional 9-5 work schedules that work in downtown Portland, OR.

Personality-wise, survey participants' scores for anxiety and patience (aggression) were fairly evenly distributed while scores for impulsive sensation-seeking and normless skewed toward lower values (i.e. the sample had low tendencies toward those personality traits). This means that the population exhibits even amounts of the anxiety and aggression personality traits and lower amounts of the most-researched "risky" personality traits. Respondents were also generally somewhat worried about getting into a crash with a motor vehicle and most believed they would be seriously injured if they were to do so.

Risky behaviors associated with driving were more frequently reported than cyclingrelated risk behaviors. Overall, the number of citations received by the survey population in the last three years was low with more people receiving driving citations than biking citations. Only one survey participant had received both.

In order to utilize some of the survey responses in future regression models, responses to one set of questions were collapsed into one overarching factor. This factor was then scored for each individual cyclist with scores representing a cyclist's willingness to justify their decision to run a red light. The set of questions used to produce this factor proved to be quite reliable in determining this cyclist characteristic. 
Stated compliance varied between the three intersections depicted in the survey. The most complex intersection depicted, with non-standard geometry, visible heavy traffic, and long crossing distance, had the highest stated compliance. Furthermore, fewer respondents cited the fact that red light running is illegal as a reason they would not run the red. The most important reasons related to compliance at this intersection had to do with cross traffic and intersection geometry. Conversely, the two less-complex intersections had more even distributions of stated compliance. These intersections also had more even distributions of the reasons for the respondent's stated level of compliance which more frequently included that the maneuver is illegal. Responses for the simplest intersection of the three, a "T" intersection with cyclists on the through street, introduced a new reason for lack of compliance. This new response questioned the validity of the signal for cyclists since, as long as there were no pedestrians, cyclists had no conflicting movements at the intersection. For this intersection, the validity of the signal was the most frequently-cited most important reason for infringement.

In general, the only variable that was consistently significantly correlated with compliance at each intersection was the score of a cyclist's ability to justify red light running. This score was the only significant determinant of compliance at the most complicated intersection. This variable and others, including age, sex, household structure, cell phone use (while operating a car or bike), helmet use, and normlessness score, were significantly correlated with compliance at the other two intersections. 
It is clear from the analysis that, while intersection characteristics have bearing on cyclists' compliance decisions, in instances where there are few concerning intersection-specific traits, cyclists' individual characteristics play a larger role in determining compliance. This includes personality factors and the ability of the cyclist to justify red light running in a variety of situations. 


\subsection{CONCLUSIONS}

This project examined cyclist red light running behavior using two data sets. Previous studies of cyclist compliance have investigated the tendencies of cyclists to run red lights on the whole by generalizing different maneuvers to their end outcome, running a red light. This project differentiates between the different types of red light running and focuses on the most egregious case: gap acceptance.

Using video data, a mathematical model of cyclist red light running was developed for cyclists accepting a gap in traffic. Similar to other studies, this analysis utilized only information about the cyclist, intersection, and scenario that can be outwardly observed.

This analysis found that the number of cyclists already waiting at the signal, the presence of a vehicle in the adjacent lane, and female sex were deterrents to red light running. Conversely, certain types of signal phasing, witnessing a violation, and lack of helmet increased the odds that a cyclist would run the red light. Interestingly, while women in general are less likely to run a red light, those who witnessed a violation were even more prone that men who had witnessed a violation to follow suit and run the red light themselves. It is likely that the differing socialization of women and men leads to being differently influenced by social interactions and group think which could lead to increased ability of women to justify their red light running if someone else has done it in front of them. 
The analysis also confirmed that a small subset of cyclists, similar to that found in the general population, are more prone to traffic violations. These cyclists are more willing to engage in multiple biking-related risk factors that include not wearing a helmet and running red lights.

Although the model has definite explanatory power regarding decisions of cyclist compliance, much of the variance in the compliance choices of the sample is left unexplained. This points toward the influence of other, not outwardly observable variables on the decision to run a red light.

Analysis of survey data from cyclists further confirms that individual characteristics not visible to the observer interact with intersection, scenario, and visible cyclist characteristics to result in a decision to comply (or not) with a traffic signal. Furthermore, cyclist characteristics, in general, and unobservable individual characteristics, specifically, play a larger role in compliance decisions as the number of compliance-inducing intersection traits (e.g. conflicting traffic volume) decrease. One such unobservable trait is the regard for the law by some cyclists, which becomes a more important determinant of compliance at simpler intersections. Cyclists were also shown to choose non-compliance if they questioned the validity of the red indication for them, as cyclists.

The video and survey data have some comparable findings. For instance, the relationship of age to compliance was explored in both data analyses. Age was not found to be a significant predictor of non-compliance in the video data analysis while it was negatively correlated with stated non-compliance for two of the survey intersections. This discrepancy 
is due to the lack of fine grain age data in the video dataset which led to the removal of that variable due to homogeneity for the entire dataset. Unfortunately, there is not currently a feasible method for obtaining someone's age via video footage so a survey instrument is the best tool for exploring compliance with respect to age.

Gender, while having significant effects on non-compliance in the video dataset, did not emerge as an important factor in the stated non-compliance of survey takers. The reason for this difference in findings is unknown but it could possibly be because of underlying differences in socialization for men and women that have an effect on stated noncompliance via other variables such as personality traits or helmet use (which would be indicative of a willingness to follow social norms).

Helmet use had a consistent relationship with compliance between the video and survey datasets. Helmet use was positively associated with compliance in the video data and negatively associated with revealed non-compliance at two of the survey intersections. When coupled with the positive association between normlessness and stated willingness to run a red light, the relationship between helmet use and compliance solidifies the notion that a class of cyclists is more likely to consistently violate signals. However, in contrast to what was initially proposed after analysis of the survey data, lack of helmet is not indicative of decreased risk-aversion. Instead, it points towards a link between red light running and individuals who do not adhere to social norms and policies as strictly as others.

Variables representing cyclists and motorists waiting at the signal were positively related to signal compliance in the video data. While an increased number of cyclists may be a 
physical deterrent to red light running, part of the influence on compliance that this variable and the variable representing the presence of a vehicle may be due to accountability of cyclists to other road users. This sentiment was echoed in the justifications section of the survey data. A large percentage (45.2\%) agreed or strongly agreed that they might run the red light if "no one [was] around to see [them] do it." In the stated non-compliance from the survey, however, the presence of other people was rarely the most important reason for choosing to hypothetically not run the red light. Considering the relative importance of these variables in the video data, one would expect that the presence of other people would be indicated as more important than what the results of the survey show. This discrepancy may be due to conflating factors in either dataset so that the true importance of accountability with respect to compliance is not visible.

Witnessing another cyclist violate the signal was a significant indicator of compliance in the video dataset. However, survey respondents rarely agreed (only $12.1 \%$ ) that this was a reason that they might run a red light. This may be an area where the ability of a stated preference survey to model behaviors fails since people may not want admit (either conscientiously or unconscientiously) how much other people's actions influence them. Alternatively, people may also be unaware of how much social interactions affect them and their subsequent actions. 


\subsection{Implications for policy and design}

Intuitively, different methods of ensuring bicyclist compliance are warranted for different intersections. While enforcement might be better approach at intersections where geometry does not naturally deter red light running, there are probably diminishing returns on the resources put into enforcement of cyclist signal compliance since the vast majority of cyclists in the video dataset ( $90 \%)$ complied with the signal. An alternative solution is to consider the applicability of traffic laws (originally designed for cars) to bicyclists. Creating separation in how laws affect motorists and cyclists might be a better solution for overly simple types of intersections where cyclists have fewer conflicts, better visibility, etc. than motorists.

In lieu of enforcement, physical impedance and changing traffic laws, education or other messaging aimed at cyclists about compliance may be warranted. Since cyclists appear to feel more justified in running red lights at low-volume, simple-looking intersections, it would probably be prudent to target messaging at these types of intersections. What this messaging should consist of is a bit trickier. Many cyclists are deterred by high-volume and/or complicated looking intersections for safety reasons. Reminding cyclists of the potential dangers at other intersections may be a successful messaging strategy. Alternatively, reminding cyclists that it is still illegal to run a red light even if they feel safe doing so may be a good message at very simple intersections. Additionally, messaging about the purpose of infrastructure such as bicycle-specific signals or lights that indicate detection at a signal may convince cyclists that stopping at the signal is in their best interest and that the wait will be minimal and/or warranted. 


\subsection{Limitations \& Future Work}

The study has several limitations for analysis of both the video and survey data. Most of these have to do with bias in the data due to site selection and sampling decisions. For video data, observations were limited to the daytime on days with tolerable weather. Considering the significant impact of these justifications on a cyclist's ability to justify red light running, empirical data to corroborate their effects is missing. Similar to the vehicle waiting and cyclist waiting variables, the addition of a variable indicating pedestrian presence would be interesting to explore. A comparison of the effect of eyes on the road from different modes could then be analyzed to see if cyclists are more or less deterred by the presence of different mode users. The value of conflicting traffic for each cyclist in the video data could be improved as well. Even though cyclists were observed at times with a wide variety cross traffic volumes, the averaged volumes are not necessarily indicative of the traffic in which the cyclist was riding. This does not allow researchers to view "opportunistic" gap accepters which may account for most of the gap accepters in the dataset.

Similar issues exist for the survey data. Respondents were predominately recruited at intercept locations with heavy commuter traffic going to and from downtown Portland. This is likely the reason for the bias in the sample toward folks with more flexible job schedules and negates the researcher's ability to robustly explore the cycling behavior of people with more stringent work tardy policies. And, although commuters comprise an important subset of all cyclists, the heavy commuter bias does not allow for the exploration of the compliance decisions of other types of cyclists (or of similar cyclists in different 
cycling scenarios such as exercising or on a leisurely ride). Also, intuitively, commuters are fairly confident in their cycling skills. So, the survey missed the opportunity to compare and contrast the compliance behaviors of cyclists with differing skill and comfort levels. Observationally, the survey response sample is overwhelmingly white with nice cycling gear. These folks are presumably "choice" cyclists that may exhibit different compliance behavior that those with fewer transportation choices. With the exclusion of more traditional socioeconomic questions that could confirm this bias, it is in itself another limitation. Lastly, socioeconomic bias could exist due to the survey format. The survey was administered online only, limiting responses only to those with regular internet access. Additionally, a QR code was added to the survey postcards to give people the option to take the survey on a smart phone. As QR codes and their use are a fairly new phenomenon, some potential respondents may have not have known that the survey could also be taken at a computer or could have been confused or technologically intimidated by the QR code and not become part of the sample.

The last notable limitation of the survey portion of this study has to do with the stated noncompliance questions. These questions are similar to stated preference survey questions in that they ask a respondent to respond to a hypothetical situation. While stated preference models have been shown to predict future behaviors with similar accuracy as revealed preference models (see Louviere \& Timmermans, 1990 for a review), a cyclist's stated level of non-compliance based on a picture while not riding their bicycle may very well be different than their choice when actually on the road. To the author's knowledge, no studies have examined the relationship between revealed and stated cyclist behavior. Knowledge 
of this relationship would be an important addition to future studies utilizing the stated preferences of cyclists in general, especially when studying choices that may make cyclists further vulnerable to injury, such as red light running.

The space for future work on the topic of cyclist compliance is vast. Studies in which the biases of this study are mediated are necessary. Also, due to the relationships between internal cyclist characteristics and external variables of the intersections, scenario, and cyclist, a study that incorporates all types of variables would be able to model cyclist compliance decisions more successfully than any existing studies, including this one. 


\subsection{REFERENCES}

American Automobile Association (AAA). (2013). Your Driving Costs. American Automobile Association (AAA). Retrieved from http://newsroom.aaa.com/wpcontent/uploads/2013/04/YourDrivingCosts2013.pdf

Bacchieri, G., Barros, A. J. D., dos Santos, J. V., \& Gigante, D. P. (2010). Cycling to work in Brazil: Users profile, risk behaviors, and traffic accident occurrence. Accident Analysis \& Prevention, 42(4), 1025-1030. doi:http://dx.doi.org/10.1016/j.aap.2009.12.009

Bai, L., Liu, P., Chen, Y., Zhang, X., \& Wang, W. (2013). Comparative analysis of the safety effects of electric bikes a signalized intersections. Transportation Research Part D: Transport and Environment, 20, 48-54.

Basford, L., Reid, S., Lester, T., Thomson, J., \& Tolmie, A. (2002). Drivers 'perceptions of cyclists (No. TRL549). Department for Transport of the United Kingdom.

Bina, M., Graziano, F., \& Bonino, S. (2006). Risky Driving and Lifestyles in Adolescence. Accident Analysis and Prevention, 38(3), 472-481.

Bitzios Consulting. (2008). Sydney CBD cycleways traffic signals optimisation (No. P0817). Roads and Maritime Services NSW.

Cacioppo, J. T., Petty, R. E., Kao, C. F., \& Rodriguez, R. (1986). Central and Peripheral Routes to Persuasion: An Individual Difference Perspective. Journal of Personality and Social Psychology, 51(5), 1032-1043. 
Caspi, A., Begg, D., Dickson, N., Harrington, H., Langley, J., Moffitt, T. E., \& Silva, P. A. (1997). Personality Differences Predict health-Risk Behaviors in young Adulthood: Evidence From a Longitudinal Study. Journal of Personality and Social Psychology, 73(5), $1052-1063$.

Cooper, J., Schneider, R., Ryan, S., \& Co, S. (2012). Documenting Targeted Behavior Associated with Pedestrian Safety. SafeTrec Safe Transportation Research \& Education Center.

Denver, CO. (2009). Bicycle Traffic Signal Behavior Study. City and County of Denver, $\mathrm{CO}$.

Dill, J., \& Carr, T. (2003). Bicycle Commuting and Facilities in Major U.S. Cities: If You Build Them, Commuters Will Use Them. Transportation Research Record, 1828, 116123.

Dill, J., Monsere, C., \& McNeil, N. (2011, January). Evaluation of Bike Boxes at Signalized Intersections. Retrieved August 10, 2011, from http://trid.trb.org/view.aspx?type=MO\&id=1098717

Donovan, D. M., Marlatt, G. A., \& Salzberg, P. M. (1983). Drinking Behavior, Personality Factors and High-Risk Driving: A Review and Theoretical Formulation. Journal of Studies on Alcohol, 44(3), 395-428. 
Donovan, J. E. (1993). Young Adult Drinking-Driving: Behavioral and Psychosocial Correlates. Journal of Studies on Alcohol and Drugs, 54(5), 600-613.

Dunn, T. J., Baguley, T., \& Brunsden, V. (2014). From alpha to omega: A practical solution to the pervasive problem of internal consistency estimation. British Jouranl of Psychology, 105, 399-412. doi:10.1111/bjop.12046

Dutzik, T., \& Baxandall, P. (2013). A New Direction: Our Changing Relationship with Driving and the Implications for America's Future (pp. 1-64). U.S. PIRG Education Fund \& Frontier Group.

Eagly, A. H., \& Chaiken, S. (1993). The Psychology of Attitudes. Fort Worth, TX: Harcourt Brace Jovanovich College Publishers.

Elander, J., West, R., \& French, D. (1993). Behavioral Correlates of Individual Differences in Road-Traffic Crash Risk: An Examination of Methods and Findings. Psychological Bulletin, 113(2), 279-294.

Elvik, R., \& Mysen, A. B. (1999). Incomplete accident reporting: meta-analysis of studies made in 13 countries. Transportation Research Record, 1665, 133-140.

Everett, S. A., Lowry, R., Cohen, L. R., \& Dellinger, A. M. (1999). Unsafe motor vehicle practices amoung substance-using college students. Accident Analysis and Prevention, 31(6), 667-673. 
Federal Highway Administration. (2009). Manual on Uniform Traffic Control Devices. Washington D.C.: Federal highway Administration.

Fietsberaad. (2003). The Bicycle friendliness of traffic control systems. Amsterdam: Fietsberaad. Retrieved from http://www.fietsberaad.nl/library/repository/bestanden/The\%20bicycle\%20friendliness\% 20of\%20traffic $\% 20$ control\%20installations.doc

Fincham, B. (2006). Bicycle messengers and the road to freedom. In Against Automobility (pp. 208-222). Blackwell Publishing/Sociological Review.

Gatersleben, B., \& Haddad, H. (2010). Who is the Typical Bicyclist? Transportation Research Part F: Traffic Psychology and Behaviour, 13(1), 41-48.

Geller, R. (2009). Four Types of Cyclists. Portland, OR: Portland Bureau of Transportation. Retrieved from http://www.portlandonline.com/transportation/index.cfm?c=44597\&a=158497.

Goodyear, S. (2013, May 13). Cyclists Aren't “Special,” and They Shouldn't Play by Their Own Rules. Retrieved from http://www.theatlanticcities.com/commute/2013/05/bikersdont-deserve-any-special-treatment/5565/

Grabar, H. (2013, May 14). Why We Should Never Fine Cyclists. Retrieved from http://www.theatlanticcities.com/commute/2013/05/why-we-should-never-finecyclists/5571/ 
Green, F. K. (2003). Red light running (No. ARR 356) (p. 60). Vermont South, Victoria, Australia: ARRB Transport Research Ltd.

Gregersen, N. P., \& Bjurulf, P. (1996). Young Novice Drivers: Towards a Model of Their Accident Involvement. Accident Analysis and Prevention, 28(2), 229-241.

Henson, R. K., \& Roberts, J. K. (2006). Use of exploratory factor analysis in published research: Common errors and some comment on improved practice. Educational and Psychological Measurement, 66(3). doi:10.1177/0013164405282485

Hunter, W. W., Stutts, J. C., Pein, W. E., \& Cox, C. L. (1996). Pedestrian and bicycle crash types of the early 1990's (No. FHWA-RD-95-163). Chapel Hill, NC: Highway Safety Research Center, University of North Carolina.

Imbert, C., \& te Brommelstroet, M. (2014). The desire lines of biycle users in Amsterdam (p. 27). Amseterdam municipality (DIVV Department). Retrieved from http://www.copenhagenize.eu/dox/Copenhagenize_Desire_Lines_Amsterdam.pdf

Johnson, M., Charlton, J., Newstead, S., \& Oxley, J. (2010). Painting a designated space: Cyclist and driver compliance at cycling infrastructure at inersections. Journal of Australasian College of Road Safety, 21(3), 67-72.

Johnson, M., Charlton, J., Oxley, J., \& Newstead, S. (2013). Why do cyclists infringe at red lights? An investigation of Australian cyclists' reasons for red light infringement. Accident Analysis \& Prevention, 50, 840-847. 
Johnson, M., Newstead, S., Charlton, J., \& Oxley, J. (2011). Riding through red lights: The rate, characteristics and risk factors of non-compliant urban commuter cyclists. Accident Analysis and Prevention, 43, 323-328.

Jonah, B. (1997). Sensation seeking and risky driving: A review and synthesis of the literature. Accident Analysis and Prevention, 29(5), 651-665.

Jones, P. M. (1990). Public Attitudes Toward Traffic Regulation, Compliance, and Enforcement in Urban Areas of the United Kingdom. Transportation Research Record: Journal of the Transportation Research Board, (1270), 66-72.

Kohn, M. L., \& Schooler, C. (1983). Work and personality: An inquiry into the impact of social stratification. Norwood, NJ: Ablex.

Laher, S. (2010). Using exploratory factor analysis in personality research: Best-practice recommendations. SA Journal of Industrial Psychology, 36(1), 7. doi:10.4102/sajip.v36i1.873

Latane, B., \& Nida, S. (1981). Ten years of research on group size and helping. Psychological Bulletin, 89(2), 308-324.

Lawson, S. D. (1991). Red-light Running: Accidents and surveillance cameras. Birmingham, United Kingdom: Foundation for Road safety Research and Birmingham City Council. 
LeBlanc, J. C., Beattie, T. L., \& Culligan, C. (2002). Effect of legislation on the use of bicycle helmets. Canadian Medical Association Journal, 166(5), 592-595.

Ledesma, R. D., \& Valero-Mora, P. (2007). Determining the number of factors to retain in EFA: An easy-to-use computre program for carrying out parallel analysis. Practical Assessment, Research \& Evaluation, 12(2), 1-11.

Lee, B. H.-Y., Schofer, J. L., \& Koppelman, F. S. (2005). Bicycle safety helmet legislation and bicycle-related non-fatal injuries in California. Accident Analysis and Prevention, 37, 93-102.

Lee, K., \& Ashton, M. C. (2004). Psychometric properties of the HEXACO personality inventory. Multivariate Behavioral Research, 39, 329-358.

Lewis-Beck, M. S., Bryman, A., \& Liao, T. F. (Eds.). (2004). Communality. In The SAGE Encyclopedia of Social Science Research Methods (pp. 148-149). Thousand Oaks, CA: Sage Publications, Inc. Retrieved from doi: http://dx.doi.org/10.4135/9781412950589.n139

Loew, T., \& Perez, E. S. (2012, December 2). Bicycle traffic signals get a green light. Retrieved from http://www.usatoday.com/story/news/nation/2012/12/02/bicycle-trafficsignals/1739299/

Louviere, J., \& Timmermans, H. (1990). Stated preference and choice models applied to recreation research: A review. Leisure Sciences, 12, 9-32. 
Macpherson, A., \& Spinks, A. (2008). Bicycle helmet legislation for the uptake of helmet use and prevention of head injuries. Cochrane Database of Systematic Reviews, (3), Art. No.: CD005401. doi:10.1002/14651858.CD005401.pub3\#sthash.VQ3gVwe4.dpuf

McGue, M., Bacon, S., \& Lykken, D. T. (1993). Personality Stability and Change in Early Adulthood: A Behavioral Genetic Analysis. Developmental Psychology, 29(1), 96-109.

Monsere, C., Figliozzi, M. A., Thompson, S., \& Paulsen, K. (2013). Operational Guidance for Bicycle-Specific Traffic Signals in the United States (No. Final Report). Oregon Department of Transportation, Federal Highway Administration.

O’Connor, J. P., \& Brown, T. D. (2007). Real cyclists don’t race: Informal affiliations of the weekend warrior. International Review for the Sociology of Sport, 42, 83-97. doi:10.1177/1012690207081831

Parker, D., \& Manstead, A. S. R. (1996). The Social Psychology of Driver Behaviour. In Applied Social Psychology (pp. 198-224). Retrieved from http://books.google.com/books?hl=en\&lr=\&id=jxr4WtStIxsC\&oi=fnd\&pg=PA198\&dq= parker+manstead+social+psychology\&ots=7VTK547oHF\&sig=QYvRK1N17iBIw90oXF $34 \mathrm{XysE}-\mathrm{OU} \# \mathrm{v}=$ onepage $\& \mathrm{q}=$ parker $\% 20$ manstead $\% 20$ social $\% 20$ psychology $\& \mathrm{f}=$ false

Parks, J., Monsere, C., McNeil, N., \& Dill, J. (2012). District Department of Transportation Bicycle Facility Evaluation (No. 11404). Washington, D.C. 
Preacher, K. J., Zhang, G., Kim, C., \& Mels, G. (2013). Choosing the optimal number of factors in exploratory factor analysis: A model selection perspective. Multivariate Behavioral Research, 48, 28-56. doi:10.1080/00273171.2012.710386

Pucher, J., Dill, J., \& Handy, S. (2010). Infrastructure, programs, and policies to increase bicycling: An International Review. Preventive Medicine, (50), S106-S125.

Pucher, J., Komanoff, C., \& Schimek, P. (1999). Bicycling renaissance in North America? Recent trends and alternative policies to promote bicycling. Transportation Research Part A, 33(7/8), 625-654.

Rabl, A., \& de Nazelle, A. (2012). Benefits of Shift from Car to Active Transport. Transport Policy, 19, 121-131.

R Core Team. (2014). R: A language and environment for statistical computing. Vienna, Austria: R Foundation of Statistical Computing. Retrieved from http://www.R-project.org/

Retting, R. A., \& Williams, A. F. (1996). Characteristics of Red Light Violators: Results of a Field Investigation. Journal of Safety Research, 27(1), 9-15.

Revelle, W. (2013). psych: Procedures for Psychological, Psychometric, and Personality Research. Evanston, Illinois: Northwestern University. Retrieved from http://CRAN.Rproject.org/package=psych 
Rimmö, P.-A., \& Åberg, L. (1999). On the Distinction Between Violations and Errors: Sensation Seeking Associations. Transportation Research Part F: Traffic Psychology and Behaviour, 2(3), 151-166.

Rissel, C., Campbell, F., Ashley, B., \& Jackson, L. (2002). Driver Road Rule Knowledge and Attitudes Towards Cyclists. Australian Journal of Primary Health, 8(2), 66-69.

Roberts, B. W., Caspi, A., \& Moffitt, T. E. (2001). The Kids Are Alright: Growth and Stability in Personality Development From Adolescence to Adulthood. Journal of Personality and Social Psychology, 81(4), 670-683.

Robinson, D. L. (1996). Head injuries and bicycle helmet laws. Accident Analysis \& Prevention, 28(4), 463-475.

Rummel, R. J. (1967). Understanding Factor Analysis. The Journal of Conflict Resolution, $11(4), 444-480$.

Schramm, A. J., Rakotonirainy, A., \& Haworth, N. L. (2008). How much does disregard of road rules contribute to bicycle-vehicle collisions? In Proceedings High risk road users - motivating behavior change: What works and what doesn't work?. Brisbane, Australia.

Schramm, A. J., Rakotonirainy, A., \& Haworth, N. L. (2010). The Role of Traffic Violations in Police-Reported Bicycle Crashes in Queensland. Journal of the Australasian College of Road Safety, 21(3), 61-67. 
Simpson, C. (2009). Cars, Climates and Subjectivity: Car Sharing and Resisting Hegemonic Automobile Culture? M/C Journal: A Journal of Media and Culture, 12(4). Retrieved from http://journal.mediaculture.org.au/index.php/mcjournal/article/viewArticle/176

Sümer, N. (2003). Personality and behavioral predictors of traffic accidents: testing a contextual mediated model. Accident Analysis and Prevention, 35(6), 949-964.

Thompson, S. R., Monsere, C., Figliozzi, M. A., Koonce, P., \& Obery, G. (2013). BicycleSpecific Traffic Signals: Results from a State-of-the-Practice Review. Transportation Research Record: Journal of the Transportation Research Board.

Ulleberg, P., \& Rundmo, T. (2002). Risk-taking attitudes among young drivers: The psychometric qualities and dimensionality of an instrument to measure young drivers' risktaking attitudes. Scandinavian Journal of Psychology, 43, 227-237.

Watson, L., \& Cameron, M. (2006). Bicycle and motor vehicle crash characteristics (Research Report No. 251). Melbourne, Australia: Monash Universtiy Accident Research Centre.

West, R., \& Hall, J. (1997). The role of personality and attitudes in traffic accident risk. Applied Psychology: An International Review, 46(3), 253-264. 
Wu, C., Yao, L., \& Zhang, K. (2011). The red-light running behavior of electric bike riders and cyclists at urban intersections in China: An observational study. Accident Analysis and Prevention, (2497). doi:10.1016/j.aap.2011.06.001

Yagil, D. (1998). Instrumental and Normative Motives for Compliance with Traffic Laws Among Young and Older Drivers. Accident Analysis and Prevention, 30(4), 417-424.

Yao, L., \& Wu, C. (2012). Traffic Safety of E-Bike Riders in China: Safety Attitudes, Risk Perception, and Aberrant Riding Behaviors. Transportation Research Record: Journal of the Transportation Research Board, 2314, 49-56.

Zhang, Y., \& Wu, C. (2013). The effects of sunshields on red light running behavior of cyclists and electric bike riders. Accident Analysis and Prevention, 52, 210-218.

Zuckerman, M. (2002). Zuckerman-Kuhlman Personality Questionnaire (ZKPQ): An alternative five-factorial model. In Big five assessment (pp. 377-396). 


\section{APPENDIX A. Survey Instrument}

Note: this survey was administered online.

Thank you for agreeing to participate! Your responses will help a Master's student inch ever closer to a completed thesis. The purpose of this research is to learn more about the various factors that affect whether or not bicyclists will wait for a green light before going through an intersection. Please know that your participation in this survey is voluntary. We are not collecting or recording any personal information that can identify you. We will ask you a few questions about your cycling behavior, your attitudes about compliance in certain scenarios, your attitudes about risk, and some brief demographics. Please be honest! Again, no information will be tied to you. The survey should take approximately 10-15 minutes to complete. You may choose to stop participating in the survey at any time with no consequences. If you have concerns or problems about your participation in this study or your rights as a research subject, please contact the Human Subjects Research Review Committee, Office of Research and Strategic Partnerships, Market Center Building Suite 620, Portland State University, (877-480-4400). If you have questions about the study itself or are experiencing technical difficulties, you may contact me directly. My contact information is: Samson Thompson Dept. Civil \& Environmental Engineering Portland State University 785-727-8234 s.r.thompson@pdx.edu 
Are you over 18 years of age and agree to participate in this survey?
Yes (1)
No (2)

\section{You on a bicycle}

Your responses to this first set of questions will help us understand you better as a user of the transportation system.

Which statement best represents how you view yourself as a bicyclist? (choose one)

I am strong and fearless. (1)

O I am enthusiastic and confident on most streets where I ride. (2)

I am confident on paths and slow speed streets with low traffic, but avoid busy roads. (4)

None of these (5) 
For each mode of transportation, please indicate your level of use.

\begin{tabular}{|c|c|c|c|c|c|c|c|c|c|}
\hline & \multicolumn{3}{|c|}{$\begin{array}{l}\text { Commute Trips } \\
\text { (to/from work or school) }\end{array}$} & \multicolumn{3}{|c|}{$\begin{array}{l}\text { Other Utilitarian Trips } \\
\text { (e.g. getting to } \\
\text { appointments, shopping, } \\
\text { running errands) }\end{array}$} & \multicolumn{3}{|c|}{ Leisure and/or Exercise } \\
\hline & $\begin{array}{l}\text { Most } \\
\text { Trips } \\
(1)\end{array}$ & $\begin{array}{l}\text { Some } \\
\text { Trips } \\
(2)\end{array}$ & $\begin{array}{l}\text { No } \\
\text { Trips } \\
(3)\end{array}$ & $\begin{array}{l}\text { Most } \\
\text { Trips } \\
(1)\end{array}$ & $\begin{array}{l}\text { Some } \\
\text { Trips } \\
(2)\end{array}$ & $\begin{array}{l}\text { No } \\
\text { Trips } \\
(3)\end{array}$ & $\begin{array}{l}\text { Most } \\
\text { Trips } \\
\text { (1) }\end{array}$ & $\begin{array}{l}\text { Some } \\
\text { Trips } \\
\text { (2) }\end{array}$ & $\begin{array}{l}\text { No } \\
\text { Trips } \\
(3)\end{array}$ \\
\hline Bicycle (1) & $\mathrm{O}$ & $\mathrm{O}$ & $\mathrm{O}$ & O & 0 & $\mathrm{O}$ & 0 & $\mathrm{O}$ & O \\
\hline $\begin{array}{l}\text { Motor } \\
\text { vehicle } \\
\text { (including } \\
\text { carpooling) } \\
\text { (2) }\end{array}$ & O & $\mathrm{O}$ & $\mathrm{O}$ & $\mathrm{O}$ & O & O & O & O & O \\
\hline Transit (3) & O & 0 & 0 & O & O & O & O & O & 0 \\
\hline Walk (4) & $\mathrm{O}$ & $\mathrm{O}$ & $\mathrm{O}$ & $\mathrm{O}$ & $\mathrm{O}$ & O & $\mathrm{O}$ & O & O \\
\hline
\end{tabular}


The next two questions ask about incidents that have occurred while riding your bike in the last 2 years. For each type of crash, indicate the severity of your crash(es) and give us a little information by the other involved road users and/or objects, if any. If you have had multiple crashes, select all that apply. 


\begin{tabular}{|c|c|c|c|c|c|c|c|c|c|}
\hline \multirow[b]{2}{*}{$\begin{array}{l}\text { Crash with } \\
\text { another road user } \\
\text { (1) }\end{array}$} & \multicolumn{4}{|c|}{ Who else was involved? } & \multicolumn{4}{|c|}{ Your Injury Severity } & \multirow[b]{2}{*}{$\begin{array}{l}\text { I haven't had } \\
\text { any crashes of } \\
\text { this type. (1) }\end{array}$} \\
\hline & $\begin{array}{l}\text { Motor vehicle } \\
\text { (1) }\end{array}$ & $\begin{array}{l}\text { Another } \\
\text { bicyclist } \\
\text { (2) }\end{array}$ & $\begin{array}{l}\text { A pedestrian } \\
\text { (3) }\end{array}$ & $\begin{array}{l}\text { None of } \\
\text { these (4) }\end{array}$ & None (1) & $\begin{array}{l}\text { Minor } \\
\text { (Scrapes) } \\
\text { (2) }\end{array}$ & $\begin{array}{l}\text { Moderate } \\
\text { (Bleeding, Deep } \\
\text { Bruising) (3) }\end{array}$ & $\begin{array}{l}\text { Severe } \\
\text { (Trip to } \\
\text { Hospital) } \\
\text { (4) }\end{array}$ & \\
\hline & $\square$ & $\square$ & $\square$ & a & 口 & $\square$ & $\square$ & $\square$ & 口 \\
\hline
\end{tabular}

\begin{tabular}{|c|c|c|c|c|c|c|c|c|c|c|}
\hline \multirow{3}{*}{$\begin{array}{l}\text { Crash with a pole, a } \\
\text { tree, or one in which } \\
\text { you lost control of } \\
\text { the bike. (2) }\end{array}$} & \multicolumn{4}{|c|}{ What did you hit? } & \multicolumn{3}{|c|}{ Your Injury Severity } & \multirow[b]{2}{*}{$\begin{array}{l}\text { Moderate } \\
\text { (Bleeding, } \\
\text { Deep } \\
\text { Bruising) } \\
(3)\end{array}$} & \multirow[b]{2}{*}{$\begin{array}{l}\text { Severe } \\
\text { (Trip to } \\
\text { Hospital) } \\
\text { (4) }\end{array}$} & \multirow[b]{2}{*}{$\begin{array}{l}\text { I haven't } \\
\text { had any } \\
\text { crashes of } \\
\text { this type. } \\
\text { (1) }\end{array}$} \\
\hline & $\begin{array}{l}\text { A roadside } \\
\text { object } \\
\text { (pole/tree/ } \\
\text { parked } \\
\text { car/etc.) } \\
\text { (1) }\end{array}$ & $\begin{array}{l}\text { A pothole } \\
\text { or } \\
\text { MAX/stre } \\
\text { etcar } \\
\text { tracks (2) }\end{array}$ & $\begin{array}{l}\text { Loose } \\
\text { gravel/san } \\
\text { d or other } \\
\text { debris (3) }\end{array}$ & $\begin{array}{l}\text { Nothing -- } \\
\text { I lost } \\
\text { control/fel } \\
\text { l over (4) }\end{array}$ & $\begin{array}{l}\text { None of } \\
\text { these (5) }\end{array}$ & None (1) & $\begin{array}{l}\text { Minor } \\
\text { (Scrapes) } \\
\text { (2) }\end{array}$ & & & \\
\hline & $\square$ & $\square$ & $\square$ & $\square$ & $\square$ & $\square$ & $\square$ & $\square$ & 口 & $\square$ \\
\hline
\end{tabular}




\section{Attitudes about running red lights}

This next set of questions will be used to obtain information about your attitudes with regard to waiting for a green light in certain scenarios. For clarification, when a question asks about "riding through a red light" it is referring to any time you enter an intersection when you, as a bicyclist, do not have a green signal. The video below shows two examples of this behavior. (if the video is not displaying/playing properly in this window, please click this youtube link: https://www.youtube.com/watch?v=Jh0tgWfHypI) 
State your level of agreement with each of the following statements. Consider these statements about a generic intersection. Each statement begins with the words "I might ride through a red light if..." 


\begin{tabular}{|c|c|c|c|c|c|}
\hline & $\begin{array}{l}\text { Strongly } \\
\text { Disagree } \\
\text { (1) }\end{array}$ & $\begin{array}{l}\text { Disagree } \\
\quad(2)\end{array}$ & $\begin{array}{l}\text { Neither Agree } \\
\text { nor Disagree } \\
\text { (3) }\end{array}$ & $\begin{array}{l}\text { Agree } \\
\text { (4) }\end{array}$ & $\begin{array}{l}\text { Strongly } \\
\text { Agree (5) }\end{array}$ \\
\hline $\begin{array}{l}\text {...I have stopped first and there is } \\
\text { no cross traffic. (1) }\end{array}$ & $\mathrm{O}$ & $\mathrm{O}$ & $\mathrm{O}$ & $\mathrm{O}$ & $\mathrm{O}$ \\
\hline $\begin{array}{l}\text {...another bicyclist also runs the } \\
\text { red light. (2) }\end{array}$ & $\mathrm{O}$ & $\mathrm{O}$ & $\mathrm{O}$ & 0 & $\mathrm{O}$ \\
\hline $\begin{array}{l}\text {...it is raining/snowing and I am } \\
\text { cold (3) }\end{array}$ & $\mathrm{O}$ & $\mathrm{O}$ & $\mathrm{O}$ & $\mathrm{O}$ & $\mathrm{O}$ \\
\hline $\begin{array}{l}\text {...I am riding with a group of } \\
\text { other adults and one of them } \\
\text { does. (4) }\end{array}$ & $\mathrm{O}$ & $\mathrm{O}$ & $\mathrm{O}$ & $\mathrm{O}$ & $\mathrm{O}$ \\
\hline ...it is dark out. (5) & $\mathrm{O}$ & $\mathrm{O}$ & O & $\mathrm{O}$ & $\mathrm{O}$ \\
\hline $\begin{array}{l}\text {...I am running late or in a hurry. } \\
\text { (6) }\end{array}$ & O & O & O & O & O \\
\hline $\begin{array}{l}\text {...I have been waiting a long time } \\
\text { and do not know when I will } \\
\text { receive a green light. (7) }\end{array}$ & $\mathrm{O}$ & $\mathrm{O}$ & $\mathrm{O}$ & $\mathrm{O}$ & $\mathrm{O}$ \\
\hline $\begin{array}{l}\text {...I have already had to stop at } \\
\text { lights several times already. ( } 8 \text { ) }\end{array}$ & $\mathrm{O}$ & $\mathrm{O}$ & $\mathrm{O}$ & $\mathrm{O}$ & $\mathrm{O}$ \\
\hline $\begin{array}{l}\text {...there is no one around to see } \\
\text { me do it. (9) }\end{array}$ & O & $\mathrm{O}$ & O & O & $\mathrm{O}$ \\
\hline $\begin{array}{l}\text {... am going uphill or downhill } \\
\text { and don't want to lose } \\
\text { momentum (10) }\end{array}$ & $\mathrm{O}$ & $\mathrm{O}$ & $\mathrm{O}$ & O & $\mathrm{O}$ \\
\hline ...I am turning right. (13) & O & $\mathrm{O}$ & $\mathrm{O}$ & O & 0 \\
\hline
\end{tabular}




\begin{tabular}{|l|l|l|l|l|l|}
\hline $\begin{array}{l}\text {..I know the signal is about to } \\
\text { turn green. (14) }\end{array}$ & O & O & 0 & 0 & 0 \\
$\ldots$ am carrying a heavy & \\
$\begin{array}{l}\text { backpack, pannier(s), or other } \\
\text { load (not including children). } \\
(15)\end{array}$ & 0 & 0 & 0 & 0 & 0 \\
\hline
\end{tabular}


The following questions will ask about the likelihood that you would comply at the intersections pictured (i.e. would you run the red light?). We will ask you about 3 intersections. Try to imagine yourself on a bicycle approaching the red light at each intersection as it appears in the picture.

If you were stopped at this intersection (similar to the cyclist in yellow), would you consider running the red light? Consider the intersection as it appears in the picture.

\author{
Definitely not (1) \\ O Probably not (2) \\ Maybe (3) \\ O Probably (4) \\ Definitely (5)
}

For the scenario above, you selected that you would \&quot; $\$\{\mathrm{q}: / / \mathrm{QID} 26 /$ ChoiceGroup/SelectedChoices $\} \& q u o t ;$ consider running the red light. Select the factors that influenced your response from the list below.

Amount or speed of traffic to cross (1)

$\square$ Distance to other side of intersection (2)

$\square$ Presence of bike infrastructure (e.g. a bike lane, a bike signal, green paint, etc.) (3)

Complexity (or simplicity) of the intersection (4)

$\square$ The presence of other people (5)

$\square$ Other (6) 
Which do you consider the most influential factor?

Amount or speed of traffic to cross (1)

O Distance to other side of intersection (2)

O Presence of bike infrastructure (e.g. a bike lane, a bike signal, green paint, etc.). (3)

O Complexity (or simplicity) of the intersection (4)

The presence of other people. (5)

O $\$\{\mathrm{q}: / / \mathrm{QID} 27 /$ ChoiceTextEntryValue/6\} (6)

If you were stopped at this intersection, would you consider running the red light? Consider the intersection as it appears in the picture.
Definitely not (1)
O Probably not (2)
O Maybe (3)
O Probably (4)
O Definitely (5)

For the scenario above, you selected that you would \&quot $\$ \$\{\mathrm{q}: / / \mathrm{QID} 35 /$ ChoiceGroup/SelectedChoices $\} \& q u o t ;$ consider running the red light. Select the factors that influenced your response from the list below.

Amount or speed of traffic to cross (1)

Distance to other side of intersection (2)

- Presence of bike infrastructure (e.g. a bike lane, a bike signal, green paint, etc.) (3)

Complexity (or simplicity) of the intersection (4)

The presence of other people (5)

Other (6) 
Which do you consider the most influential factor?

Amount or speed of traffic to cross (1)

Distance to other side of intersection (2)

Presence of bike infrastructure (e.g. a bike lane, a bike signal, green paint, etc.). (3)

Complexity (or simplicity) of the intersection (4)

The presence of other people. (5)

O $\$\{\mathrm{q}: / / \mathrm{Q} I D 65 /$ ChoiceTextEntryValue/6\} (6) 
If you were stopped at this intersection, would you consider running the red light? Consider the intersection as it appears in the picture.
Definitely not (1)
O Probably not (2)
O Maybe (3)
O Probably (4)
O Definitely (5)

For the scenario above, you selected that you would \&quot $\$\{$ q://QID40/ChoiceGroup/SelectedChoices $\} \& q u o t ;$ consider running the red light. Select the factors that influenced your response from the list below.

Amount or speed of traffic to cross (1)

Distance to other side of intersection (2)

- Presence of bike infrastructure (e.g. a bike lane, a bike signal, green paint, etc.) (3)

Complexity (or simplicity) of the intersection (4)

The presence of other people (5)

$\square$ Other (6)

Which do you consider the most influential factor?

Amount or speed of traffic to cross (1)

O Distance to other side of intersection (2)

O Presence of bike infrastructure (e.g. a bike lane, a bike signal, green paint, etc.). (3)

O Complexity (or simplicity) of the intersection (4)

O The presence of other people. (5)

O $\$\{\mathrm{q}: / /$ QID67/ChoiceTextEntryValue/6\} (6) 


\section{Behaviors and violations}

These questions ask about traffic citations and behaviors while driving/bicycling.

Remember that your answers are completely confidential and we will make no attempt to connect these answers to a person so PLEASE answer honestly.

How often do you do the following?

\begin{tabular}{|l|c|c|c|c|c|}
\hline & $\begin{array}{c}\text { Never } \\
(1)\end{array}$ & Rarely (2) & $\begin{array}{c}\text { Occasionally } \\
(3)\end{array}$ & $\begin{array}{c}\text { Often } \\
(4)\end{array}$ & $\begin{array}{c}\text { Always } \\
(5)\end{array}$ \\
\hline $\begin{array}{l}\text { Wear a helmet when riding a bicycle. (1) } \\
\text { (2) }\end{array}$ & 0 & 0 & 0 & 0 & 0 \\
$\begin{array}{l}\text { Wear a seatbelt while driving or riding } \\
\text { in a personal motor vehicle. (3) }\end{array}$ & 0 & 0 & 0 & 0 & 0 \\
$\begin{array}{l}\text { Use a cell phone (not hands free) while } \\
\text { driving a motor vehicle. (4) }\end{array}$ & 0 & 0 & 0 & 0 & 0 \\
$\begin{array}{l}\text { Use a hands free cell phone while } \\
\text { driving a motor vehicle (5) }\end{array}$ & 0 & 0 & 0 & 0 & 0 \\
$\begin{array}{l}\text { Text while driving and the motor } \\
\text { vehicle is in motion. (6) }\end{array}$ & 0 & 0 & 0 & 0 & 0 \\
$\begin{array}{l}\text { Use a cell phone or text while riding a } \\
\text { bicycle (7) }\end{array}$ & 0 & 0 & 0 & 0 \\
\hline
\end{tabular}


In the last 3 years, have you received a traffic citation for any of the following offenses while driving a motor vehicle? Running a red light Exceeding the speed limit by more than 10 mph Reckless driving DUI Lack of seatbelt use Using a cell phone while driving
Yes (1)
No (2)

In the last 3 years, have you received a traffic citation for any offense while riding a bicycle?
O Yes (1)
No (2) 


\section{Personality}

In this section, questions will not necessarily pertain to your experiences as a person riding a bicycle. Pick the answer for each question that best represents your true feelings/likes or dislikes. 
Indicate whether or not you agree or disagree with each of the following statements. In some instances, you may not feel strongly one way or another but choose the answer that best represents your level of agreement.

\begin{tabular}{|c|c|c|}
\hline & $\begin{array}{l}\text { Agree } \\
(1)\end{array}$ & $\begin{array}{l}\text { Disagree } \\
(2)\end{array}$ \\
\hline I like 'wild' parties. (1) & 0 & 0 \\
\hline I am an impulsive person. (2) & 0 & O \\
\hline I think it's alright to do anything you want as long as you stay out of trouble. (3) & O & O \\
\hline $\begin{array}{l}\text { I enjoy getting into new situations where you cannot predict how things will } \\
\text { turn out. (4) }\end{array}$ & O & $\mathrm{O}$ \\
\hline $\begin{array}{l}\text { I would like the kind of life where one is on the move and traveling a lot, with } \\
\text { lots of changes and excitement. (5) }\end{array}$ & $\mathrm{O}$ & O \\
\hline It is okay to get around the law as long as you don't actually break it. (6) & O & O \\
\hline I prefer friends who are excitingly unpredictable. (7) & O & O \\
\hline $\begin{array}{l}\text { I often get so carried away by new and exciting things and ideas that I never } \\
\text { think of possible complications. }(8)\end{array}$ & O & $\mathrm{O}$ \\
\hline If something works, it doesn't matter if it's right or wrong. (9) & $\mathrm{O}$ & O \\
\hline I often do things on impulse. (10) & 0 & 0 \\
\hline
\end{tabular}


Do you believe that it's alright to do whatever the law allows, or are there some things that are wrong even if they are legal?

Whatever the law allows is okay. (1)

Some things are wrong even if they are legal. (2) 
Indicate whether or not you agree or disagree with each of the following statements. Please choose the answer that best represents your level of agreement.

\begin{tabular}{|l|c|c|c|c|c|}
\hline & $\begin{array}{c}\text { Strongly } \\
\text { Disagree } \\
(1)\end{array}$ & $\begin{array}{c}\text { Disagree } \\
(2)\end{array}$ & $\begin{array}{c}\text { Neither Agree } \\
\text { nor Disagree } \\
(3)\end{array}$ & $\begin{array}{c}\text { Agree } \\
(4)\end{array}$ & $\begin{array}{c}\text { Strongly } \\
\text { Agree } \\
(5)\end{array}$ \\
\hline $\begin{array}{l}\text { People think of me as someone who } \\
\text { has a quick temper. (1) }\end{array}$ & 0 & 0 & 0 & 0 & 0 \\
$\begin{array}{l}\text { I rarely, if ever, have trouble sleeping } \\
\text { due to stress or anxiety. (2) }\end{array}$ & 0 & 0 & 0 & 0 & 0 \\
$\begin{array}{l}\text { I get very anxious when waiting to hear } \\
\text { about an important decision. (3) }\end{array}$ & 0 & 0 & 0 & 0 & 0 \\
$\begin{array}{l}\text { I rarely feel anger, even when people } \\
\text { treat me quite badly. (4) }\end{array}$ & 0 & 0 & 0 & 0 & 0 \\
$\begin{array}{l}\text { I worry a lot less than most people do. } \\
\text { (5) }\end{array}$ & 0 & 0 & 0 & 0 & 0 \\
$\begin{array}{l}\text { I sometimes can't help worrying about } \\
\text { little things. (8) }\end{array}$ & 0 & 0 & 0 & 0 \\
quickly than I do. (6) & 0 & 0 & 0 & 0 \\
\hline
\end{tabular}


On a scale of 1-10, how worried are you about getting into a crash with a motor vehicle while on your bike?(move the slider to the correct number on the scale with 0 being 'Not worried at all' and 10 being "Extremely worried".)

It is likely that I will be seriously injured if I get into a crash with a motor vehicle while on my bike.
Strongly Disagree (4)
Disagree (5)
Neither Agree nor Disagree (6)
Agree (7)
Strongly Agree (8) 


\section{Demographics}

These last few questions ask about a few common demographics.

What is your age?

With which gender do you most identify?

O Male (1)

Female (2)

○ (4)

Which best represents your relationship status?

O Single (Not married or in long-term partnership), no children (1)

S Single, with child(ren) (2)

Married or long-term partnership, no children (3)

Married or long-term partnership, with child(ren) (4)

Which statement best represents the flexibility of your job/school schedule?

My schedule is very flexible. (1)

O My start time is flexible enough that I can be a little late if need be. (2)

I should be clocked in by the start of my shift but there is no penalty for being a few minutes late. (3)

I need to be clocked in by the start of my shift or I could be penalized or fired. (4)

I do not have a job. (5) 